EVERTON RODRIGUES REIS

PROFTS: A Multi-Agent Automated Trading System 
EVERTON RODRIGUES REIS

\section{PROFTS: A Multi-Agent Automated Trading System}

Dissertação apresenteada à Escola Politécnica da Universidade de São Paulo para obtenção do título de Mestre em Ciências

Área de Concentração:

Engenharia de Computação

Orientador:

Prof.Dr. Jaime Simão Sichman 
Autorizo a reprodução e divulgação total ou parcial deste trabalho, por qualquer meio convencional ou eletrônico, para fins de estudo e pesquisa, desde que citada a fonte.

\section{Catalogação-na-publicação}

Reis, Everton

PROFTS: A Multi-Agent Automated Trading System / E. Reis -- São Paulo, 2019.

$97 \mathrm{p}$.

Dissertação (Mestrado) - Escola Politécnica da Universidade de São Paulo. Departamento de Engenharia de Computação e Sistemas Digitais.

1.Multi-agent System 2.Automated Trading System 3.Machine Learning 4.Portfolio Management I.Universidade de São Paulo. Escola Politécnica. Departamento de Engenharia de Computação e Sistemas Digitais II.t. 


\section{ACKNOWLEDGEMENTS}

I would like to firstly thank God for blessing me in everything that I have done during my life. One of the best blessing that I have received was my family.

I would like to thank my parents for all support that they gave me and for being always encouraging my studies. I would also thank my beautiful wife, Karla Martins de Oliveira Reis for all the support and patience that she had with me, sacrificing our time together to achieve our goals.

Besides, I want to thank my advisor, prof. Dr. Jaime Simão Sichman for his availability and insightful advices. He also introduced me to the academic world that opened doors for several professional opportunities. In addition, special thanks to my lab mates and lab professors that helped me with paperwork and revisions.

Lastly, I would like to thank my friends and relatives that helped me revising the text, in special, Patricia Murphy and Renato Zimberknopf. 


\section{RESUMO}

O gerenciamento de portfólio é um problema complexo e desafiador. A utilização de sistemas de negociação automatizados (ATS) para gerenciar tais portfólios está se tornando cada vez mais comum. No entanto, a maioria deles objetivam a maximização do retorno, sem levar em consideração o risco, enquanto poucos consideram a relação entre risco-retorno e as preferências do investidor. Além disso, a maioria dos ATS usam análise/dados técnicos, poucos usam análise fundamentalista, e quase nenhum sistema combina as duas técnicas, que é como a maioria dos analistas humanos tratam este problema. Neste trabalho, é proposto uma arquitetura para um sistema de negociação automatizado que gerencia um portfólio de ações ativamente, combinando análise técnica e fundamentalista, para diferentes perfis de investidores. Tal arquitetura, denominada PROFTS, foi construída utilizando a abordagem de sistemas multiagentes e técnicas de aprendizado de máquina. As simulações utilizaram como ambiente o mercado de ações brasileiro, onde os resultados quantitativos obtidos foram comparados ao índice do IBrX 100 com a estratégia de buy and hold. Um modelo de previsão de falências também foi utilizado para diferenciar empresas desvalorizadas de empresas em situação de falência. Os resultados obtidos, considerando custos de operações, mostraram que o PROFTS foi lucrativo. $\mathrm{O}$ resultado dos portfólios que utilizaram recomendações de agentes baseados em análise técnica em conjunto com a análise fundamentalista mostraram-se estatisticamente superiores àqueles que usaram apenas a análise fundamentalista. Já os portfólios que utilizaram o modelo de previsão de falência apresentaram um menor risco médio em relação aos que não o usaram.

Palavras-chave: sistemas multi-agentes; gerenciamento autônomo de portfólio; aprendizado de máquina; análise técnica; análise fundamentalista. 


\section{ABSTRACT}

Portfolio management is a challenging and complex problem. The use of automated trading systems (ATS) is becoming common nowadays. However, most of them focus on maximizing return, without considering the risk, while few consider the relation between risk and return and investor's preferences. Moreover, most ATS use technical analysis/data, very few apply fundamental analysis, and quite none apply both of them, which is the way how most human analysts deal with this problem. In this work, it was proposed an architecture for an automated trading system (ATS) that manages an active stock portfolio, combining both fundamental and technical analysis, for different types of investor's risk profile. The architecture, called PROFTS, was built using a multi-agent approach and machine learning techniques, and validated through simulations of the Brazilian stock market. The results were compared with the performance of the IBrX 100 using a buy and hold strategy. A financial distress prediction model was also utilized, in order to filter out companies that were bankrupting from those that were undervalued. From the results, considering trading costs, the PROFTS was profitable. Portfolios that used technical analysis combined with fundamental analysis presented statistically better results than those that just used fundamental analysis. Moreover, portfolios that used the financial distress prediction model also presented statistically significant average lower risk when compared with those that did not use them.

Keywords: multi-agent systems; autonomous portfolio management; automated trading system; machine learning; technical analysis; fundamental analysis. 


\section{LIST OF FIGURES}

Figure 1 - Capital Market . . . . . . . . . . . . . . . . 16

Figure 2 - Efficient frontier and indifference curves. . . . . . . . . . . . . . 20

Figure 3 - ZigZag of 6\% applied to Ibovespa (2010) to create labels for classification. . 25

Figure 4 - Intelligent agent and its environment . . . . . . . . . . . . 26

Figure 5 - Horizontal layering . . . . . . . . . . . . . 28

Figure 6 - Information and control flow in vertical architectures . . . . . . . . . 28

Figure 7 - FIPA Contract Net Interaction Protocol. . . . . . . . . . . . . . . 31

Figure $8-$ SVM and its soft margin . . . . . . . . . . . . . 34

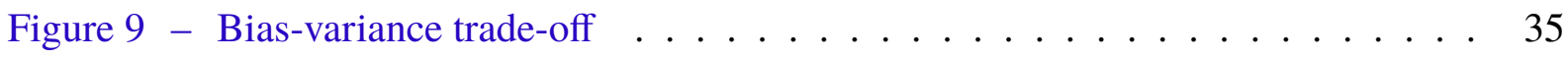

Figure $10-$ Kernel functions . . . . . . . . . . . . . . . . . . . 36

Figure 11 - COAST architecture. . . . . . . . . . . . . . . . . 40

Figure 12 - FAS - Fundamentalist Agents System. . . . . . . . . . . . . . . . 41

Figure 13 - PROFTS architecture . . . . . . . . . . . . . . . . 46

Figure 14 - Information agent life-cycle. . . . . . . . . . . . . . . . . . . . 47

Figure 15 - Fundamentalist agent life-cycle . . . . . . . . . . . . . . . . . 48

Figure 16 - Technical agent life-cycle. . . . . . . . . . . . . . . 53

Figure 17 - Coordinator agent life-cycle. . . . . . . . . . . . . . . 54

Figure 18 - Agents running on JADE. . . . . . . . . . . . . . . . 57

Figure 19 - 6-Fold Time Series Cross Validation . . . . . . . . . . . . . . 58

Figure 20 - Creating labels for 2015 with ZigZag indicator. . . . . . . . . . . . . . . . 59

Figure 21 - Max Acceptable Risk against Benchmark for 2015 . . . . . . . . . . . . 78

Figure 22 - Desired Target Return against Benchmark for 2015 . . . . . . . . . . . . . 79

Figure 23 - Limited Risk Return against Benchmark for 2015 . . . . . . . . . . . . . . 80

Figure 24 - Free Risk Return against Benchmark for 2015 . . . . . . . . . . . . . . . 81

Figure 25 - Max Acceptable Risk against Benchmark for 2016. . . . . . . . . . . . . . 82

Figure 26 - Desired Target Return against Benchmark for 2016. . . . . . . . . . . . . 83

Figure 27 - Limited Risk Return against Benchmark for 2016 . . . . . . . . . . . . . . . 84

Figure 28 - Free Risk Return against Benchmark for 2016 . . . . . . . . . . . . . . . 85

Figure 29 - Max Acceptable Risk against Benchmark for 2017 ～. . . . . . . . . . . . 86

Figure 30 - Desired Target Return against Benchmark for 2017. . . . . . . . . . . . . 87

Figure 31 - Limited Risk Return against Benchmark for 2017 . . . . . . . . . . . . . . 88

Figure 32 - Free Risk Return against Benchmark for 2017 . . . . . . . . . . . . . . . 88 


\section{LIST OF TABLES}

Table 1 - ATS using MAS. . . . . . . . . . . . . . . . . 42

Table 2 - Possible system's objectives for different market scenarios and Investor's profile 46

Table 3 - Trend Indicators . . . . . . . . . . . . . . . . . . 51

Table 4 - Volume Indicators . . . . . . . . . . . . . . . . . 51

Table 5 - Oscillator Indicators $\ldots \ldots \ldots \ldots$. . . . . . . . . . 52

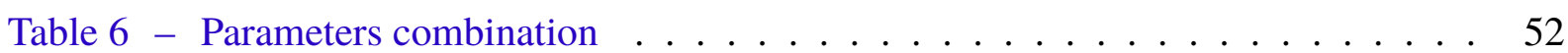

Table 7 - List of stocks tickers used by Technical Agent . . . . . . . . . . . 58

Table 8 - Technical agent's selected stocks for each year. . . . . . . . . . . . 60

Table 9 - Companies by sector for FDP modelling. . . . . . . . . . . . . . . 61

Table 10 - Train and test dataset for FDP modelling. . . . . . . . . . . . . . . . 61

Table 11 - Financial Indicators . . . . . . . . . . . . . . . . . . . . . . . . . 62

Table 12 - Selected Financial Indicators . . . . . . . . . . . . . . . . . . . 62

Table 13 - Training set Results . . . . . . . . . . . . . . . . . . . . . 62

Table 14 - Confusion Matrix . . . . . . . . . . . . . . . . . . . . . . . . 63

Table 15 - Test set results . . . . . . . . . . . . . . . . . . 63

Table 16 - Experiments description. . . . . . . . . . . . . . . 63

Table 17 - Experiments duration in minutes. . . . . . . . . . . . . . . . . 64

Table 18 - Portfolios comparison for 2015 . . . . . . . . . . . . . . . 65

Table 19 - Portfolios comparison for 2016. . . . . . . . . . . . . . . . . . 66

Table 20 - Portfolios comparison for 2017. . . . . . . . . . . . . . . . . 66

Table 21 - Final Result . . . . . . . . . . . . . . . . . . . . . . . . . 67

Table 22 - Hypotheses test results for FDP model. . . . . . . . . . . . . . 68

Table 23 - Hypothesis test results for risk metrics using technical agent recommendation. 69

Table 24 - Hypothesis test results for performance metrics using technical agent recommendation. . . . . . . . . . . . . . . . . . . 69

Table 25 - ZigZag parameters for each year and stock and class balance. . . . . . . . . 71

Table 26 - SVM model's results and picked stocks for 2015 . . . . . . . . . . . . . 72

Table 27 - SVM model's results and picked stocks for 2016 . . . . . . . . . . . . . 73

Table 28 - SVM model's results and picked stocks for 2017. . . . . . . . . . . . . . . . 74

Table 29 - Investor's profile parameters . . . . . . . . . . . . . . . . 75

Table 30 - Technical and Fundamentalist Agents parameters . . . . . . . . . . 75

Table 31 - Trading parameters . . . . . . . . . . . . . . . . . . 76

Table 32 - Max Acceptable Risk - Portfolio Metrics for 2015 . . . . . . . . . . . . . . 77

Table 33 - Desired Target Return - Portfolio Metrics for 2015 . . . . . . . . . . . . . 78

Table 34 - Limited Risk Return - Portfolio Metrics for 2015 . . . . . . . . . . . . . . 79

Table 35 - Free Risk Return - Portfolio Metrics for 2015 . . . . . . . . . . . . . . . . . 80 
Table 36 - Max Acceptable Risk - Portfolio Metrics for 2016 . . . . . . . . . . . . . . . 81

Table 37 - Desired Target Return - Portfolio Metrics for 2016 . . . . . . . . . . . . 82

Table 38 - Limited Risk Return - Portfolio Metrics for 2016 . . . . . . . . . . . . . . 83

Table 39 - Free Risk Return - Portfolio Metrics for 2016 . . . . . . . . . . . . . . . . . 84

Table 40 - Max Acceptable Risk - Portfolio Metrics for 2017 . . . . . . . . . . . . . . 85

Table 41 - Desired Target Return - Portfolio Metrics for 2017. . . . . . . . . . . . . . 86

Table 42 - Limited Risk Return - Portfolio Metrics for 2017 . . . . . . . . . . . . . . 87

Table 43 - Free Risk Return - Portfolio Metrics for 2017 . . . . . . . . . . . . . . 87

Table 44 - Standard deviation and maximum drawdown results for hypotheses testing of FDP model. . . . . . . . . . . . . . . . . . . . . 89

Table 45 - Standard deviation and maximum drawdown results for hypotheses testing. . 90

Table 46 - Return and sharpe ratio results for hypotheses testing. . . . . . . . . . . . . 90 


\section{LIST OF ABBREVIATIONS AND ACRONYMS}

\begin{tabular}{ll} 
AgEx & Agent Exchange \\
AI & Artificial Intelligence \\
ANN & Artificial Neural Network \\
ATS & Automated Trading System \\
AUC & Area Under Curve \\
BDI & Belief-Desire-Intention \\
BIC & Bayesian Information Criterion \\
CAPEX & Capital Expenditures \\
CAPM & Capital Asset Pricing Model \\
CFP & Call For Proposals \\
CFS & Correlation-based Feature Selection \\
COAST & Competitive Agent Society \\
DTR & Desired Target Return \\
EBIT & Earnings before interest and taxes \\
EBITDA & Earnings before interest, taxes, depreciation and amortization \\
EMH & Efficient Markets Hypotheses \\
EPS & Earnings per share \\
ETF & Exchange-Traded Fund \\
EV & Enterprise Value \\
FAS & Fundamentalist Agents System \\
FCFF & Free Cash Flow to Firm \\
FDP & Financial Distress Prediction \\
FRR & Free Risk-Return \\
IPO & Initial Public Offering \\
\hline
\end{tabular}




$\begin{array}{ll}\text { LTCM } & \text { Long-Term Capital Management } \\ \text { LRR } & \text { Limited Risk Return } \\ \text { MAR } & \text { Max Acceptable Risk } \\ \text { MAS } & \text { Multi-Agent Systems } \\ \text { MLE } & \text { Maximum Likelihood Estimate } \\ \text { MSE } & \text { Mean Squared Error } \\ \text { NPM } & \text { Net Profit Margin } \\ \text { PAM } & \text { Partitioning Around Medoids } \\ \text { P/B } & \text { Price to Book value ratio } \\ \text { P/E } & \text { Price to Earnings ratio } \\ \text { PROFTS } & \text { PROfitable Fundamentalist and Technical System } \\ \text { PSR } & \text { Price to Sales ratio } \\ \text { QR } & \text { Quick Ratio } \\ \text { ROA } & \text { Return on Assets } \\ \text { ROE } & \text { Return on Equity } \\ \text { RSS } & \text { Residual Squared Sum } \\ \text { SDP } & \text { Standard \& Poor's 500 } \\ \text { Suport Vector Machine }\end{array}$




\section{CONTENTS}

INTRODUCTION . . . . . . . . . . . . . . . . . . . . . 12

Motivation . . . . . . . . . . . . . . . . . . . 12

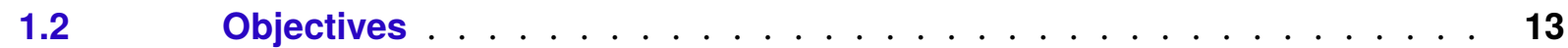

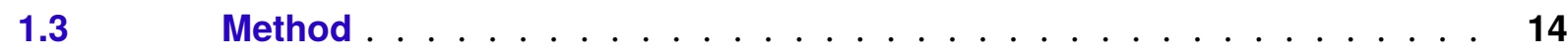

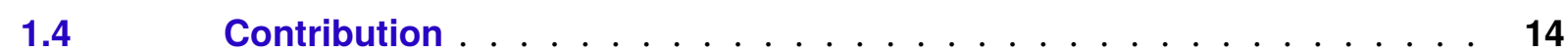

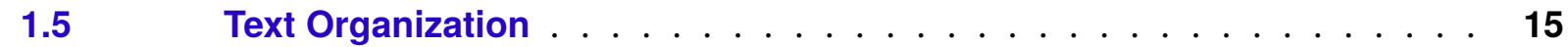

2 FINANCE THEORY $\ldots \ldots \ldots \ldots \ldots \ldots$

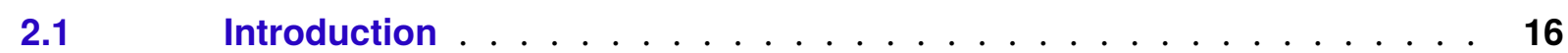

$2.2 \quad$ Modern Portfolio Theory . . . . . . . . . . . . . . . . . 18

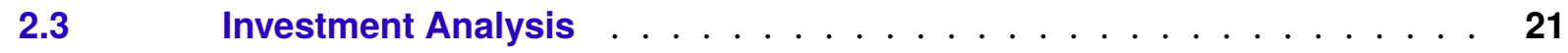

2.3.1 Fundamental Analysis . . . . . . . . . . . . . . . 21

$2.3 .2 \quad$ Technical Analysis . . . . . . . . . . . . . . . . . . . . . 24

$3 \quad$ ARTIFICIAL INTELLIGENCE THEORY . . . . . . . . . . . . . . . 26

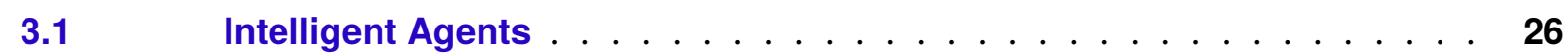

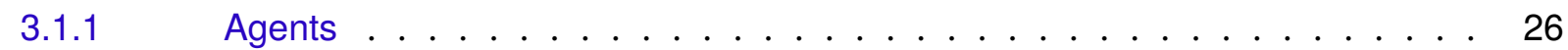

3.1 .2 Multi-Agent Systems . . . . . . . . . . . . . . . . 29

$3.2 \quad$ Machine Learning . . . . . . . . . . . . . . . . . 32

$3.2 .1 \quad$ Feature Selection $\ldots \ldots \ldots \ldots \ldots \ldots$

3.2.2 Supervised Learning . . . . . . . . . . . . . . . . . . 33

3.2.3 Unsupervised Learning . . . . . . . . . . . . . . . . . 35

$4 \quad$ RELATED WORK $\ldots \ldots \ldots \ldots \ldots$

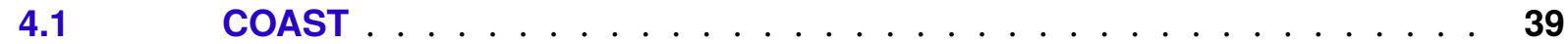

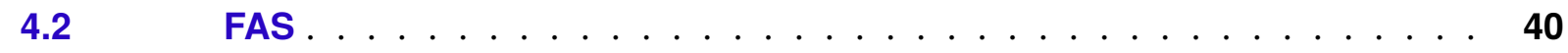

$4.3 \quad$ Relative valuation comparison . . . . . . . . . . . . . 41

$4.4 \quad$ Concluding Remarks . . . . . . . . . . . . . . . . . . . . 42

5 PROFTS: PROFITABLE FUNDAMENTALIST AND TECHNICAL SYSTEM . 43

$5.1 \quad$ System Concepts . . . . . . . . . . . . . . 43

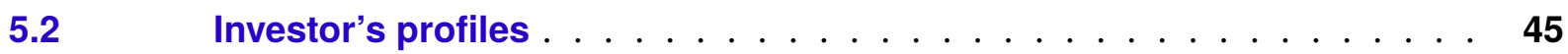

$5.3 \quad$ Agents Description . . . . . . . . . . . . . . . . . 46

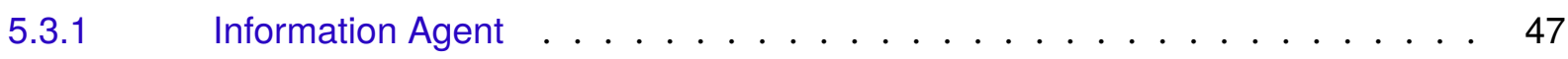

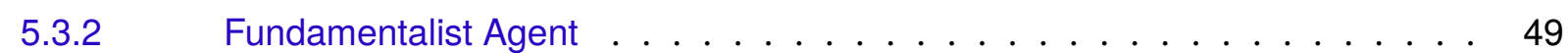

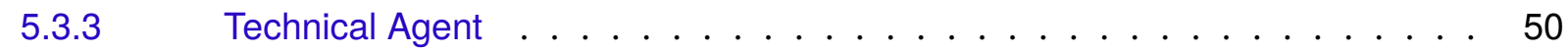


$6 \quad$ EXPERIMENTS AND RESULTS $\ldots \ldots \ldots \ldots \ldots \ldots$

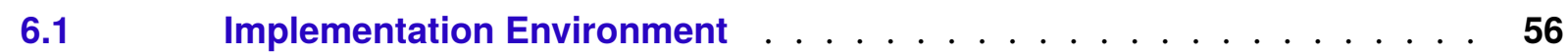

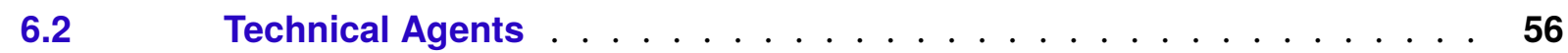

$6.3 \quad$ Financial Distress Prediction model . . . . . . . . . . . . . 59

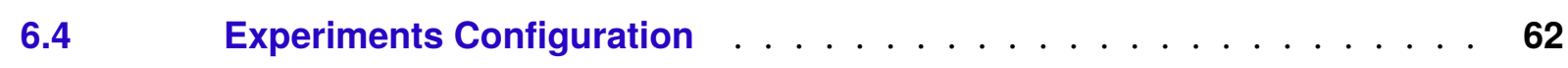

$6.5 \quad$ PROFTs Results $\ldots \ldots \ldots \ldots \ldots \ldots$

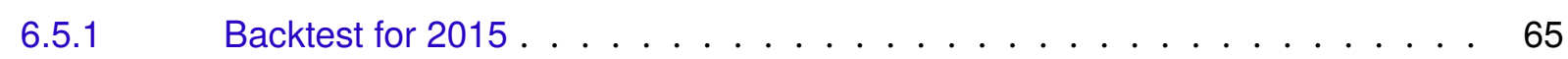

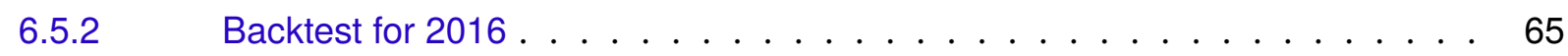

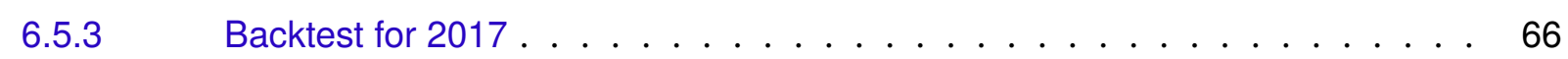

$6.6 \quad$ Results Analysis . . . . . . . . . . . . . . . 67

6.6.1 Financial distress prediction hypotheses . . . . . . . . . . . 67

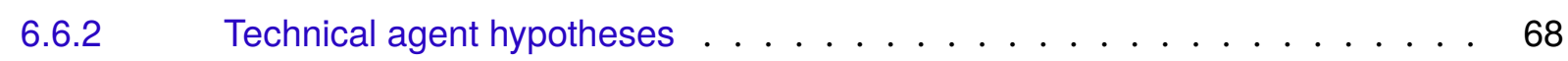

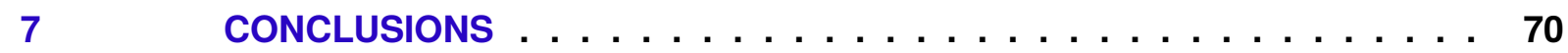

A TECHNICAL AGENTS RESULTS . . . . . . . . . . . . . 71

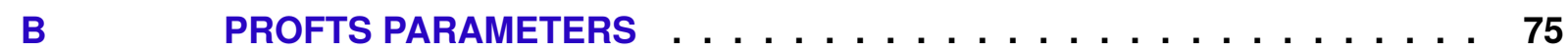

C PROFTS RESULTS . . . . . . . . . . . . . . . 77

C.1 Backtest for $2015 \ldots \ldots \ldots \ldots \ldots$

C.2 Backtest for $2016 \ldots \ldots \ldots \ldots \ldots$

C.3 Backtest for $2017 \ldots \ldots \ldots \ldots$

D HYPOTHESES TESTING RESULTS $\ldots \ldots \ldots \ldots$

D.1 Financial distress prediction hypothesis . . . . . . . . . . . 89

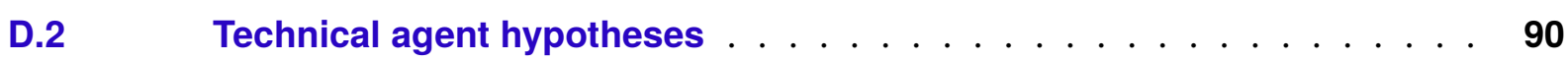

BIBLIOGRAPHY . . . . . . . . . . . . . . . . . . . 91 


\section{INTRODUCTION}

Multi-Agent Systems (MAS) have been studied as a scientific field since 1980, and gained recognition in the mid of 1990s. Its popularity is in part motivated by the belief that it is an appropriate software paradigm to deal with distributed systems (WOOLDRIDGE, 2009). Although there have been an extensive discussion and investigation about the subject in the scientific community for several years, its commercial application is relatively new. It ranges from small systems, as personal assistants, to open and complex systems, as transportation logistics (BELLIFEMINE; CAIRE; GREENWOOD, 2007).

One of these complex applications belongs to the field of Computational Finance ${ }^{1}$, and is related to automated trading systems (ATS). An ATS can manage a portfolio of assets autonomously. Portfolio management is a problem with unknown optimal solution, and the stock market is a complex and dynamic environment. Based on these characteristics, an agent-oriented system is a suitable approach to solve this problem, because (i) agents are autonomous, they operate without human interference and have control about their actions and internal states, (ii) they are social, they can cooperate and/or compete to achieve their tasks, (iii) they are reactive, perceiving their environment and acting to change it, and (iv) they are also proactive, exhibiting a goal-directed behaviour (BELLIFEMINE; CAIRE; GREENWOOD, 2007).

\subsection{MOTIVATION}

The problem of creating an optimal portfolio come from the economic theory of choice, and it is complex because stocks are risky, leading to a decision problem under uncertainty (ELTON, 2014).

In order to create an optimal portfolio, one should consider investor's objectives. The optimal portfolio is the efficient portfolio that has the highest utility for a given investor (REILLY, 2012).

An utility function is formed by estimates of probability distribution of returns combined with a level of risk aversion. However, most people are not able to form estimates of probability without bias, because they always prefer a known risk when faced with an uncertain risk: this is called ambiguity aversion in financial decision making. Since prior probabilities are unavailable for analysts, they subjectively quantify this ambiguity, thus paying for their subjectivity by not maximizing their utility (KUMIEGA; VLIET, 2012).

This favours the use of automated trading systems, because there is no such subjectivity in a computer. They follow rules and can create objective and unbiased estimates of risk. This is

\footnotetext{
${ }^{1} \mathrm{~A}$ branch of applied computer science and finance.
} 
why Kumiega and Vliet (2012) claimed that ATS represents a revolution in art and theory of finance.

One suitable approach to build an ATS is by using Multi-Agent Systems (MAS). A MAS is composed of a number of agents that interact exchanging messages throught some network infrastructure. They can have different goals and motivations for acting, and for a successful interaction, they may need to cooperate, coordinate, and negotiate with one another. There are many definitions of agents, one of them states that "an agent is a computer system that is situated in some environment, and that is capable of autonomous action in this environment in order to meet its delegated objectives" (WOOLDRIDGE, 2009).

In this case, the environment is the the stock market, and it is a complex environment, due to its characteristics, that are: partially observable, multi-agent, stochastic, sequential, dynamic, continuous, and unknown ${ }^{2}$, what turns the development of a MAS for automated trading very challenging.

Most automated trading system and strategies relies on technical analysis/data (see Table 1), that is the investigation of market past patterns to forecast future price trends (MURPHY, 1999). Just a few works utilize the fundamental analysis/data, that relies on company's financial characteristics as expected growth, risk profile and cash flow (DAMODARAN, 2010), and fewer consider the use of both. However, there are evidence that the use of both provide better results (BETTMAN; SAULT; SCHULTZ, 2009; ZWART et al., 2009), and human traders also use both analysis (LUI; MOLE, 1998; OBERLECHNER, 2001), using fundamental analysis for a longer time horizon and technical for shorter.

Faced with the challenging task of portfolio management, we propose in this work an architecture for an automated trading system that manages an active stock portfolio, combining both fundamental and technical analysis, for different types of investor's risk profile.

\subsection{OBJECTIVES}

The main objective of this dissertation is to propose a possible solution to the problem of autonomous portfolio management.

As a specific goal, we propose a MAS based architecture to autonomously manage an active portfolio of stocks, using both fundamental and technical analysis. It uses fundamental analysis for long-term trades, and technical analysis for short-term opportunities, and also to control portfolio's risk-return goals, based on investor's profile. Additionally, we propose the use of a financial distress prediction model for stock picking aiming to reduce risk.

${ }^{2}$ More details about each of these characteristics may be found in Russell and Norvig (2010). 


\subsection{METHOD}

To pursue the proposed objectives, this work was developed on the following steps:

1. The first step was a bibliographic survey and theoretical basis research about the subjects that were present in this work and related work. It was a continuous step to keep up with recent publications on the field;

2. Secondly, with the theoretical background acquired, it was formulated and presented the proposed system architecture (see chapter 5);

3. The next step was the agents implementation, i.e. information, technical, fundamentalist and coordinator agents;

4. With the system operational, the experiments and hypotheses were defined;

5. The experiments were conducted, combining different agents and investor's profiles, and the hypotheses were tested throughout a statistical method;

6. Finally, the conclusions were drawn and further works were proposed.

The architecture will be composed by technical and fundamentalist agents, responsible for the above mentioned analysis, whose activities are controlled by a coordinator agent. Additionally, information agents gather information about the companies in the internet. This architecture is detailed in section 5.3.

\subsection{CONTRIBUTION}

Our first contribution is the use of relative valuation with peer group average adjusted for differences in the fundamentalist agent (DAMODARAN, 2006, p. 49), but instead of using comparable companies from the same sector, we propose the use of a partitioning-based clustering algorithm, to autonomously find similar companies based on its characteristics. As far as we know, there has not been any automated trading system built based on it.

Despite its use in exploring short-term opportunities, our second contribution is the use of technical analysis to control portfolio goals. The technical agents use a support vector machine model to make their recommendations, where the inputs are technical indicators and its output is a probability of an upward movement or a downward movement in prices. The expected risk, return and sharpe ratio are used to control portfolio goals.

A third contribution is the combined use of a financial distress prediction model while using relative valuation, in the fundamentalist agent. Relative valuation compares if a company is undervalued relatively to its peers, but it does not consider if this company is financially health, 
hence, after selecting potential undervalued companies, a financial distress prediction model is applied to filter out companies that has a high probability of going bankrupt.

\subsection{TEXT ORGANIZATION}

This dissertation is organized as follow: chapter 2 presents the finance theory on which this dissertation relies and chapter 3 presents the artificial intelligence theory, that covers some theory about agents and multi-agent systems, and machine learning. In chapter 4 , the related works are presented with our proposed architecture detailed in chapter 5 . In chapter 6 , the experiments are outlined and their results are presented, concluding with chapter 7 with some final remarks and further work. 


\section{FINANCE THEORY}

In this chapter, the main concepts of Finance Theory that were used in this work are presented. It starts with an introduction to capital markets and some theories about its efficiency. In section 2.2, the modern portfolio theory and active portfolio management are presented, concluding in section 2.3 with fundamental and technical analysis.

\subsection{INTRODUCTION}

The Financial System can be basically divided into four big markets: Capital Market, Money Market, Credit Market and Interbank Market. Each of them have their peculiarities and rules. They are basically providing financial flow between capital savers and takers, or buyers and sellers. This section presents a brief introduction to the Capital Market and the Stock Market. Its contents are based in CVM (2013).

In the Capital Market, the surplus agent, the one that has money to invest, lends to the deficit agent. This operation is intermediated by a financial institution and is represented in Figure 1. Capital market securities includes instruments with maturities greater than one year and those with no maturity at all.

Figure 1 - Capital Market

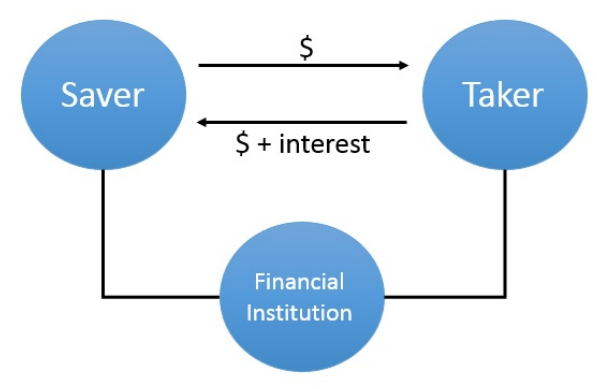

Source: Adapted from CVM (2013)

These financial institutions provide liquidity to the market, structure the operations, as many other services, while the supplier of capital provide capital for businesses, government and individuals to put it to long-term productive use. Capital Market includes the primary market, where new stocks and bonds are sold to investors, and the secondary market, where stocks and bonds are later traded.

Stocks are negotiated at the Stock Market, i.e. the secondary market, where it is possible to buy/sell shares (a.k.a. equity securities) of publicly traded companies. When an investor buy a share of a company, she or he acquire ownership of this company, being eligible to receive 
dividends (a distribution of a company's earnings) and even decide about management issues through the vote in corporate actions.

A privately held company can be transformed into a public company offering its shares through an Initial Public Offering (IPO). This is done at the primary market. The Brazilian stock market was BM\&FBOVESPA, that has recently merged with Cetip (Over-The-Counter market), originating B3 (Brasil, Bolsa, Balcão). The Brazilian legislation allows different kind of stocks, that gives to its owners different rights. They are:

- Common Share $(\mathrm{ON})$ - The owner has the right to vote in the Shareholder's meeting;

- Preferred Share (PN) - Owner cannot vote, but the owner has priority on the distribution of dividends and the repayment of capital. PNs can have an additional classification as "A","B", etc, where the specific rights of each class is described at the Company's Bylaws.

Most modern capital markets are hosted on computer-based electronic trading system, including B3, that can be accessed directly by the public. These electronic trading system are an ideal environment for the development of automated trading systems.

The price of a stock can be affected by several reasons such as political decisions, acquisitions, accidents, among other events. The price, by some measure, should reflect all the available information about a company. There are some theories that explains this market efficiency and its inefficiencies.

\title{
EFFICIENT-MARKET HYPOTHESES
}

In 1970, Eugene F. Fama published its definitive paper on the efficient markets hypotheses. According to Fama (1970), an efficient market is:

\begin{abstract}
[...]In general terms, the ideal is a market in which prices provide accurate signals for resource allocation: that is, a market in which firms can make production-investment decisions, and investors can choose among the securities that represent ownership of firm's activities under the assumption that security prices at any time "fully reflect" all available information. A market in which prices always "fully reflect" available information is called "efficient".
\end{abstract}

Although Fama was highly enthusiastic with its conclusion for market efficiency, in his first article (FAMA, 1970), he also reported some anomalies, like slight serial dependencies ${ }^{1}$ in stock market returns, which he minimized.

Throughout the next years, a lot of other anomalies were reported, starting with the work of Officer (1975 apud DIMSON, 1988) on seasonals for the Australian share market, and Rozeff

\footnotetext{
${ }^{1} \mathrm{~A}$ random time-series variable has serial dependence if the value at some time $t$ in the series is statistically dependent on the value at another time $s$.
} 
and Kinney (1976 apud DIMSON, 1988) for the US market. Then, Basu (1977 apud DIMSON, 1988) detailed a price/earnings anomaly, as well as Marsh (1979 apud DIMSON, 1988) with small firm regularity.

These anomalies are empirical results inconsistent with EMH and theories of asset-pricing behaviour, because through its exploration it was possible to get an abnormal return compared to the market. Economic bubbles are another kind of anomaly, driven by investor's irrationality. All these issues, lead to a new theory called Behavioural Finance.

\section{BEHAVIORAL FINANCE}

Through the next years, researchers and practitioners discovered that key forces that support efficient market, such as arbitrage ${ }^{2}$, were much more weak and limited than expected. Behavioural finance has emerged as an alternative view of financial markets. It explains, empirically, anomalies that appears in markets and generates new predictions for them (SHLEIFER, 2000, p. 11).

Behavioural finance study human fallibility in competitive markets. It is based on two major foundations, the first one is limited arbitrage, and the second is investor sentiment (a.k.a. cognitive psychology) (SHLEIFER, 2000, p. 33). Arbitrage, in real-world, is far from perfect. Many securities do not have perfect or even good substitutes, and even when there is a good substitute it is still risky, because prices do not converge to fundamental values instantaneously. Regarding investor sentiment, cognitive psychologists have documented many behavioural patterns, like overconfidence and conservatism. More patterns can be found in Ritter (2003).

Behavioural finance has provided theory and evidence which explain the deviations of securities prices from fundamental values and why they persist over time, without being eliminated by arbitrage. The term "Anomalies" used in EMH become "regularities" explained by behavioural finance.

\subsection{MODERN PORTFOLIO THEORY}

Market agents need to efficiently balance their resources among different types of return/risk securities, generally combining high return/risk securities with lower ones. Choosing the best mix of securities is necessary to make optimal capital allocation decisions. The following theory is based on Alexander (2008).

What is regarded as optimal depends on investor's perceived trade-off between risk and return. Its preference is represented by a utility function $U: \Omega \rightarrow \mathbb{R}$, where $\Omega$ is the space of all

\footnotetext{
${ }^{2}$ It is a risk-free trade that explore the differences of identical or similar financial instruments on different markets or in different forms. It ensures prices do not deviates substantially from its fair value for a long period of time, reinforcing market efficiency.
} 
possible outcomes to the real numbers $\mathbb{R}$. The expected utility of an investment $P$ is defined by Equation 2.1

$$
E[U(P)]=\sum_{i=1}^{n} p_{i} U\left(W_{i}\right)
$$

where $W_{1}, \ldots, W_{n}$ are the possible outcomes from investments with probabilities $p_{1}, \ldots, p_{n}$. A rational investor always prefers the investment that has maximum expected utility, so the optimal allocation problem may be approximated by the optimization in Equation 2.2. This is the mean-variance criterion.

$$
\underset{w}{\operatorname{Maximize}}\left\{\mathbf{w}^{\prime} E(\mathbf{r})-\frac{1}{2} \gamma \mathbf{w}^{\prime} \mathbf{V} \mathbf{w}\right\}
$$

The expected portfolio return is $\mu=\mathbf{w}^{\prime} E(\mathbf{r})$ where $\mathbf{w}$ is the vector of weights and $\mathbf{r}$ is the vector of returns. The portfolio variance is $\sigma^{2}=\mathbf{w}^{\prime} \mathbf{V w}$ where $\mathbf{V}$ is the covariance matrix of the asset returns.

Mean-variance analysis is the fundamental principle of portfolio diversification to reduce risk, introduced by Markowitz (1952). It assumes that assets have already been selected, and asks how to make the best choice for the portfolio weights $w$.

The problem of choosing $w$, so that portfolio variance is minimized, can be formulated by Equation 2.3

$$
\begin{array}{ll}
\underset{w}{\operatorname{Minimize}} & \mathbf{w}^{\prime} \mathbf{V w} \\
\text { subject to } & \sum_{i=1}^{n} w_{i}=1
\end{array}
$$

where $\mathbf{V}$ is the covariance matrix of asset returns and $\mathbf{w}$ is the vector of portfolio weights. It is necessary to add a constraint of non-zero allocation, otherwise the obvious solution would be $\mathbf{w}=0$, because if you do not make any investment you have no risk.

In 1959, Markowitz introduced another constraint on the minimum variance problem, that the portfolio should meet or exceed a desired target return DTR. The optimization problem becomes Equation 2.4

$$
\begin{array}{ll}
\underset{w}{\operatorname{Minimize}} & \mathbf{w}^{\prime} \mathbf{V w} \\
\text { subject to } & \sum_{i=1}^{n} w_{i}=1 \\
& \mathbf{w}^{\prime} E(\mathbf{r})=D T R
\end{array}
$$


where $E(\mathbf{r})$ is the vector of expected returns on each asset and $E(r)=D T R$ is a target level for the portfolio return. Many other constraints can be added, but the optimization problem can become unsolvable. Another common constraint is that no short sales are allowed, i.e. the weights should never be negative

$$
\begin{array}{ll}
\underset{w}{\operatorname{Minimize}} & \mathbf{w}^{\prime} \mathbf{V} \mathbf{w} \\
\text { subject to } & \sum_{i=1}^{n} w_{i}=1 \\
& \mathbf{w}^{\prime} E(\mathbf{r})=D T R \\
& w_{i} \geq 0, \forall i
\end{array}
$$

In Figure 2a, the bold line is called efficient frontier, because if a portfolio lies on the bold line, it is not possible to have a higher expected return for the same level of risk, or less risk for the same level of expected return. It is also possible to see the global minimum variance portfolio and a minimum variance portfolio having return at least $R$, that is given by Equation 2.4.

Figure 2 - Efficient frontier and indifference curves.

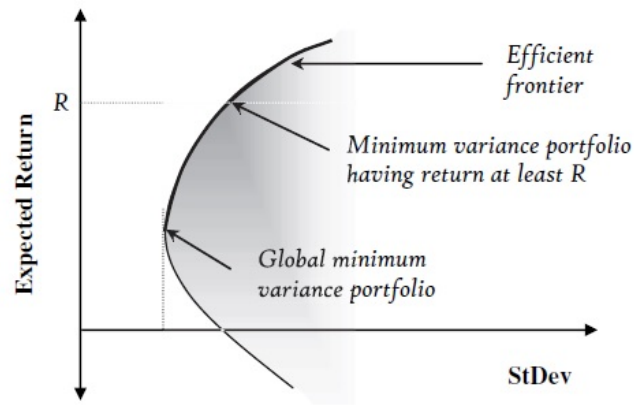

(a) The efficient frontier.

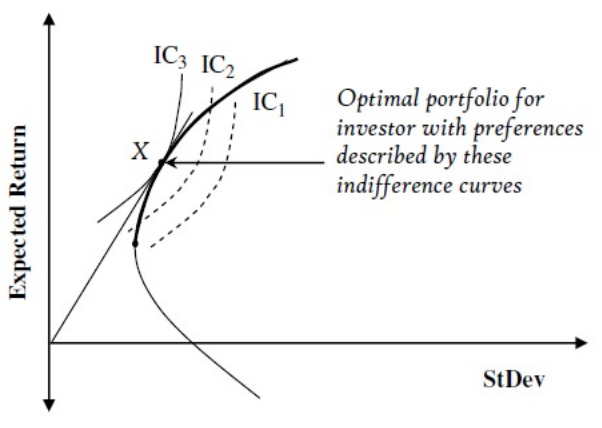

(b) Indifference curves of risk averse investor.

Source: Alexander (2008)

An optimal allocation is subjective and depends on investor's preferences, i.e. its utility curve. Different efficient portfolios are chosen by different investors. When analysing an investor preference and its optimal efficient allocation, it is necessary to analyse its indifference curves. At an indifference curve, each point has the same level of utility. In Figure $2 b$ it is possible to see at $I C_{2}$, that the investor is indifferent between some high risk and high return and some low risk and low return portfolios. The maximum achievable utility is represented by $I C_{3}$, and this is the optimal portfolio for this investor, actually this is also the tangency portfolio, which is called the portfolio with maximum Sharpe ratio. It has the highest possible mean-standard deviation ratio. 


\section{PORTFOLIO MANAGEMENT}

Portfolio management can be active or passive. In order to establish a distinction between them, it is necessary to decompose the total actual return produced by the portfolio according to Equation 2.6

$$
\begin{aligned}
\text { Total Actual Return } & =[\underbrace{[\text { Expected Return }]+[\text { 'Alpha'] }}_{\text {Pctive }} \\
& =\underbrace{[\text { Risk-Free Rate }+ \text { Risk Premium }]}_{\text {Passive }}+[\text { 'Alpha'] }
\end{aligned}
$$

Passive portfolio management tries to receive the expected return consistent with its risk level ${ }^{3}$, while active portfolio management tries to beat the market with an extra performance, capturing the "alpha", i.e. the excess return relative to the return of a benchmark index, net of transaction costs and on a risk-adjusted basis.

Active management tries to beat the market using a single or combined investment analysis strategies, that can be fundamental or technical. More information about the difference between them is presented in the next section.

\subsection{INVESTMENT ANALYSIS}

In this section, it is presented two kinds of investment analysis, fundamental analysis in subsection 2.3.1 and technical analysis in subsection 2.3.2.

\subsubsection{FUNDAMENTAL ANALYSIS}

Fundamental analysis intend to identify the intrinsic value of a company. It relies on statistic, examining auditor's reports, profit-and-loss statement, balance sheets, managerial reports, etc (EDWARDS; MAGEE; BASSETTI, 2012).

It can be "Top down" or "Bottom up". Top down starts analysing the country and asset class allocations, and progresses down through sector allocation decisions, finishing with the selection of individual stocks. At bottom up, the stock is analysed without an initial market or sector investigation, that can be later considered.

A bottom-up approach, forms a portfolio of undervalued securities. It uses some valuation model to capture the real (or intrinsic) value of a company, it can be (i) a discounted cash flow model or (ii) the price comparison between similar firms, to find over/undervalued companies through relative valuation.

${ }^{3}$ more information about passive portfolio management can be found in Reilly (2012). 
The discounted cash flow approach values an asset calculating the present value of its expected future cash flows. It considers expected growth, cash flows and risk, more information can be found in Damodaran (2006).

For relative valuation, there are two components that need to be determined. The first one is to value assets on a relative basis. To do that, it is used multiples, that are price standardization. The multiples used in this dissertation are:

- P/E: Price to Earnings ratio - It is the ratio of a company's share price to the company's earnings per share.

$$
\mathrm{P} / \mathrm{E}=\frac{\text { share price }}{\text { earnings per share }}
$$

- P/B: Price to Book Value - It is the ratio of a company's share price to the company's book value per share.

$$
\mathrm{P} / \mathrm{B}=\frac{\text { share price }}{\text { book value per share }}
$$

- PSR: Price to Sales ratio - It is the ratio of a company's share price to the company's sales per share.

$$
\text { PSR }=\frac{\text { share price }}{\text { sales per share }}
$$

- EV/EBITDA: Enterprise value to Earnings Before Interest, Taxes, Depreciation and Amortization - It is the ratio used to determine the value of a company.

$$
\begin{aligned}
& \mathrm{EV}=\text { Market value of equity }+ \text { Market value of debt }- \text { Cash holdings } \\
& \mathrm{EV} / \mathrm{EBITDA}=\frac{\mathrm{EV}}{\mathrm{EBITDA}}
\end{aligned}
$$

The second component is to find similar assets, which is where the challenge remains, because even assets from the same sector can have different characteristics. (DAMODARAN, 2010).

Companies can be compared using: (i) Direct comparisons, (ii) Peer group average, and (iii) Peer group average adjusted for differences (DAMODARAN, 2006).

Direct comparison is the approach utilized when an analyst tries to find one or two very similar companies and compares their prices, estimating the value of the target company based on the others very similar companies. The challenge here is to identify these similarities (DAMODARAN, 2006).

Peer group average is the approach utilized when an analyst compares the price of a company with the average of the peer group. A stock is considered undervalued if the multiple used for comparison is below the average multiple of the peer group, and overvalued otherwise. It assumes that, despite companies can vary widely across a sector, the average for the sector is representative (DAMODARAN, 2006). 
The final approach is the peer group average adjusted for differences. In this approach, the analyst accepts that there are differences between the company that is being evaluated and those from the comparable companies group, and tries to control these differences, e.g. thought a multivariable regression (DAMODARAN, 2006).

The last approach is used in this dissertation and the similar companies are clustered using an unsupervised learning algorithm (PAM). To adjust the differences through a multivariable regression, it is necessary to represent each multiple as a function of some determinants variables. Damodaran (2010) exemplifies some multiples and its determinants in Equation 2.7

$$
\begin{aligned}
P / E & =f(\text { growth,payout ratio,risk) } \\
P / B & =f(\text { growth,payout ratio,risk, } \mathrm{ROE}) \\
P S R & =f(\text { growth,payout ratio,risk,margin) }
\end{aligned}
$$

The determinants variables used in this dissertation are:

- Beta: It is a measure of risk. It measures the volatility of a stock compared to the market as a whole (Generally it is used an index like Ibovespa).

$$
\beta_{s}=\frac{\operatorname{Cov}\left(r_{s}, r_{m}\right)}{\operatorname{Var}\left(r_{m}\right)}
$$

where $r_{s}$ and $r_{m}$ are the return of stock $s$ and index $m$, representing the market.

- Volatility: It is another measure of risk. It is the standard deviation of returns. It was used the annualized volatility.

$$
\sigma_{\text {annually }}=\sigma_{\text {daily }} \sqrt{252}
$$

- ROE: Return on Equity - It is a measure of profitability. It takes the amount of net income returned as a percentage of shareholders equity.

$$
\mathrm{ROE}=\frac{\text { Net Income }}{\text { Shareholder's Equity }}
$$

- Payout Ratio: It is the proportion of earnings paid out as dividends to shareholders.

$$
\text { Payout Ratio }=\frac{\text { Distributed Dividends }}{\text { Net Profit }}
$$

- Expected Growth in Net Income: It is the product between reinvestment rate and return on equity, where:

$$
\begin{aligned}
& \text { Reinvestment rate }=\frac{\text { CAPEX }- \text { Depreciation }+\Delta \text { Working Capital }-\Delta \text { Debt }}{\text { Net income }} \\
& \text { Expected growth in net income }=\text { Reinvestment rate } * \text { ROE }
\end{aligned}
$$


- Expected Growth in EPS: It is the product between retention rate and return on equity, where:

$$
\begin{aligned}
& \text { Retention rate }=1-\text { Payout Ratio } \\
& \text { Expected growth in EPS }=\text { Retention rate } * \text { ROE }
\end{aligned}
$$

Each determinant variable that will define the multiple are chosen through an exhaustive regression subset selection.

\section{Financial Distress Prediction Model}

This subject is an interdisciplinary topic that combines Supervised Learning (subsection 3.2.2) and Finance Theory. This research field is also known as corporate failure, bankruptcy prediction or default probability and aims to predict whether or not a company will suffer some financial difficulty (SUN et al., 2014).

There are several definitions for financial distress, all of them are related to some level of insufficiency of liquidity. In this work, a company with financial distress is the one that entered in a statutory bankruptcy proceeding, more specifically, companies that went bankrupt or entered under court-supervised reorganization (BRASIL, 2005).

Predicting such events can avoid large loses when investing in the stock market, specially when using relative valuation, as it is a simpler way of evaluating a company comparing itself to its peers and using few or none information about company's liquidity capacity.

The prediction models can be built using mathematical, statistical or intelligent models. Recent researches concluded that intelligent methods are superior to the traditional statistical ones regarding accuracy (OLSON; DELEN; MENG, 2012; SUN et al., 2014; ABELLÁN; MANTAS, 2014; ALAKA et al., 2018).

\subsubsection{TECHNICAL ANALYSIS}

Technical analysis uses past stock price to imply about future price movements. It assumes that (i) past stock price trends will continue in the same direction, or (ii) they will reverse themselves. This section is based in Murphy (1999) and Edwards, Magee and Bassetti (2012).

The first assumption derives the price momentum strategy, with the assumption that stocks that are on a trend will continue in the same movement. This can be due to economic reasons (e.g. company's revenue and earning are continually growing), or because investors periodically underreact to the arrival of new information (evidence from behavioural finance).

The second assumption derives the constraint investment strategy, and is based on the belief that the best time to buy is when the majority of other investors are bearish (a downside trend) and sell when they are bullish (an upside trend). In other words, the strategy tries to buy 
when stock price is near to its lowest price and sell it when it is near its peak. It assumes that stock returns are mean reverting.

To support these strategies, an analyst uses a lot of different indicators, e.g. trend, volume, oscillators indicators, etc. Each indicator can also have different parameters, e.g. a moving average with different periods to capture short, medium or long term trends.

In this dissertation, these technical indicators are used as input features for a machine learning model. As they are numerous, a feature selection is applied and they are chosen through cross-validation.

The most important technical indicator, in our case, is the ZigZag indicator. It is used to create the labels for supervised classification and work as a filter for noise and pattern identification (RAFTOPOULOS, 2003). It ignores movements that are less than a specific threshold. In Figure 3 the ZigZag indicator was applied at Ibovespa index with a $6 \%$ threshold and it is represented by the blue line. When the line has an inclination greater than zero, then a "buy" label is assigned to the observation, when its inclination is lower than zero, then a "sell" label is assigned.

Figure 3 - ZigZag of $6 \%$ applied to Ibovespa (2010) to create labels for classification.

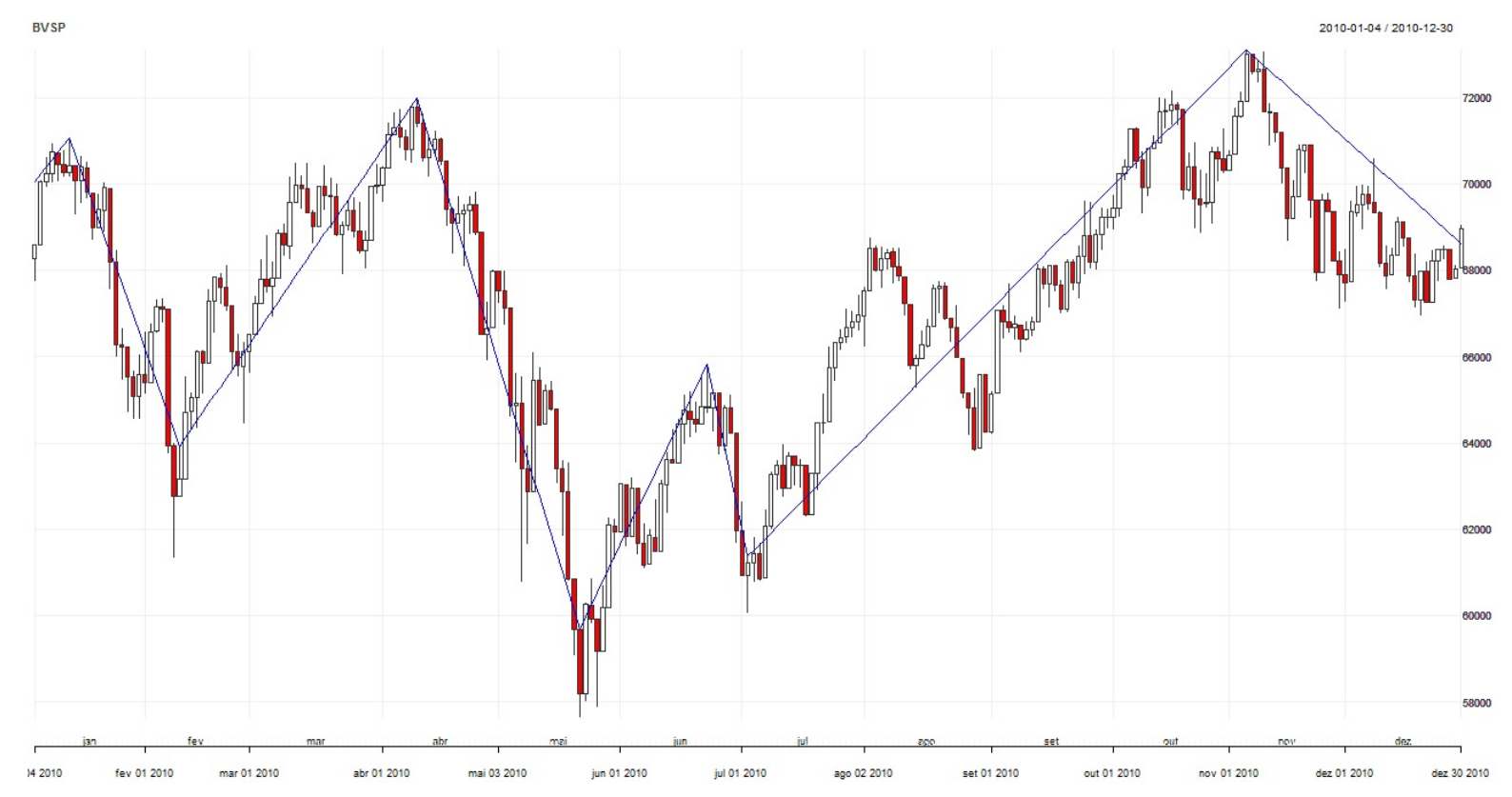




\section{ARTIFICIAL INTELLIGENCE THEORY}

In this chapter, a brief theoretical basis of each topic that was necessary to develop this work is presented. It starts with section 3.1, where the theory about intelligent agents and multi-agent systems are presented. In section 3.2, the theory about machine learning is briefly described.

\subsection{INTELLIGENT AGENTS}

\subsubsection{AGENTS}

Despite the fact that there is not a universally accepted definition for agent, there is a common consensus that autonomy is a central point for agency. Autonomy is domain dependent, here it expresses the ability of an agent to act without the intervention of humans or other systems, through the control of its internal state and its behaviour (WOOLDRIDGE, 1999, p. 28-29).

An abstract, top-level view of an agent is presented in Figure 4. The agent perceives its environment through some kind of sensor and performs some action, transforming it. The concept of environment is an important one for MAS.

When an environment is complex, an agent does not have complete control over it, and an action may not have always the same result or can even fail, duo to a non-deterministic environment.

Figure 4 - Intelligent agent and its environment

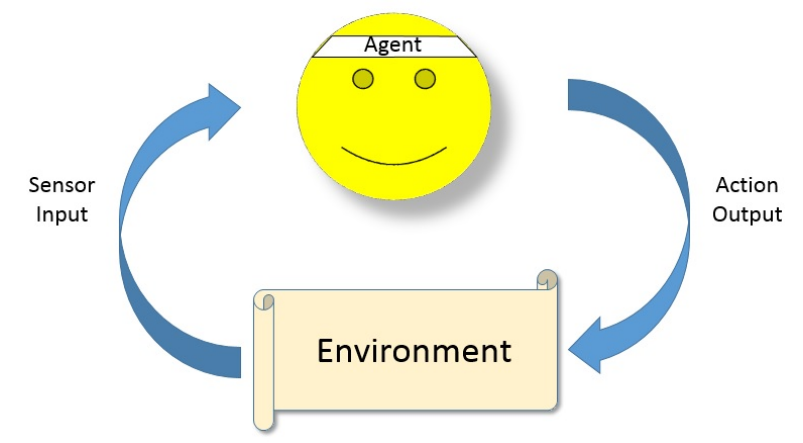

Source: Adapted from (WOOLDRIDGE, 1999).

An agent architecture is a software architecture for decision making systems embedded in an environment (WOOLDRIDGE, 1999, p. 30). 


\section{REACTIVE AGENTS}

Reactive agents are based on reactive architectures. These architectures are founded in the rejection of symbolic representation and syntactic manipulation for decision making. Intelligent behaviour is linked to the environment an agent occupies, it is not disembodied, but is a product of the interaction the agent maintains with its environment. Intelligent behaviour emerges from the interaction of various simpler behaviours (WOOLDRIDGE, 2009).

Reactive architectures are simple, economic, computational tractable, robust against failure and elegant. However, such architectures presents some problems, as pointed out by Wooldridge (2009):

- If the agent does not have a model of its environment, then must have sufficient information available in its local environment to act.

- A purely reactive agent make decision based on local information, then non-local information could be a problem for decision making, leading to a "short term" view of acting.

- The properties "Learn from experience" and "improve its performance" are difficult do design in purely reactive agent.

- Design purely reactive agents is a trial and error process, because the relationship between individual behaviours, environment, and overall behaviour is not understandable, and from this relationship is what emerges intelligent behaviour.

- Finally, if an agent contain too much layers, it become too complex to understand, so it is necessary to design agents with small number of behaviours.

This type of agent is used to model the Information, Fundamentalist and Technical Agents. Each agent is detailed in subsection 5.3.1, subsection 5.3.2 and subsection 5.3.3 respectively.

\section{HYBRID AGENTS}

Before introducing hybrid agents, it is worth mentioning practical reasoning agents. Practical reasoning is composed of deliberation and means-end reasoning. The agent selects intentions considering its options and plans its actions to achieve its goals. The most famous model is the Belief-desire-intention (BDI) architecture. It is based on data structures (representing beliefs, desires, and intentions), and functions (representing its deliberation process and meansends reasoning). Through its functions, the agent decides what to do, and how to do that (WOOLDRIDGE, 2009). 
Hybrid agents are proposed when are necessary reactive and pro-active behaviour. They decompose its behaviours into separated subsystems, leading to a class of architectures in which various subsystems are arranged into a hierarchy of interacting layers.

At least two layers are necessary, to deal with reactive and pro-active behaviour. Its control flow within layered architectures can be done horizontally or vertically.

In horizontally layered architectures, the layers are directly connected to the sensory input and action output, as if each layer was an individual agent, producing suggestions of which action to perform. This architecture is presented in Figure 5.

Figure 5 - Horizontal layering

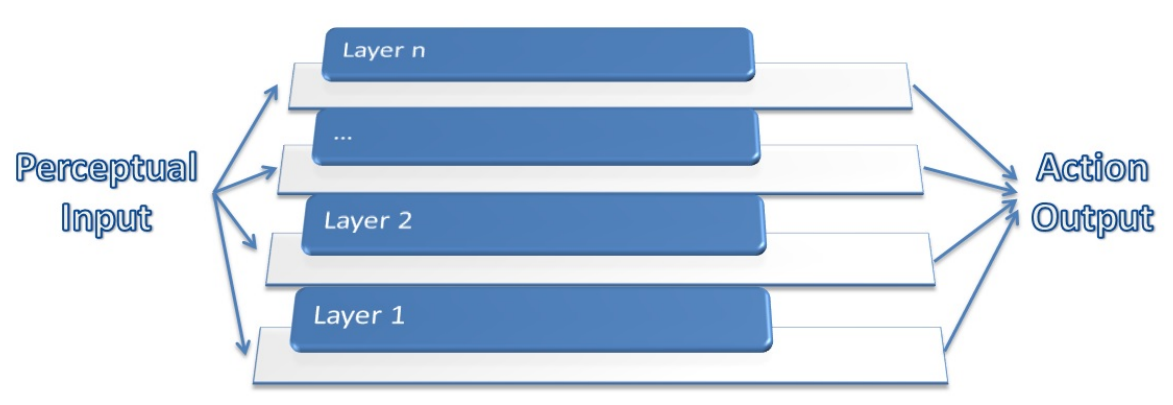

Source: Adapted from Wooldridge (1999)

In vertically layered architectures, sensory input and action output are each dealt by at most one layer. The architecture and its variations are presented in Figure 6a and Figure 6b.

Figure 6 - Information and control flow in vertical architectures

(a) Vertical Layering (One pass control)

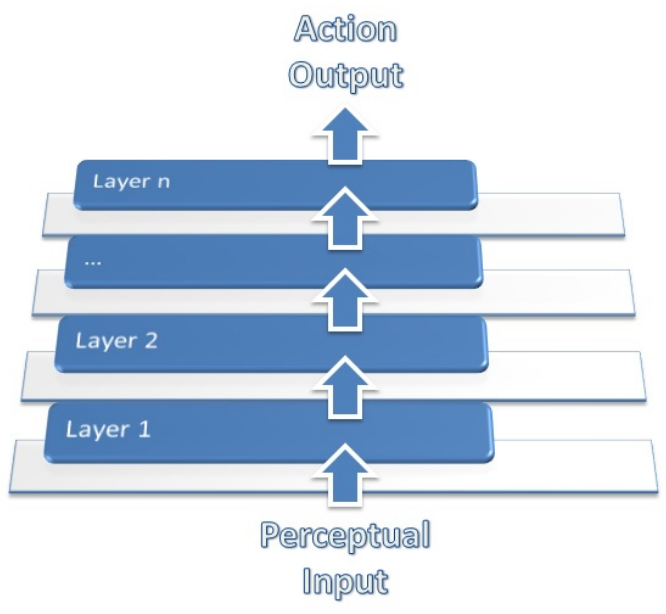

Source: Adapted from Wooldridge (1999) (b) Vertical Layering (Two pass control)

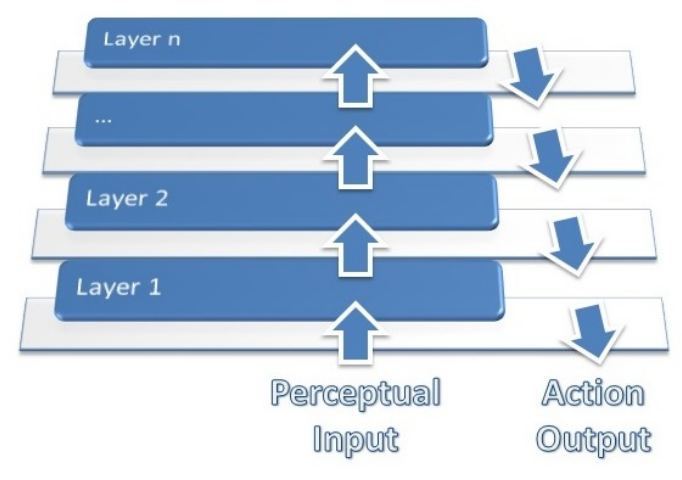

Source: Adapted from Wooldridge (1999)

Horizontally layered architectures are conceptually simple. If one needs an agent to exhibit $n$ different types of behaviour, then just implement $n$ different layers. However, it may cause an incoherent overall behaviour, because layers are in effect competing with one-another. In 
order to solve this problem, sometimes it is necessary a mediator function, selecting which layer has "control" over others at any given time. The adoption of a mediator function is problematic in two ways, the first one regards the design of all possible interaction between layers. If there are $n$ layers, and each layer is capable of suggesting $m$ possible action, then there are $m^{n}$ possible interactions to be considered in the design process. The second problem is that, the architecture becomes dependent of the mediator function, it introduces a bottleneck in the architecture.

These problems are partially alleviated in a vertically layered architecture. In one-pass architectures (Figure 6a), control flows sequentially through each layer, and the final layer produces an action output. In two-pass architectures (Figure 6b), information flows-up, and then control flows down (it is similar to an organization, where information flows up and commands flow down). In both architectures, the complexity of interactions decrease to a possible $m^{2}(n-1)$ number of interactions between layers. This came with the loss of flexibility, because control must pass between each different layer, and it is not fault tolerant, because if any layer fails, then the agent's performance can be seriously affected.

The architecture used in this work is similar to the one proposed by Castro (2009) called horizontally layered architecture with independent coordination. In his architecture, a failure in one layer does not affects critically the society, and the scalability problem of $m^{n}$ possible conflicts are minimized to $N(\mu) \times N(\phi)$, where $N(\mu)$ represents the number of possible strategies ( 2 in our case) and $N(\phi)$ is the number of stocks managed by the society. The architecture is detailed in section 5.3 and the Coordinator agent in subsection 5.3.4.

\subsubsection{MULTI-AGENT SYSTEMS}

Reactive agents have behavioural architectures, because they can be modelled in terms of their behaviours, as if each behaviour was a single agent. The same occurs with hybrid agents, that are based on a layered architecture, as if each layer was a single agent. These architectures were proposed to build single agents, but they can also be a multi-agent system, on condition that each behaviour, or layer, is implemented as a single agent.

Utility function

An important concept related to agents is the utility function. An agent acts based on its motivations and preferences. Given a situation, an agent has different preferences over each possible outcome, and the utility is a real number that expresses how "good" a certain outcome is for a given agent. The larger the number, the better its utility function (WOOLDRIDGE, 2009).

Utility function is a way of representing an agent's preference, and it is possible to think about them as money. The more money, the better. This comparison is well-suitable for the problem addressed in this dissertation.

For multi-agent decision making, utility functions are used to select outcomes. There 
are some solution concepts and properties that are used to select "the best" outcome, some of them are: dominant strategies, nash equilibria, Pareto efficiency and maximizing social welfare (WOOLDRIDGE, 2009).

\section{Social Welfare}

Social Welfare is not generally a way of directly selecting outcomes, but it is an important property of outcomes. The idea is simple: it measures how much utility is created by an outcome in total. Social welfare $s w(\omega)$, is denote by the sum of the utilities of each agent for an outcome $\omega$ and its formulation is given by Equation 3.1.

$$
s w(\omega)=\sum_{i \in A g} u_{i}(\omega)
$$

Where $A g$ is a set of agents, and $u_{i}$ is agent's utility function. The outcome that maximizes social welfare is the one that maximizes Equation 3.1. It considers the total wealth created instead of individuals pay-offs. This approach is relevant when the system have the same "owner", it is not important to worry about how utility is divided among agents, but how much is the overall utility, that is, how the system functions as a whole (WOOLDRIDGE, 2009).

\section{Combinatorial auctions}

Another important problem in multi-agent system is how to allocate scarce resources, and the mechanisms used to reach these agreements are auctions. Resources are scarce, and they are typically desired by more than one agent. Auctions are effective at allocating resources efficiently. When the resource is divisible, or there are many goods (identical or different), agents will have preferences over the possible bundles of goods. In order to deal with this kind of problem it is used combinatorial auctions (WOOLDRIDGE, 2009).

A combinatorial auction is a type of social choice where the outcomes correspond to the possible allocation of goods, and the preferences of each agent is given by its valuation function. It can be used to maximize social welfare. Let $s w(.$.$) be a function of social welfare in terms of$ agent's allocations:

$$
s w(\underbrace{Z_{1}, \ldots, Z_{n}}_{\text {allocation }}, \underbrace{v_{1}, \ldots, v_{n}}_{\text {valuations }})=\sum_{i=1}^{n} v_{i}\left(Z_{i}\right)
$$

Given a set of goods $\mathcal{Z}$ and a collection of valuation functions $v_{1}, \ldots, v_{n}$, one for each agent $i \in A g$, the goal is to find an allocation $Z_{1}^{*}, \ldots, Z_{n}^{*}$ that maximizes the function $s w$, i.e.

$$
Z_{1}^{*}, \ldots, Z_{n}^{*}=\underset{\left(Z_{1}, \ldots, Z_{n}\right) \in \operatorname{arloc}(\mathcal{Z}, A g)}{\arg \max } \operatorname{sw}\left(Z_{1}, \ldots . Z_{n}, v_{1}, \ldots, v_{n}\right)
$$


The problem of computing the optimal allocation $Z_{1}^{*}, \ldots, Z_{n}^{*}$ is called the winner determination problem (WOOLDRIDGE, 2009).

One popular approach to solve the winner determination problem is to formulate it as an integer linear programming problem, and it has the form of Equation 3.2.

$$
\begin{array}{cl}
\operatorname{maximize} & f\left(x_{1}, \ldots, x_{k}\right) \\
\text { subject to } & \phi_{1}\left(x_{1}, \ldots, x_{k}\right) \\
& \phi_{2}\left(x_{1}, \ldots, x_{k}\right) \\
& \vdots \\
& \phi_{l}\left(x_{1}, \ldots, x_{k}\right)
\end{array}
$$

These ideas are used by the Coordinator agent when it needs to decided where to allocate its resources between different Technical agent recommendations. The recommendations are received as a result of a call for proposals, that is part of a contract net protocol. The contract net protocol is a high-level protocol where one agent (the Initiator), i.e. the coordinator agent, wishes to have some task performed, i.e open a long position, and asks for other agents (the Participants) for proposals, i.e. technical agent recommendations, trying to optimize a function that characterizes the task, i.e. the investor profile's goal (SMITH, 1980). The best proposal is chosen and a new position is opened. The FIPA implementation of contract Net-Protocol used by coordinator agent is presented in Figure 7.

Figure 7 - FIPA Contract Net Interaction Protocol.

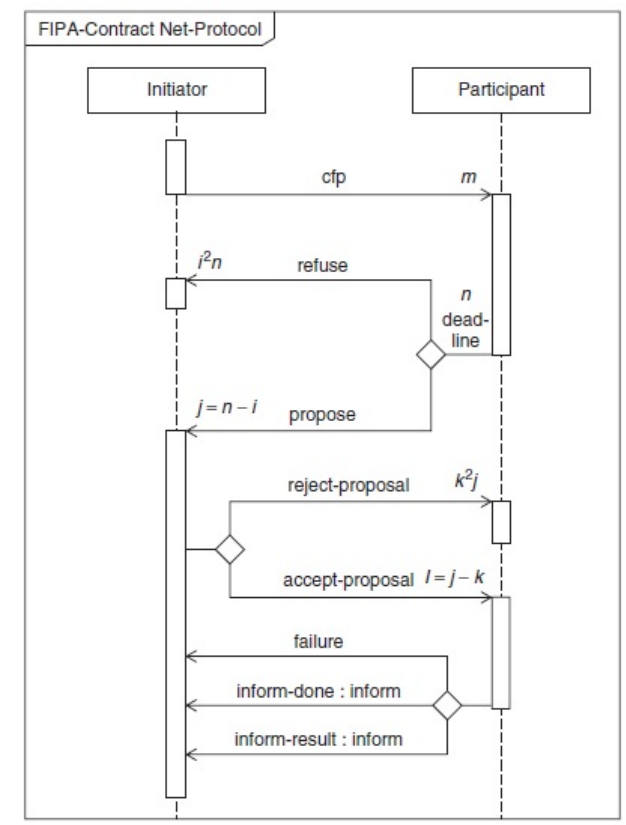

Source: Bellifemine, Caire and Greenwood (2007)

This process is better detailed in subsection 5.3.4. 


\subsection{MACHINE LEARNING}

According to Mitchell (1997), the field of machine learning is concerned with the question of how to develop computer programs that automatically improve with experience. Machine learning tasks are typically divided into two broad categories: supervised and unsupervised learning.

In supervised learning algorithms, a training set of examples with the correct responses (targets) are given and, based on this training set, the algorithm generalizes to respond correctly to all possible inputs (MARSLAND, 2009).

In unsupervised learning, the algorithm has no information about the correct output, and tries to find similarities between different inputs without external guidance. Throughout its exploration, it can cluster the observations that are similar, classifying them automatically. So, the main goal of unsupervised learning is to find clusters of similar inputs in the data without being explicitly told to, grouping similar observation by classes (MARSLAND, 2009, p. 195).

This section introduces the necessary theory regarding artificial intelligence and machine learning for this dissertation. At subsection 3.2.1, feature selection is introduced and the selected method is explained. In subsection 3.2.2, supervised learning methods are introduced, and unsupervised methods are described in subsection 3.2.3.

\subsubsection{FEATURE SELECTION}

Feature selection is the process of selecting a subset of relevant features to build a machine learning model. It is used when data contains many features that are either redundant or irrelevant. This process is necessary because an exhaustive search, in most cases, is prohibitive, the search space is $2^{N}$, where $N$ is the number of features.

According to Guyon and Elisseeff (2003, p. 1158), other benefits of using feature selection include: "facilitating data visualization and data understanding, reducing the measurement and storage requirements, reducing training and utilization times, [and] defying the curse of dimensionality to improve prediction performance".

We have realized an experiment applied to Ibovespa index comparing different feature selection methods, including different combinations of them (REIS; CASTRO; SICHMAN, 2016) . Based on the results, it was chosen the Correlation-based feature selection filter (CFS) to be used in this work. This filter is used in Technical Agent process, and its complete description is given in subsection 5.3.3.

CFS is a filter algorithm that ranks feature subsets according to a correlation based heuristic evaluation function. The hypotheses on which the heuristic is based is: "Good feature subsets contain features highly correlated with the class, yet uncorrelated with each other". The heuristic is given by Equation 3.3, and it uses the same principle adopted by Ghiselli (1964 apud 
HALL, 2000) in test theory.

$$
\text { Merit }_{s}=\frac{k \overline{r_{c f}}}{\sqrt{k+k(k-1) \overline{\overline{r_{f f}}}}}
$$

Merit $t_{s}$ is the heuristic "merit" of a feature subset $S$ containing $k$ features, $\overline{r_{c f}}$ is the average feature-class correlation, and $\overline{r_{f f}}$ is the average feature-feature intercorrelation. Equation 3.3 is Pearson's correlation with all variables standardized. The numerator provides an indication of how predictive a class of features are, and the denominator indicates how much redundancy there are among the features (HALL, 1999, p. 70).

One of the possibles heuristic search strategy to use in CFS is the best first. Best first starts with a subset with no feature or all features. When it is empty, the search progresses forward through the search space adding single features, when it started with all features, the search moves backward through the search space deleting single features. In order to avoid searching the entire search space, a stopping criterion is used, and it terminates if five consecutive fully expanded subsets show no improvement over the current best subset. More details about CFS filter can be found in Hall (1999) and Hall (2000).

\subsubsection{SUPERVISED LEARNING}

There are basically two approaches to predict the stock market. The first one tries to predict price, and for this problem researchers use regression methods. The second approach, tries to predict the direction of the market, i.e. its trend, if prices will go up or down. This is a binary classification problem, and the last approach is adopted in this dissertation.

There are a lot of published work in this field. Atsalakis and Valavanis (2009) surveyed a lot of different soft computing methods that addresses the problem of stock market forecasting. Some authors surveyed specific techniques, such as Support Vector Machine (SVM) (SAPANKEVYCH; SANKAR, 2009) and artificial neural network (ANN) (SONI, 2011).

When comparing different machine learning algorithms that tries to predict stock market direction, there is no consensus about superiority. Patel et al. (2015) compared Random Forest, ANN, SVM and naive-Bayes, where Random Forest was superior, on the other hand, Kumar and Thenmozhi (2006) compared Random Forest to SVM, and claimed that SVM was better than Random Forest. Kara, Boyacioglu and Baykan (2011) compared ANN to SVM, where ANN model was better than SVM, on the other hand, Kim (2003), Huang, Nakamori and Wang (2005) pointed out that SVM outperformed ANN and some other methods.

The SVM classifier has fewer hyper-parameters for optimization and need less time to train, compared to ANN and Random Forest. As there is no consensus about superiority, for this dissertation, it was chosen SVM as the supervised machine learning algorithm to predict stock prices directions. 


\section{Support Vector Machine}

The following theory about SVM is based on James et al. (2013, p. 337-353). The Support Vector Machine (SVM) has a hyperplane that does not perfectly separate two classes of observations. This misclassifying enhance the robustness of the classifier to individual observations, and its generalization power. It is done using soft margins, that allows some observations to be in the incorrect side of the margin, or even in the incorrect side of the hyperplane that separates the classes.

Consider the example in Figure 8. There are two classes of observations, the purple and the blue, and the observations are the numbers. The full line is the hyperplane that is separating the classes and the dotted lines are the margins. Observations that are on the margin (2,7 and 9), or on the wrong side of the margin (12) are the support vectors.

Figure $8-$ SVM and its soft margin

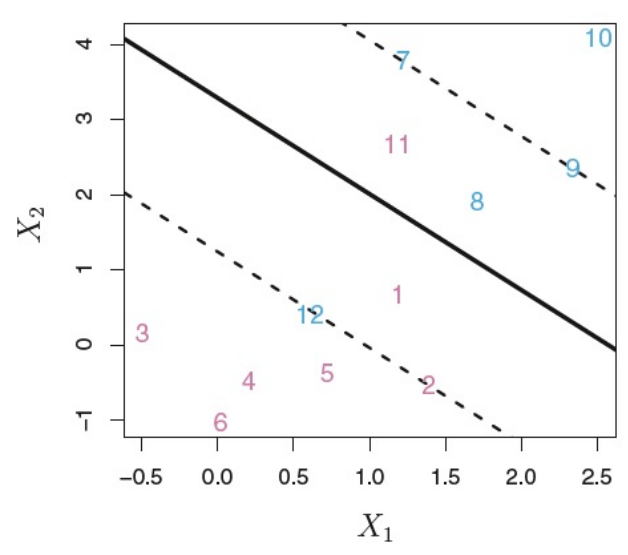

Source: James et al. (2013)

To control the width of the margin, and consequently control the number and severity of violations to the margin and hyperplane, there is a parameter $C$ that is optimized. If $C=0$, then there is no budget for violations. For $C>0$ no more than $C$ observations can be on the wrong side of the hyperplane. $C$ is generally chosen via cross-validation, and controls the bias-variance trade-off. When $C$ is small, margins are rarely violated, making the classifier be highly fitted to the data, which may have low bias, but high variance (see Figure 9a). When $C$ is large, the margin is wider, allowing more violations, resulting in a classifier more biased, but with a lower variance (see Figure 9b).

The inner product of two observations $x_{i j}, x_{i^{\prime} j}$ can be generalized as $K\left(x_{i}, x_{i^{\prime}}\right)$, where $K$ is a kernel function, used to quantify the similarity of two observations. The linear kernel of a SVM is presented in Equation 3.4

$$
K\left(x_{i}, x_{i^{\prime}}\right)=\sum_{j=1}^{p} x_{i j} x_{i^{\prime} j}
$$


Figure 9 - Bias-variance trade-off

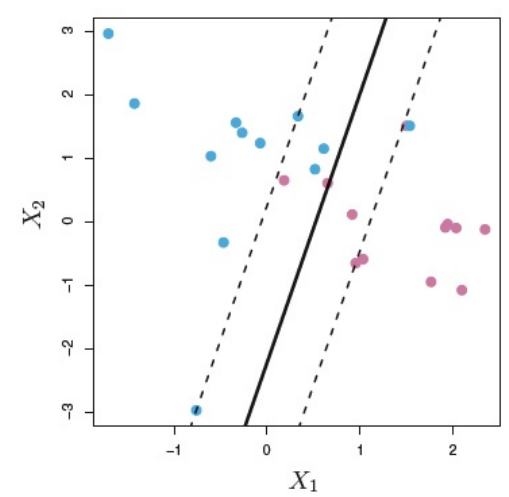

(a) Low bias, high variance (few observations are support vectors)

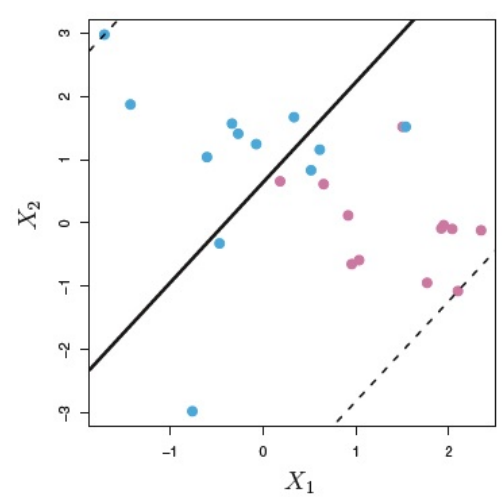

(b) High bias, low variance (many observations are support vectors)

Source: James et al. (2013)

the kernel is linear in its features and to quantifies the similarity of a pair of observations it uses the Pearson correlation. When the boundary between the classes is non-linear, it can be used the polynomial kernal, with a positive integer degree $d$ (see Equation 3.5).

$$
K\left(x_{i}, x_{i^{\prime}}\right)=\left(1+\sum_{j=1}^{p} x_{i j} x_{i^{\prime} j}\right)^{d}
$$

For $d>1$, instead of a linear hyperplane, it is possible to achieve a more flexible decision boundary (see Figure 10a). Another well-known kernel is the radial (see Figure 10b), which takes the form of Equation 3.6

$$
K\left(x_{i}, x_{i^{\prime}}\right)=\exp \left(-\gamma \sum_{j=1}^{p}\left(x_{i j}-x_{i^{\prime} j}\right)^{2}\right) .
$$

where $\gamma$ is a positive constant that represents the precision of the Gaussian distribution.

\subsubsection{UNSUPERVISED LEARNING}

Firstly, it is explained the K-means clustering algorithm, a simple and elegant approach for partitioning a data set into $\mathrm{K}$ distinct, non-overlapping clusters. Then, the partitioning around medoids algorithm is introduced, a better clustering algorithm to avoid outliers and capable of dealing with non-numeric features.

K-means

This section is based on James et al. (2013, p. 386-390). K-means is an algorithm to cluster data into $K$ distinct, non-overlapping clusters. It is necessary to manually assign the number $K$ of clusters. 
Figure 10 - Kernel functions

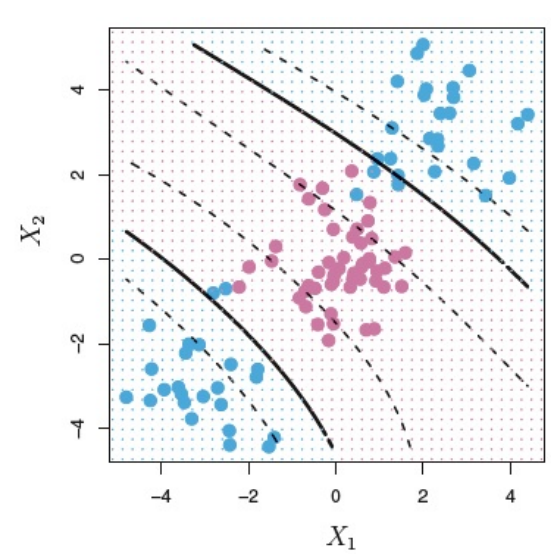

(a) Polynomial kernel example.

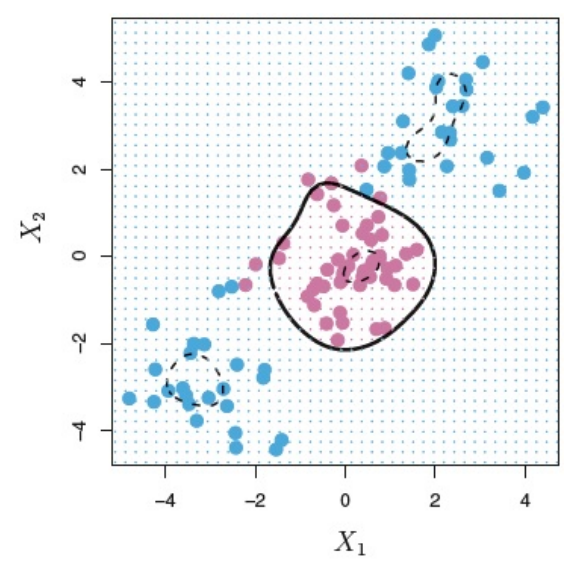

(b) Radial kernel example

Source: James et al. (2013)

It has two important properties, the first states that each observation belongs to at least one of the $K$ clusters. The second, that each observation belongs to no more than one cluster, the clusters are non-overlapping. If the $i$ th observation is in the $k$ th cluster, then $i \in C_{k}$.

A good clustering is the one where the within-cluster variation $W\left(C_{k}\right)$ is as small as possible. It is a measure of the amount by which the observations within a cluster differ from one another. Leading to the optimization problem of Equation 3.7

$$
\underset{C_{1}, \ldots, C_{K}}{\operatorname{Minimize}}\left\{\sum_{k=1}^{K} W\left(C_{k}\right)\right\}
$$

where the within-cluster variation is usually defined as the squared Euclidean distance, given by Equation 3.8

$$
W\left(C_{K}\right)=\frac{1}{\left|C_{k}\right|} \sum_{i, i^{\prime} \in C_{k}} \sum_{j=1}^{p}\left(x_{i j}-x_{i^{\prime} j}\right)^{2}
$$

and $\left|C_{k}\right|$ is the number of observations in the $k$ th cluster.

The algorithm 1 solves the optimization problem by partitioning the observations into $K$ clusters and minimizing it. It provides a local optimum.

As it provides local optimum solution, the results obtained will depend on the initial (random) cluster assignment, so it is necessary to run the algorithm more than once, with different random initialization, to achieve a better result. Another bottleneck is the $K$ determination and the use of means, that make it susceptible to outliers. 


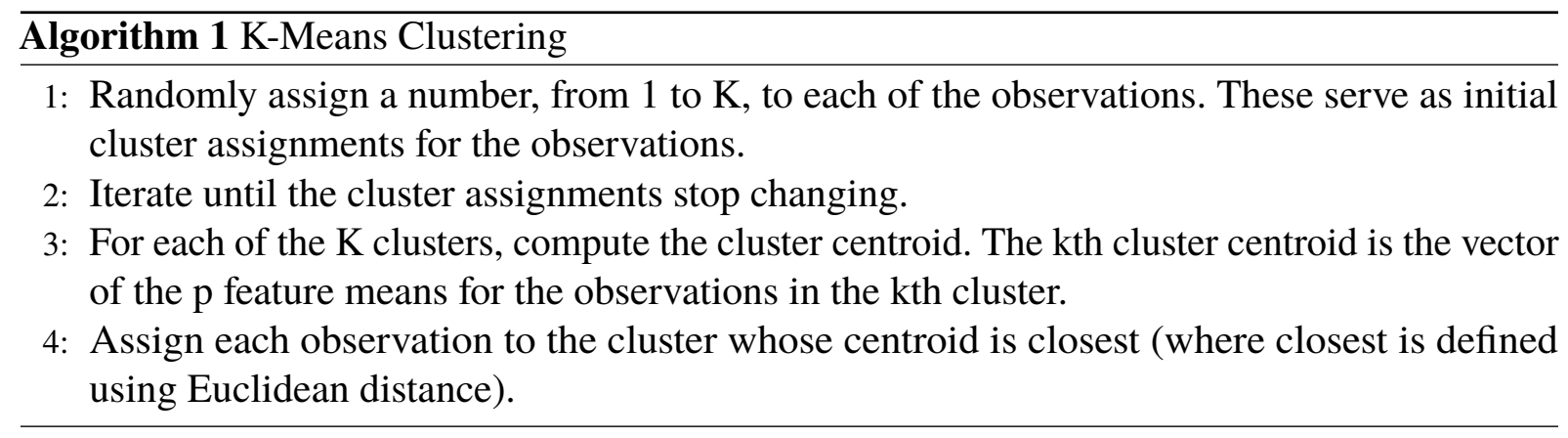

\section{Partitioning Around Medoids}

This section is based on Kaufman and Rousseeuw (2009, p.68-108). Contrary to K-means, partitioning around medoids, a.k.a PAM and K-median, minimizes a sum of dissimilarities instead of a sum of squared euclidean distances (like in K-means), making it more robust against outliers. A large number of statistics can also be derived from it e.g. the medoids of the clusters (with their coordinates), the diameters and separations of the clusters and a graphical representation of the clusters called silhouettes.

The average silhouette width can be used to find the number $K$ of clusters, where the $K$ representative objects are chosen in a way that the average silhouette width is maximized, representing the trade-off between similarity in the same clustering (cohesion) and dissimilarity compared to other clusters (separation).

A medoid is the representative object that represents various aspects of the structure of the data that one wants to cluster. It is a cluster object for which the average dissimilarity to all the other objects of the same cluster is minimal. In the algorithm, it minimizes the sum of the dissimilarities, where these dissimilarities can be calculated by several ways, making it possible to work with binary, ordinal or nominal values.

The algorithm is similar to K-means, and it proceeds interactively until the medoid of the the cluster is found. It is given by Algorithm 2

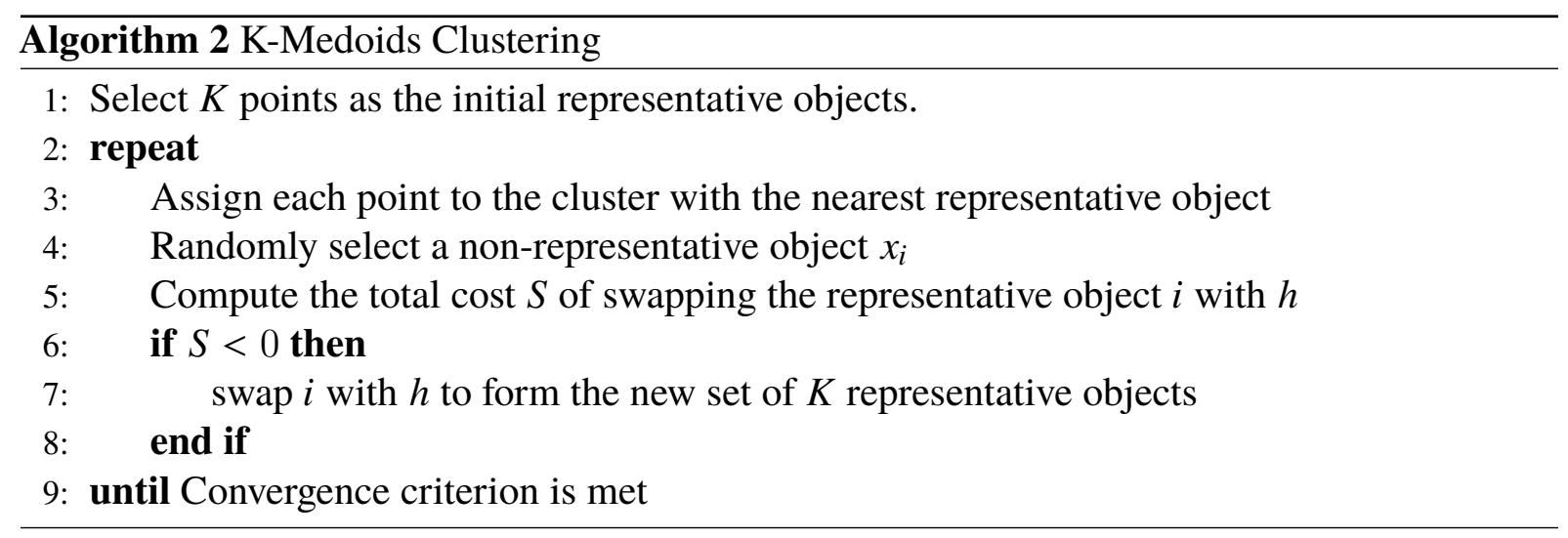

where the cost $S$ of swapping is calculated as the absolute error criterion and is given by 
Equation 3.9.

$$
C_{j i h}=d(j, h)-d(j, i)
$$

For each reassignment operation, the cost of swapping is calculated and this contribute to the overall cost function:

$$
T_{i h}=\sum_{j} C_{j i h}
$$

The pair $(i, h)$ which minimizes $T_{i h}$ is selected. If the minimum $T_{i h}$ is negative, the swap is carried out otherwise it stops, as stated on line 6 of Algorithm 2.

\section{CONCLUSION}

In chapter 2, finance theory was presented and in chapter 3, AI, MAS and ML were discussed. In the literature, there are some attempts to use AI, MAS and ML to build ATS. In the next section, we will see some of these works. 


\section{RELATED WORK}

A recent survey published by Cavalcante et al. (2016), analysed several machine learning methods applied to solve financial market problems. The studies were categorized following five attributes: (i) the main goal of the research; (ii) the financial application investigated; (iii) the input variables used; (iv) the intelligent techniques proposed and (v) whether the work propose some kind of trading system.

When analysing the input variables used, from 56 studies, 47 or 83,93\% of them used technical analysis, and just 5 or 10,64\% of them used fundamental analysis. The other 4 used web information (2), financial news (1) and financial reports (1). The studies that proposed some kind of trading system were 11 or $19,64 \%$, of which just 2 or $3,57 \%$ used fundamental analysis to develop a trading system.

The authors concluded that, the majority use of technical analysis is due the fact that it works directly with quantitative, objective attributes, whereas fundamental analysis handle qualitative, subjective data, difficulting the modelling of market behaviour with computational intelligence approaches. They also reinforced the need for money evaluation, i.e. when the work propose some kind of trading system and costs are considered.

In the next three sections, some selected works that served as reference for the developement of our system are further investigated. The first one is the work developed by Castro (2009), and its application to the Brazilian stock market (CASTRO; SICHMAN, 2011), followed by the study developed by Araújo and Castro (2010), that used fundamental analysis, concluding with the study developed by Junior and Galdi (2012), where the authors compared the use of similar companies, in relative valuation, grouped by sector and those clustered by unsupervised learning.

\subsection{COAST}

Castro (2009) developed a multi-agent system called COAST (COmpetitive Agent SocieTy) that is composed of advisers and coaches. Advisers suggests to buy or sell stocks following a specific strategy based on technical indicators, and coaches receive these advices, evaluating the advisers, negotiating with others coaches and defining orders to submit to the market. It is represented in Figure 11.

Advisers are competitive agents that give recommendations based on a fixed strategy $\mu_{i}$. In his thesis, the author cited 5 strategies based on the following technical indicators: (i) RSI Relative Strength Index, (ii) Stochastic, (iii) Moving Average, (iv) MACD - Moving Average Convergence Divergence, and (v) Price Oscillator (CASTRO, 2009, p. 47-48).

Coordinators at COAST create expectation about a recommendation using fuzzy logic 
Figure 11 - COAST architecture.

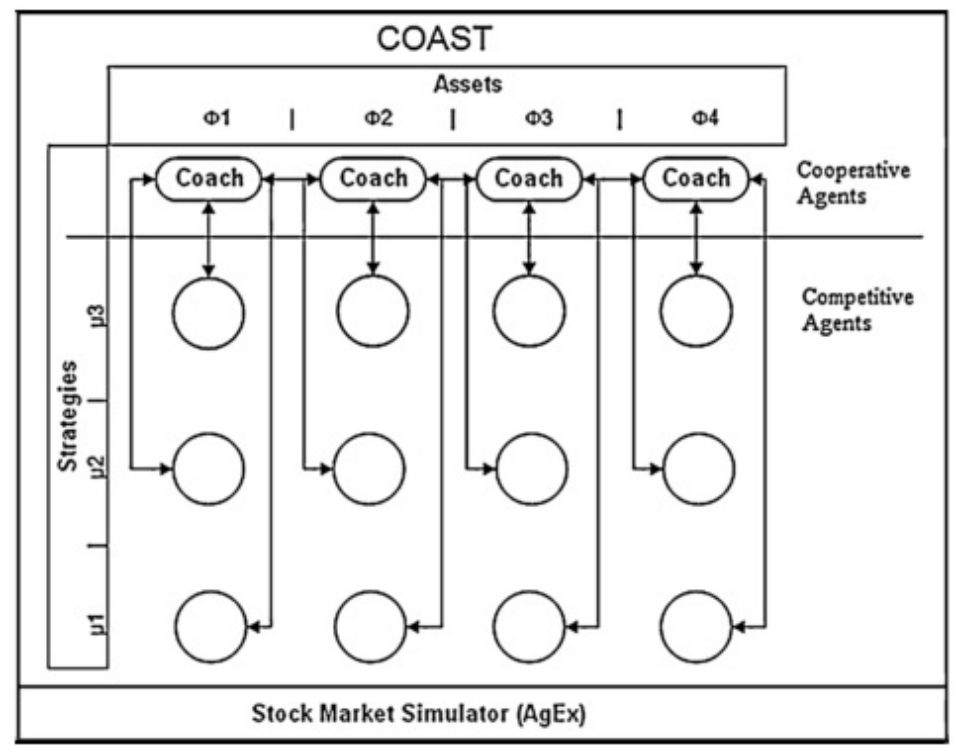

and evaluate the performance of each advisor classifying them as low, average, and high, based on advisor's recommendation accuracy.

The COAST architecture is capable of dealing with four different investor's profile, i.e. (i) investor with limited maximum risk, (ii) investor with limited minimum return, (iii) investor with limited risk and return and (iv) investor with free risk and return. Depending on market situation and investor profile, the society can pursue a different goal: (i) minimize risk, (ii) maximize return or (iii) maximize efficiency.

\subsection{FAS}

Moving to the work of Araújo and Castro (2010), the authors developed the FAS (Fundamentalist Agents System) architecture, presented in Figure 12.

The Growth Estimator receives fundamental data about companies (payout ratio, ROA, debt, equity, tax rate and interest rate) and macroeconomic data (GDP growth and the company's growth). Using these data, it estimates growth based on one of the four following methods:

1. Estimation by compound annualized growth rate of the last five years of GDP growth of the country that the company is held;

2. Estimation by compound annualized growth rate of the last three years of GDP growth of the country that the company is held;

3. Estimation of profit growth based on financial data;

4. Estimation of EBIT growth based on financial data; 
Figure 12 - FAS - Fundamentalist Agents System.

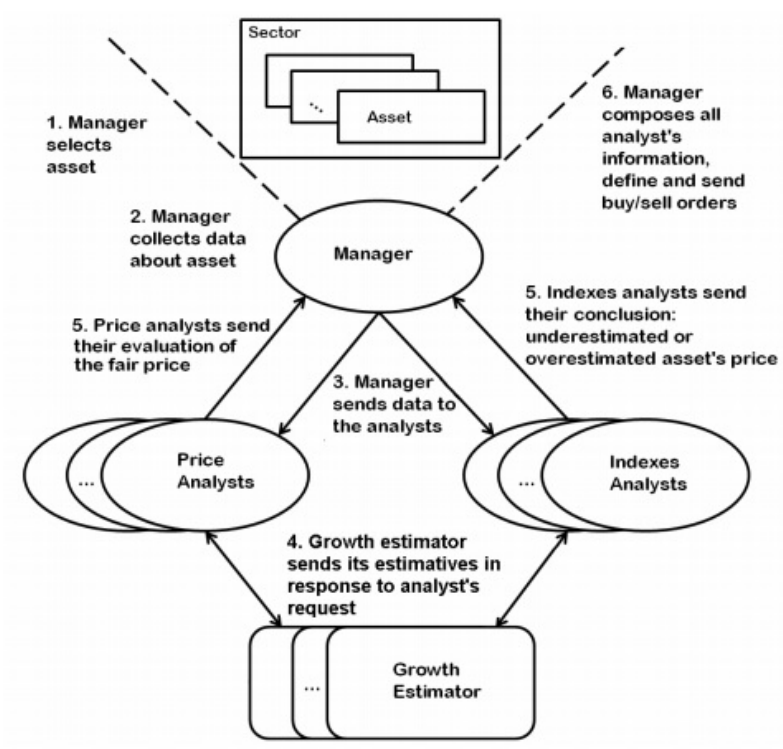

Source: Adapted from Araújo and Castro (2010)

Estimates 3 or 4 are passed to Price Analyst, that also uses company financial data (EBIT, debt, equity, dividend, outstanding stocks, depreciation, investments, interest rates, tax rates, working capital and beta), and macroeconomic data (risk free rate and historic premium). Using these data, it calculates free cash flow, WACC and cost of equity, to feed Gordon model and the Free Cash Flow to Firm model (FCFF), that gives an estimative of the fair price of a company.

Finally, there are the Indexes Analyst. It uses fundamental indicator strategies to identify under or over valued companies. The multiples used in each strategy are: P/E, P/B and PS (Price/Sell). For each multiple there are generally three strategies: (i) select the stock that has the lowest multiple compared to stocks from the same sector, (ii) compare the multiple with the estimated multiple using growth rate estimates, (iii) compare the multiple with company's fundamental data and sometimes compare these values with companies from the same sector. More details about each strategy can be found in Araújo and Castro (2010, p. 117).

\subsection{RELATIVE VALUATION COMPARISON}

The final worth detailing study was developed by Junior and Galdi (2012). They did a comparative analysis of relative valuation with peer group average adjusted for differences, with similar companies from the same sector and those clustered using unsupervised learning.

They first perform a hierarchical clustering using Ward's method to identify and remove outliers, define the number $K$ of cluster and its initial centroids. Then, a k-means was performed using information given by the hierarchical method. A relative valuation with peer group average adjusted for differences was performed using companies from the same sector, and those given 
by k-means clusters.

\subsection{CONCLUDING REMARKS}

The previous three works were the most important ones to the development of our work. Although, there are some other related work in the literature, however, when analysing the use of MAS in the stock market, most studies are about stock prediction or recommendation systems.

Decker, Sycara and Zeng (1996) proposed a multi-agent system framework that uses fundamental analysis, technical analysis, news, and considers user's profile to produce recommendations, however, they did not implemented it. Similarly, Luo, Liu and Davis (2002) proposed a multi-agent system that uses fundamental analysis, technical analysis and has risk management to make recommendations, but it was just partially implemented.

Gamil, Elfouly and Darwish (2007) developed a multi-agent and fuzzy logic model based on technical analysis for stock recommendation. Lee et al. (2007) developed a multi-agent system to make buy and sell suggestions for investors in their daily stock trading using four cooperative Q-learning agent. Tirea, Tandau and Negru (2012) developed a multi-agent recommendation system that use technical analysis and neural networks to provide its recommendations. Hafezi, Shahrabi and Hadavandi (2015) developed a multi-agent system that predicts DAX stock price in quarterly periods, using fundamental and technical data with an artificial neural network, trained with BAT algorithm. Souza, Ralha and Hoelz (2017) are developing a multi-agent system for portfolio optimization where the behaviour of agents are based on supervised learning and reinforcement learning, giving recommendations to user based on user's constraints of which assets to consider, how much capital to allocate and a time frame.

All studies that used fundamental analysis were just using the fundamental data as input variables for their strategy. Additionally, the recommendation systems listed, are mechanic trading systems, the use of MAS in ATS is really rare. Table 1 summarises published studies that developed ATS using the MAS approach.

Table 1 - ATS using MAS.

\begin{tabular}{l|l|l|l|l}
\hline Authors & Main goal & Application & Input Variables & Techniques \\
\hline Seo, Giampapa and Sycara (2004) & Forecasting & Stock Prices & News & Text Analysis \\
Russell and Yoon (2005) & Simulation & Stock Prices & Technical & Trading Rules \\
Castro (2009) & Forecasting & Stock Prices & Technical & Trading Rules \\
Barbosa and Belo (2010) & Forecasting & Forex Prices & Technical & Ensemble of classification and regression \\
Araújo and Castro (2010) & Forecasting & Stock Prices & Fundamental & Fundamental Analysis, Trading Rules \\
Freitas, Freitas and Souza (2016) & Forecasting & Stock Prices & Technical & Trading Rules \\
\hline
\end{tabular}

To overcome these problems, we proposed and implemented a MAS called PROFTS. As far as we know, this is the only work that combine technical and fundamental analysis in a MAS that was fully implemented and did a complete money evaluation, including trading costs. 


\section{PROFTS: PROFITABLE FUNDAMENTAL- IST AND TECHNICAL SYSTEM}

This chapter presents our proposed architecture for portfolio management. It follows, when possible, the same terminology used by Castro (2009).

\subsection{SYSTEM CONCEPTS}

The following concepts are used in the architecture:

- $\phi$ : Is the set of all stocks symbols, where $\phi=\left\{\phi_{1}, \ldots, \phi_{n}\right\} . \phi_{i}$ represents the ticker symbol of a stock $i$ e.g. PETR4. $i=1,2, \ldots, n$, where $n$ is the number of available stocks.

- $\operatorname{Price}\left(\phi_{i}, t\right)$ : Is a price function of stock $\phi_{i}$ at time $t$. Prices are always positive, i.e. $\operatorname{Price}\left(\phi_{i}, t\right) \in \mathbb{R}^{+}$. Current price is indicated as $\operatorname{Price}\left(\phi_{i}\right)$.

- $T$ : Is the set of all technical agents, where $T=\left\{T_{i}, \ldots, T_{n}\right\}$. Each agent $T_{i}$ is defined by a tuple $<X_{i}, \phi_{i}>$ where $X_{i}$ is the set of selected features (technical indicators) for its stock $\phi_{i}$

- $F$ : Is the fundamentalist agent.

- $I$ : Is the Information agent.

- $C$ : Is the Coordinator agent.

- $\theta_{i}$ : Is an order sent by Coordinator agent. It is defined by the tuple $<\phi_{i}, q, y>$ where $\phi_{i}$ is the stock, $q$ is the quantity and $y \in\{b u y$, sell $\}$. All orders will be executed at market price (the current price). Stocks are negotiated by lots, so $q$ will be some multiple of 100 or 1000 , depending on the minimal lot size, $q \in \mathbb{Z}$.

- $\omega_{i}(t)$ : Is the quantity $q$ of stocks $\phi_{i}$ managed by a coordinator $C$ at moment $t, \omega_{i}(t)=q\left(\phi_{i}, t\right)$. The set of all assets available is $\omega=\left\{m, \omega_{i}, \ldots, \omega_{n}\right\} \forall i \in C$, where $m$ is the cash, the money that is not allocated at any stock.

- $V\left(\omega_{i}, t\right)$ : Is a function that quantifies the value of resources $\omega_{i}$ managed by coordinator $C$ at moment $t$, and is given by Equation 5.1

$$
V\left(\omega_{i}, t\right)=\operatorname{Price}\left(\phi_{i}, t\right) \omega_{i}(t)
$$


- $V(\omega, t)$ : Is a function that expresses the total resources hold by the society at time $t$, given by Equation 5.2:

$$
V(\omega, t)=m(t)+\sum_{i \in C}^{N} V\left(\omega_{i}, t\right)
$$

- $R\left(\omega_{i}, t\right)$ : Is the \% return relative to a previous moment, expressed by Equation 5.3:

$$
R\left(\omega_{i}, t\right)=\frac{V\left(\omega_{i}, t\right)-V\left(\omega_{i}, t-1\right)}{V\left(\omega_{i}, t-1\right)}
$$

- $K\left(\omega_{i}, t\right)$ : Is the risk of the agent $C$ at moment $t$ for a given stock $\phi_{i}$. It is defined as the standard deviation ( $\sigma$, a.k.a. volatility, used in section 2.2) of returns from a period, and is given by Equation 5.4. The mean return $(\bar{R})$ is given by Equation 5.5:

$$
\begin{gathered}
K\left(\omega_{i}, t\right)=\sqrt{\frac{1}{N-1} \sum_{t=1}^{N}\left(R\left(\omega_{i}, t\right)-\overline{R\left(\omega_{i}\right)}\right)^{2}} \\
\overline{R\left(\omega_{i}\right)}=\frac{1}{N} \sum_{t=1}^{N} R\left(\omega_{i}, t\right)
\end{gathered}
$$

analogously, return, mean return and risk can be defined for the society by Equation 5.6, Equation 5.7, and Equation 5.8:

$$
\begin{gathered}
R(\omega, t)=\frac{V(\omega, t)-V(\omega, t-1)}{V(\omega, t-1)} \\
\overline{R(\omega)}=\frac{1}{N} \sum_{t=1}^{N} R(\omega, t) \\
K(\omega, t)=\sqrt{\frac{1}{N-1} \sum_{t=1}^{N}(R(\omega, t)-\overline{R(\omega)})^{2}}
\end{gathered}
$$

- Sharpe $(\omega, t)$ : Is the Sharpe Ratio function for calculating risk-adjusted return. It measures the average excess return compared to a risk-free $\left(r_{f}\right)$ rate per unit of volatility. It is used to compare two or more investment options and is given by Equation 5.9:

$$
\operatorname{Sharpe}(\omega, t)=\frac{\overline{R(\omega)}-r_{f}}{K(\omega, t)}
$$

One common method used to develop an estimate of expected return, risk and sharpe ratio, is to simply use the historical returns. With historical return it is possible to calculate all expected values using the same equations. 


\subsection{INVESTOR'S PROFILES}

The investor's profiles defined by Castro (2009) were adapted to be used in PROFTS. Investors are rational in the sense that, when presented two investments with same return, it chooses the one with lower risk. The investor's profiles classes are the following:

- Max acceptable risk (I1): A maximal acceptable risk is determined. The Coordinator agent tries to maximize sharpe ratio respecting the maximal risk defined, if risk is above the limit, coordinator tries to minimize it. The portfolio is created by fundamentalist agent solving Equation 2.3, and technical agent recommendations, when available, are chosen based on current risk level to achieve investor goals.

- Desired target return (I2): A desired monthly target return is specified. The Coordinator agent tries to achieve its desired target return, if it is within limit, the sharpe ratio is maximized. The portfolio is created by fundamentalist agent solving Equation 2.5, and technical agent recommendations, when available, are chosen based on current monthly return.

- Limited Risk-return (I3): At this profile, the minimum variance portfolio is chosen. It is the most risk averse profile. The fundamentalist agent creates the portfolio by solving Equation 2.3, with additional constraints that no short sales are allowed. Coordinator agent will always chooses technical agent recommendation that minimizes risk.

- Free risk and return (I4): There are no limitation for risk nor to return. The Coordinator agent tries to optimize the trade-off between risk-return always maximizing sharpe ratio. The portfolio is created by fundamentalist agent as the tangency portfolio, represented by the point $X$ in Figure $2 b$, the tangent point between the efficient frontier and the Capital Market Line is the portfolio with maximal Sharpe Ratio.

At each moment, a portfolio manager can have three possible objectives:

- 01: Minimize risk;

- O2: Maximize return;

- O3: Maximize "efficiency".

Where efficiency means the risk-return ratio adopted, in this case, the sharpe ratio. Translating it to the multi-agent society, its objective changes depending on investor's profile and portfolio scenario. There are basically two possible situations for the portfolio:

- S1: risk or return at acceptable level; 
- S2: risk or return at unacceptable level.

Combining the different investor's profiles and portfolio scenarios, it is possible to get the society's objective, as presented in Table 2.

Table 2 - Possible system's objectives for different market scenarios and Investor's profile

\begin{tabular}{|l|c|c|}
\cline { 2 - 3 } \multicolumn{1}{c|}{} & \multicolumn{2}{c|}{ Market Scenario } \\
\cline { 2 - 3 } \multicolumn{1}{c|}{} & Risk and return at acceptable level (S1) & Risk and return at unacceptable level (S2) \\
\hline Max acceptable risk (I1) & Maximize efficiency (O3) & Minimize risk (O1) \\
\hline Desired target Return (I2) & Maximize efficiency (O3) & Maximize return (O2) \\
\hline Limited risk-return (I3) & Minimize risk (O1) & Minimize risk (O1) \\
\hline Free risk-return (I4) & Maximize efficiency (O3) & Maximize efficiency (O3) \\
\hline
\end{tabular}

In the next section it is presented an architecture capable of dealing with all these investor's profile and portfolio scenarios autonomously.

\subsection{AGENTS DESCRIPTION}

The architecture proposed, called PROfitable Fundamentalist and Technical System (PROFTS), is represented in Figure 13 for 3 stocks $\phi_{i}$, each of them associated to a particular technical agent.

Figure 13 - PROFTS architecture

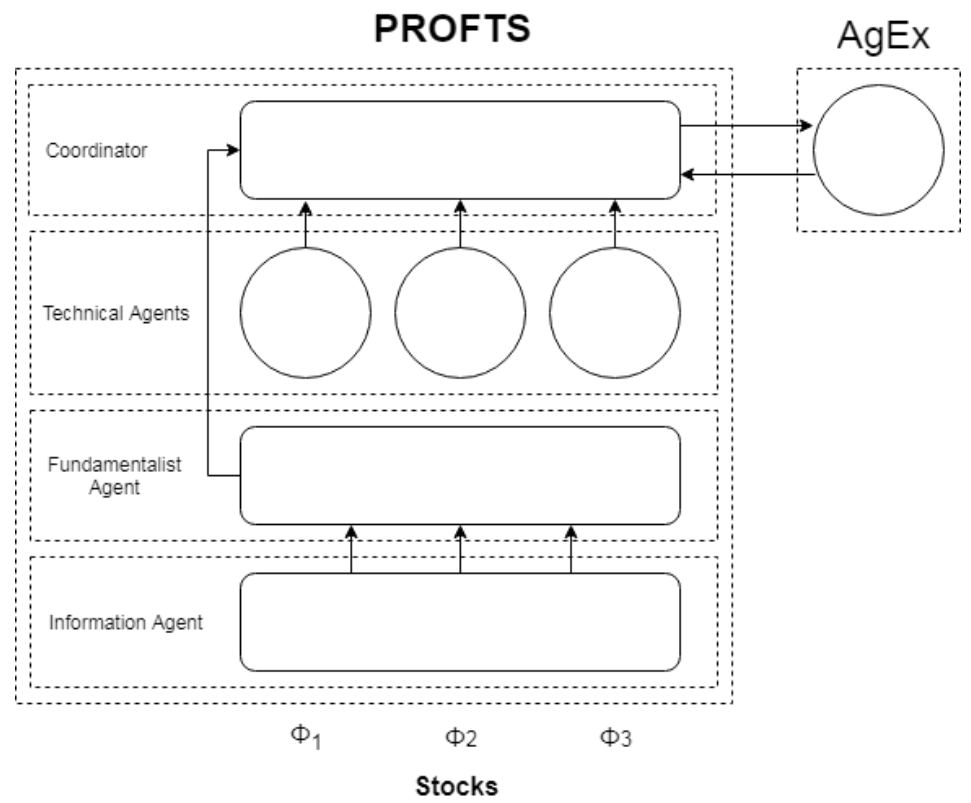

AgEx is not part of PROFTS architecture, but it is the financial market simulation tool designed for software agents used. The communication among agents in AgEx uses the addressing and delivering services provided by JADE (BELLIFEMINE; POGGI; RIMASSA, 2001), a Java 
Agent DEvelopment Framework, and it is possible to do real price simulations, including the charge of brokerage fees and commissions (CASTRO; SICHMAN, 2009).

Each agent is explained in details in the next sections.

\subsubsection{INFORMATION AGENT}

Starting from the bottom level, the Information agent gets data from companies in the Internet through a web scraper, calculates fundamental indicators and multiples, and applies a financial distress prediction model (FDP) to predict company's financial health. These data are used to feed the Fundamentalist Agent. Its life-cycle is summarized in Figure 14. In this work, just one information agent was implemented for all stocks, but parallelization could be easily allowed.

Figure 14 - Information agent life-cycle.

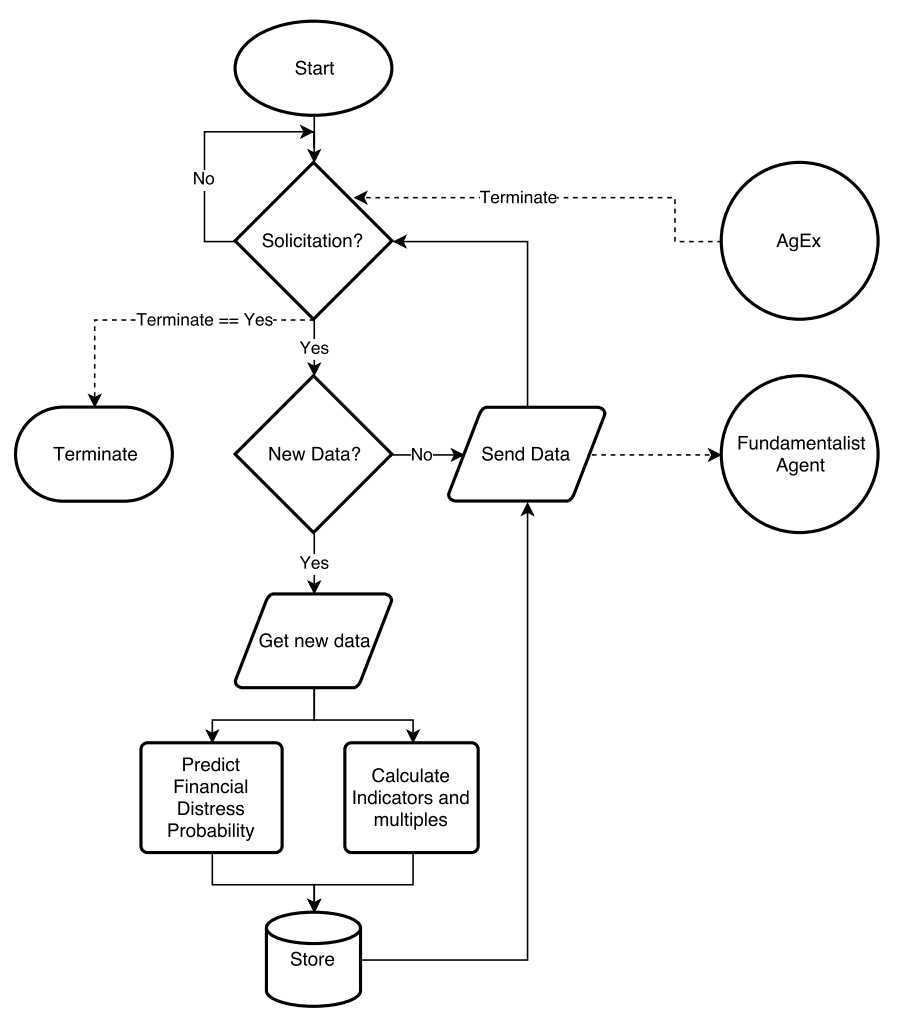

In Figure 14, each dotted line is an external process, while continuous lines are an internal one. When the society becomes active, each agent is initialized. The information agent registers its services at the Directory Facilitator (DF) agent implemented by JADE and specified by FIPA (BELLIFEMINE; CAIRE; GREENWOOD, 2007), thus enabling the fundamentalist agent to later asks for its services. Whenever this is required, it scrapes the web-page of the desired company to see if there is new information available. If there is new data, they are used to calculate some indicators and multiples, to predict the probability of a company having financial distress in the next year, and they are stored. After concluding theses processes, it sends the calculated 
information to the fundamentalist agent, otherwise it just send the latest stored data. If a terminate order is sent by $\mathrm{AgEx}$, the information agent terminates its operation.

It was used the income statement, balance sheet and cash flow of each company to calculate the necessary indicators by fundamentalist agent, i.e. (i) determinant variables, (ii) multiples and (iii) health indicators. Their calculation are based in Damodaran (2010). Each fundamental indicator was described in subsection 2.3.1.

Figure 15 - Fundamentalist agent life-cycle.

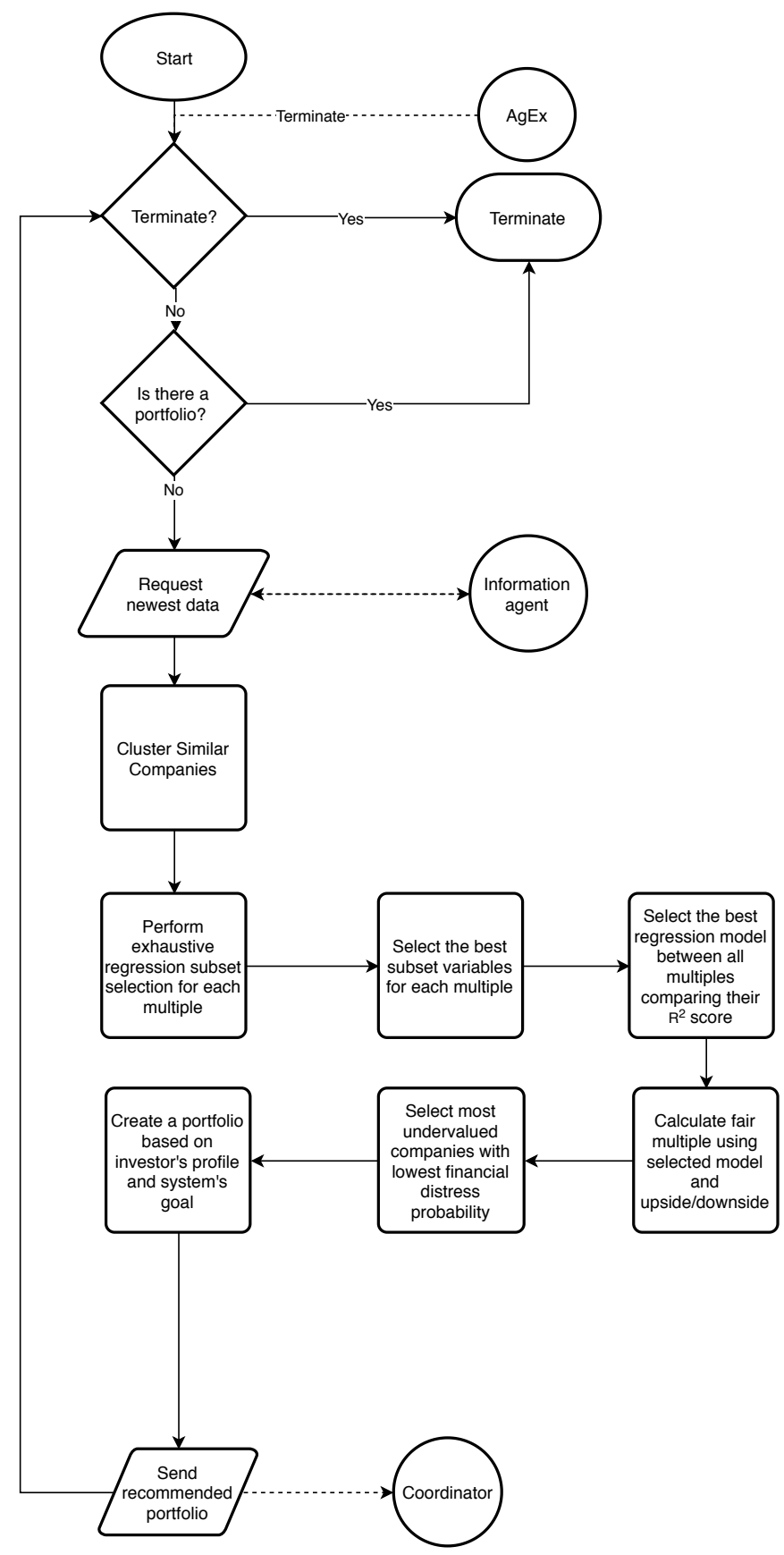




\subsubsection{FUNDAMENTALIST AGENT}

Fundamentalist agent uses unsupervised learning to cluster similar companies for further comparison through relative analysis with peer group average adjusted for differences. Its life-cycle is described in Figure 15.

Every time the fundamentalist agent is initiated, it checks if there is already a created portfolio or if it is time to create a new one.

If there is not a portfolio created, or it is time to recreate a new one due to some price target achievement, the fundamentalist agent queries the necessary data from information agent, and similar companies are clustered into $K$ clusters using the PAM algorithm. The number $K$ of clusters is determined by maximizing the silhouette width. Clusters that have less than a specific number of members are discarded, as a regression is performed later, so it is necessary to have a minimum number of companies for this.

For each multiple, it is performed a regression subset selection using all determinant variables through an exhaustive search. As there are just 6 determinants variables, an exhaustive search is not prohibitive. This method creates a regression model for each possible combination of determinants variables, and the best model for each multiple is selected, based on their adjusted $R^{2}$. Maximize the adjusted $R^{2}$ is equivalent to minimize the residual sum of squares (RSS). The $R^{2}$ always increases as more variables are added, so in adjusted $R^{2}$, the number $d$ of variables is added to the denominator to control this overfitting (JAMES et al., 2013, p. 70). Its calculation is presented in Equation 5.10.

$$
\text { Adjusted } R^{2}=1-\frac{\frac{R S S}{(n-d-1)}}{\frac{T S S}{(n-1)}}
$$

where $R S S$ is the residual sum of squares given by Equation 5.11, $y_{i}$ is the true value, $\hat{y}$ is the predicted value,

$$
\left.R S S=\sum_{i=1}^{n}\left(y_{i}-\hat{y}\right)\right)^{2}
$$

$T S S$ is the total sum of squares given by Equation 5.12, and $\bar{y}$ is the mean value.

$$
\left.T S S=\sum_{i=1}^{n}\left(y_{i}-\bar{y}\right)\right)^{2}
$$

After the best model for each multiple is found, each model is compared and the multiple's model with the highest adjusted $R^{2}$ is chosen. Using the selected model, the multiple is recalculated, and it is determined if a company is over or under valued compared to its peers, i.e. its fair value is calculated. In order to filter out those companies that are really undervalued from those that are bankrupting, the FDP model is used to predict this probability for the next year. 
The undervalued companies with good financial health, given by FDP model, are considered in the portfolio creation, based on investor's profile as described in section 5.2.

Each portfolio has additional constraints that just long positions are allowed (buy orders) and the maximal weight of an asset in the portfolio is $20 \%$. Once the optimal portfolio is created, each buy recommendation with its weights are sent to coordinators. If fundamentalist agent receives a terminate signal from AgEx, it terminates. All parameters from fundamentalist agent can be found in Table 30.

\subsubsection{TECHNICAL AGENT}

In the next level, there are the Technical Agents. Their life-cycle are described in Figure 16. If there is not a trained model, it accesses historical data from a database to train a support vector machine with technical indicators features. As there are a lot of technical indicators and possible parameters (see Table 3, Table 4 and Table 5), each model is built after a feature selection process using the CFS filter.

On each new year, a new model is also trained, incorporating the new data to keep the model accurate. Daily, when AgEx's stock data is received, it predicts stock direction and sends a buy/sell recommendation to coordinator with its probability, that is used as a confidence level by coordinator agent.

The technical agents seek to generate an extra alpha to the portfolio and offer some options that enable the coordinator agent to control the portfolio's risk-return metrics according to the society's goal. They explore the short-term anomalies from the market to profit and help controlling the system goals and portfolio metrics.

Previously, it was discussed that technical analysis is based in two premises: (i) past stock price trends will continue in the same direction, or (ii) they will reverse themselves. Trend indicators are used to identify trends in financial market and are presented in Table 3 with some of its possible parameters. Oscillator indicators show price deviation from its average value and can be used to identify reversions, they are presented in Table 5. Finally, volume indicators are useful to confirm previous patterns, they are presented in Table 4 with its parameters.

There are 33 possible combinations for trend indicators, 23 for oscillators, and 4 for volumes, resulting in 60 features. The 5-days exponential moving average and standard deviation were removed, and the Open, High, Low, Close (OHLC) prices were added, totalling 62 features. An Adaptive Moving Average $(n, F, S)$ can have parameters [9, 2, 30], [21,5,50] or [50,10,100], but indicators that has method and volume, like Chaikin Oscillator, can have much more combinations, as it is exemplified in Table 6. 
Table 3 - Trend Indicators

\begin{tabular}{|c|c|}
\hline Name & Parameters \\
\hline \multirow{3}{*}{ Adaptive Moving Average $(n, F, S)$} & $\operatorname{Period}(n)=[9,21,50]$ \\
\hline & FastEMA $(F)=[2,5,10]$ \\
\hline & $\operatorname{SlowEMA}(S)=[30,50,100]$ \\
\hline Average Directional Movement Index $(n)$ & $\operatorname{Period}(n)=[14]$ \\
\hline \multirow{2}{*}{ Double Exponential Moving Average $(n, S)$} & $\operatorname{Period}(n)=[14]$ \\
\hline & $\operatorname{Shift}(S)=0$ \\
\hline \multirow{2}{*}{ Fractal Adaptive Moving Average $(n, S)$} & $\operatorname{Period}(n)=[14]$ \\
\hline & $\operatorname{Shift}(S)=0$ \\
\hline \multirow{3}{*}{ Moving Average $(n, S$, method $)$} & $\operatorname{Period}(n)=[5,21,50]$ \\
\hline & $\operatorname{Shift}(S)=0$ \\
\hline & method $=[$ Simple, Exp., Smoothed, LinearWeighted $]$ \\
\hline \multirow{2}{*}{ Parabolic Stop and Reverse system (St, Max) } & Step $(S t)=0.02$ \\
\hline & $\operatorname{Maximum}(\operatorname{Max})=0.2$ \\
\hline \multirow{3}{*}{ Standard Deviation $(n, S$, method $)$} & $\operatorname{Period}(n)=[5,21,50]$ \\
\hline & $\operatorname{Shift}(S)=0$ \\
\hline & method $=[$ Simple, Exp., Smoothed, LinearWeighted $]$ \\
\hline \multirow{2}{*}{ Tripel Exponential Moving Average $(n, S)$} & $\operatorname{Period}(n)=[14]$ \\
\hline & $\operatorname{Shift}(S)=0$ \\
\hline \multirow{2}{*}{ Variable Index Dynamic Average $(C n, E m, S)$} & CMOPeriod $(\mathrm{Cn})=9$ \\
\hline & $\operatorname{EMAPeriod}(P n)=12$ \\
\hline
\end{tabular}

Table 4 - Volume Indicators

\begin{tabular}{ll}
\hline Name & Parameters \\
\hline Accumulation/Distribution $(V)$ & $\operatorname{Volume}(V)=[$ Real $]$ \\
\hline Money Flow Index $(n, V)$ & $\operatorname{Period}(n)=[14]$ \\
\hline Volume $(V)=[$ Real $]$ \\
\hline Volumes $(V)$ & $\operatorname{Volume}(V)=[$ Real $]$ \\
\hline
\end{tabular}


Table 5 - Oscillator Indicators

\begin{tabular}{|c|c|}
\hline Name & Parameters \\
\hline Average True Range $(n)$ & $\operatorname{Period}(n)=[14]$ \\
\hline Bears Power $(n)$ & $\operatorname{Period}(n)=13$ \\
\hline Bulls Power $(n)$ & $\operatorname{Period}(n)=13$ \\
\hline Chaikin Oscillator $(F, S$, method, $V)$ & $\begin{array}{l}\text { FastEMA }(F)=[3,5] \\
\text { SlowEMA }(S)=[10,21] \\
\text { method }=[\text { Simple,Exp., Smoothed,Lin.Weighted }] \\
\operatorname{Volume}(V)=[\text { real }]\end{array}$ \\
\hline Commodity Channel Index $(n)$ & $\operatorname{Period}(n)=[14]$ \\
\hline DeMarker $(n)$ & $\operatorname{Period}(n)=[14]$ \\
\hline Force Index $(n$, method,$V)$ & $\begin{array}{l}\operatorname{Period}(n)=13 \\
\operatorname{method}=[\text { Simple,Exp., Smoothed,Lin.Weighted }] \\
\operatorname{Volume}(V)=[\text { tick,real }]\end{array}$ \\
\hline Moving Average Convergence/Divergence $(F, S, S i g)$ & $\begin{array}{l}\text { FastEMA } M(F)=12 \\
\text { SlowEMA } M)=26 \\
\text { Signal }(\text { Sig })=9\end{array}$ \\
\hline Momentum (n) & $\operatorname{Period}(n)=[14]$ \\
\hline Moving Average of Oscillator $(F, S, S i g)$ & $\begin{array}{l}\text { FastEMA }(F)=12 \\
\text { SlowEMA }(S)=26 \\
\text { Signal }(\text { Sig })=9\end{array}$ \\
\hline Relative Strength Index $(n)$ & $\operatorname{Period}(n)=[14]$ \\
\hline Triple Exponential Average $(n)$ & $\operatorname{Period}(n)=[14]$ \\
\hline Williams' Percent Range $(n)$ & $\operatorname{Period}(n)=[14]$ \\
\hline
\end{tabular}

Table 6 - Parameters combination

\begin{tabular}{c|c|c|c}
\hline \multicolumn{4}{c}{ Chaikin Oscillator $(F, S$, method, $V)$} \\
\hline FastEMA(F) & SlowEMA $(S)$ & method & Volume $(V)$ \\
\hline 3 & 10 & Simple & real \\
5 & 21 & Simple & real \\
3 & 10 & Exp. & real \\
5 & 21 & Exp. & real \\
3 & 10 & Smoothed & real \\
5 & 21 & Smoothed & real \\
3 & 10 & Lin. Weighted & real \\
5 & 21 & Lin. Weighted & real \\
\hline
\end{tabular}


Figure 16 - Technical agent life-cycle.

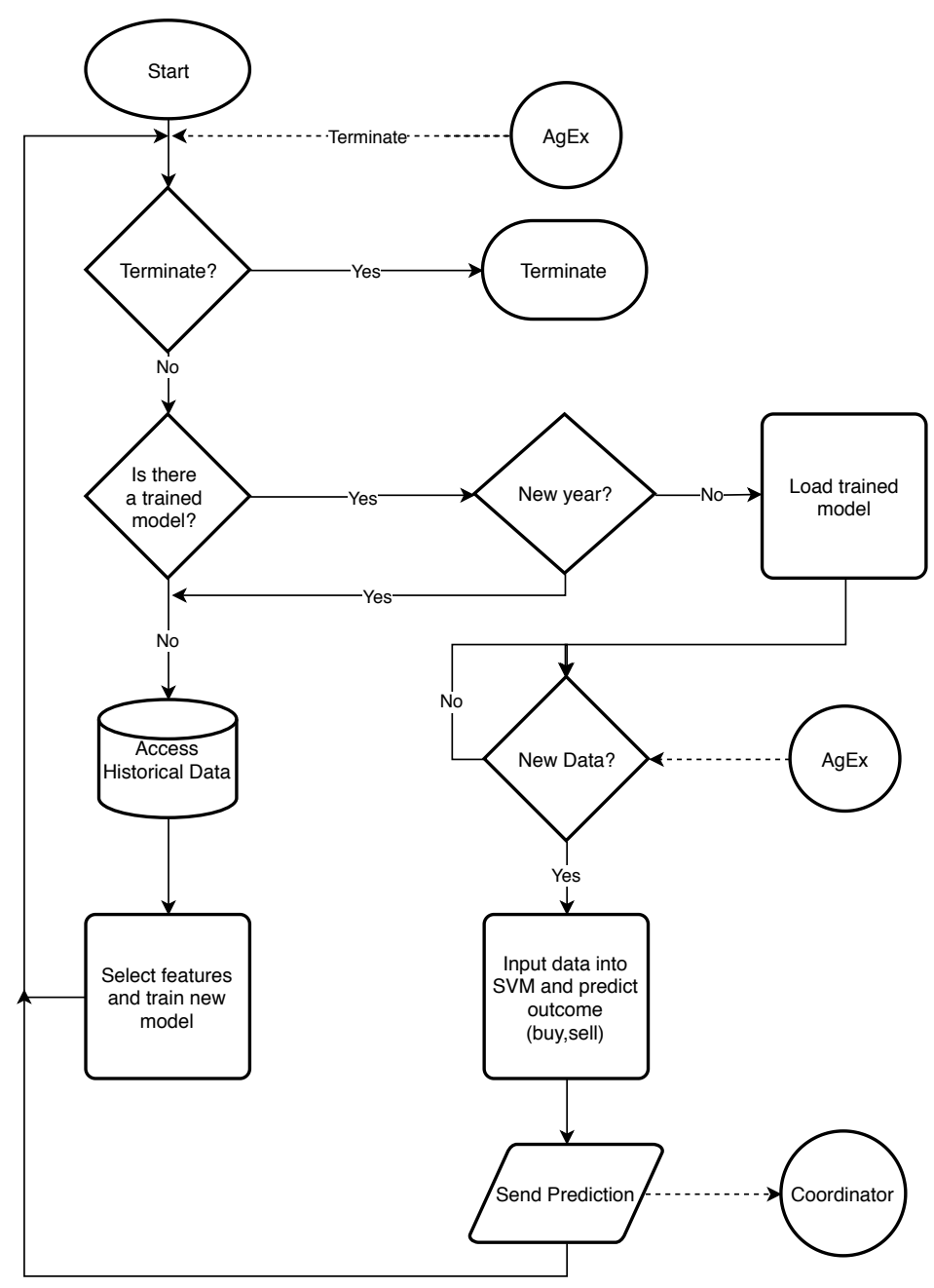


Figure 17 - Coordinator agent life-cycle.

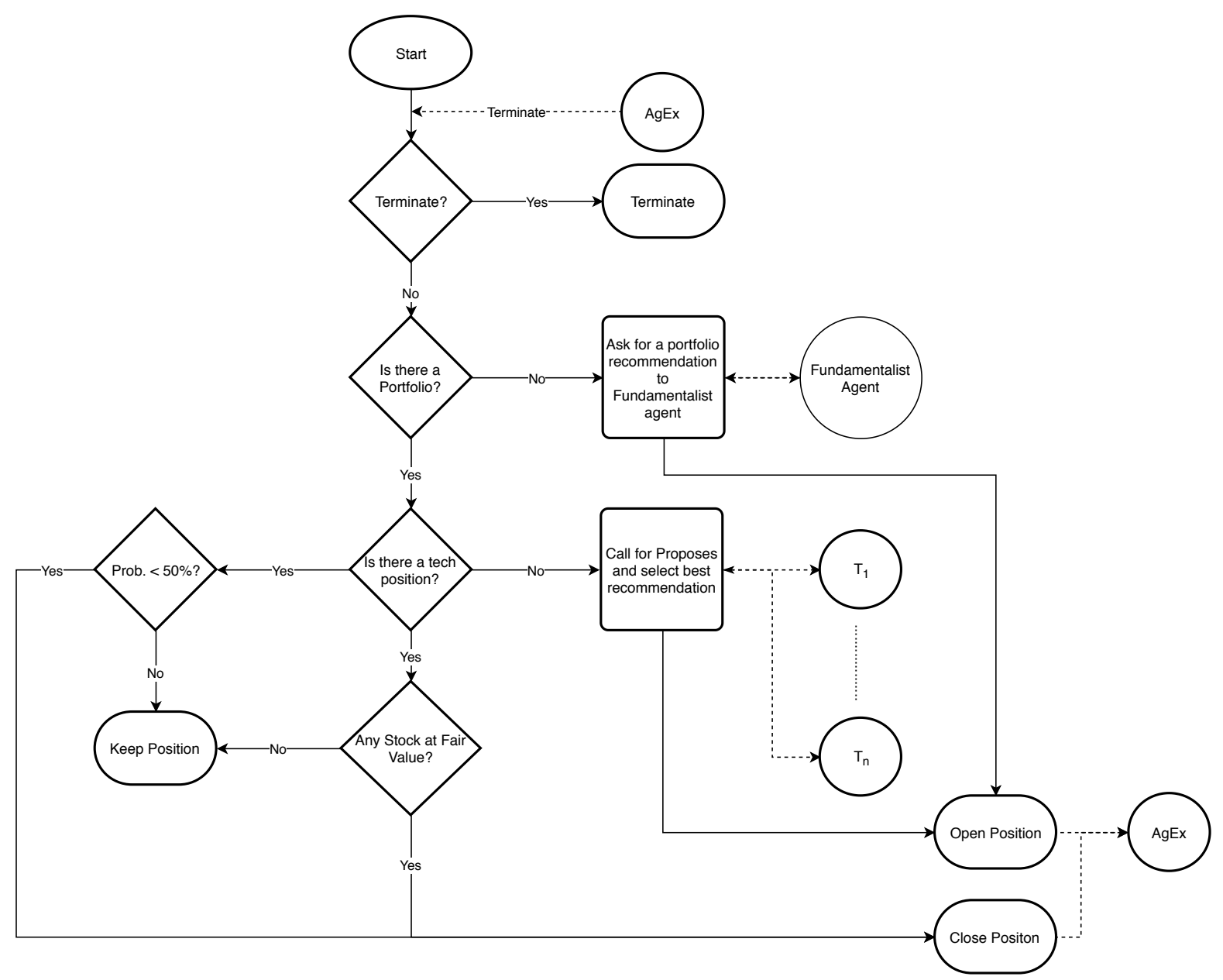

\subsubsection{COORDINATOR AGENT}

Concluding the architecture, there is the coordinator agent. Comparing with a traditional asset management, the coordinator agent would be the portfolio manager, while fundamentalist agent and technical agents would be its research team of analysts. The coordinator agent is responsible for deciding which technical recommendation should be accepted, how the resources will be allocated, to control risk, and for sending the final orders to AgEx. Its life-cycle is described in Figure 17.

If there is not a portfolio, the coordinator agent asks fundamentalist agent for one. When it receives fundamentalist agent's recommendations, the orders are sent to AgEx. Once a portfolio is created, the coordinator agent checks if there is any technical agent position opened, if so, it checks with the responsible technical agent what is the probability of an upward movement in prices, if it is below $50 \%$, the order is closed, otherwise, the position is kept. If there is not a technical agent position, the coordinator agent opens a call for proposals (CFP).

The decision between each technical agent recommendation depends on the system's current goal, that is a combination of its investor profile and market situation, as given in Table 2 . To calculate the new portfolio metrics, the coordinator agent simulates the technical agent 
recommendation with a weight of $20 \%$ and recalculate the existing portfolio's weights, generating a new potential portfolio. The expected return, risk and sharpe ratio are calculated and the technical agent recommendation that optimizes system's goals is chosen. Just recommendations with at least $70 \%$ of confidence are considered. In T2 portfolios, are considered the the top 2 recommendation, and coordinator agent decides between them, while in T3 portfolios, the coordinator agent has three options to choose.

Parallel to this process, the coordinator agent checks if any position in its current portfolio achieved $80 \%$ of its fair value ${ }^{1}$, if any of them achieved this target, the position is closed and in the next day a new portfolio will be requested for fundamentalist agent. When requesting for a new portfolio, positions that are already in the portfolio can be rebalanced or excluded, according to fundamentalist agent's recommendation. 


\section{EXPERIMENTS AND RESULTS}

In this chapter, the experiments are detailed and results obtained discussed. First, we detail our implementation environment in section 6.1. In section 6.2, we present the technical agents training phase: how features were chosen and validated, and which was the final set of technical agents that was considered in each year. In section 6.3, the results of the FDP model that was used to filter out financial unhealthy companies are presented. In section 6.4, we describe how the PROFTS's experiments were conducted, which hypotheses were tested, followed by the obtained results in section 6.5 and analysis in section 6.6.

\subsection{IMPLEMENTATION ENVIRONMENT}

Technical and fundamental analysis, machine learning models, portfolio optimization and information agents, were implemented using R (R Development Core Team, 2008) and its libraries (RYAN; ULRICH, 2017; PETERSON; CARL, 2015; PETERSON; CARL, 2014).

The machine learning library used was "caret" (WING et al., ). For feature selection with CFS it was used the library "FSelector" (ROMANSKI; KOTTHOFF, 2016). All models were trained with seed $=1$ for reproducibility.

The integration between $R$ and Java was done using Rserve (URBANEK, 2013), a TCP/IP server that allows other programs to use R's functionalities.

In Figure 18 it is possible to see each agent initialized in JADE, and it is also possible to see another agent called AgExManager, this agent is part of AgEx system, and it is responsible for validating and processing messages addressed to AgEx system, and the AgEx Broker, that receives and executes buy and sell orders and informs AgExManager about the results of execution.

\subsection{TECHNICAL AGENTS}

In subsection 5.3.3, technical agents were described. In this section, the implementation details and results for each model are presented. The stock's tickers used to build each technical agent are listed in Table 7.

As discussed previously, in each year, for each stock, the technical agent checks if exists a trained model for current year: if exists, the model is loaded, otherwise, a new model is trained.

To train each model, it was used the last 2 years of available that. So, for 2015, it was used the whole period of 2013-2014, for 2016, it was used 2014-2015 and for 2017 the period of 2015-2016. The periods should be chosen carefully to not use future information in the models. 
Figure 18 - Agents running on JADE.

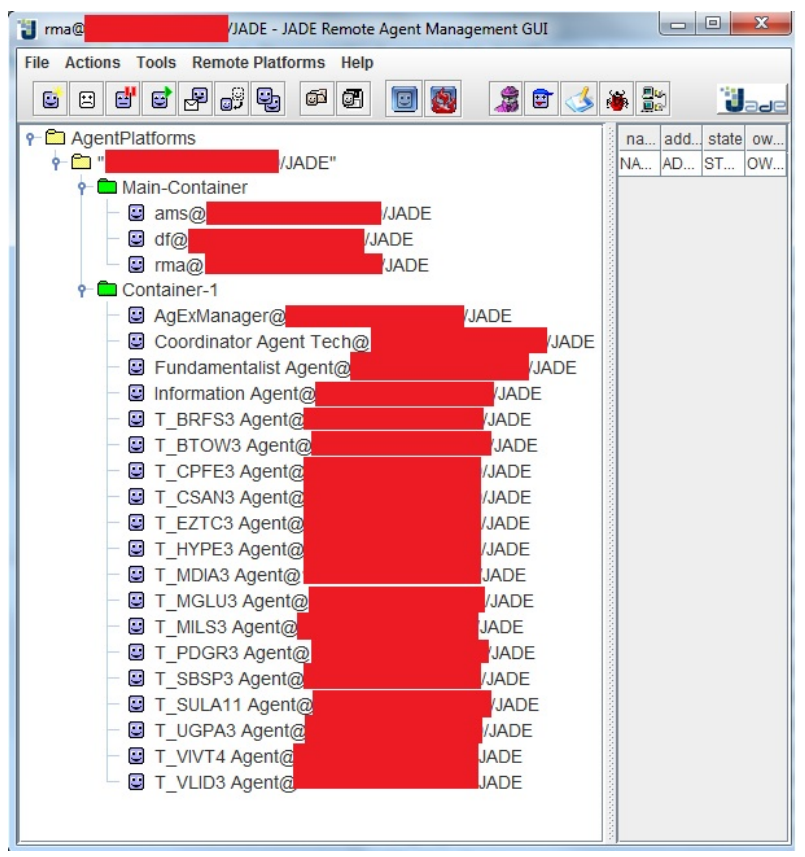

The classification algorithm used was a Support vector machine with a Gaussian Radial basis function kernel. This kernel has a hyper parameter to be optimized, i.e. Gamma $(\gamma)$ and it represents the precision of the Gaussian distribution (the inverse of variance), while the SVM has the hyper-paramenter cost (C) that is the regularization coefficient that controls the trade-off between minimizing training errors and controlling model complexity (BISHOP, 2006).

To select the best pair $(C, \gamma)$ of hyper-parameters, it was used a grid-search with a 6-fold time series cross-validation. The grid space for $\mathrm{C}$ was $\log _{2} C\{-5,-3, \ldots, 15\}$ and for $\gamma$ was $\log _{2} \gamma\{-15,-13, \ldots, 3\}$, while the parameters used to create the time slices for cross-validation were:

- initialWindow $=120$ : the amount of data used for training was approximately six months;

- horizon $=60$ : the amount of data used for validation was approximately three months;

- fixedWindow $=$ True: each training sample started at a different time, at fold $k+1$ it was added the value of skip;

- skip $=60$ : the amount of data points that was skipped on each fold.

For the year of 2015 the 6-fold times series cross validation is given in Figure 19, for the following years it uses the same approach. These six folds are used to train the SVM, testing each 
Table 7 - List of stocks tickers used by Technical Agent

\begin{tabular}{c|c|c|c|c|c}
\hline \multicolumn{5}{c}{ Technical Agent } \\
\hline$T_{1}$ & ABEV3 & $T_{28}$ & ESTC3 & $T_{55}$ & NATU3 \\
$T_{2}$ & BBAS3 & $T_{29}$ & EVEN3 & $T_{56}$ & ODPV3 \\
$T_{3}$ & BBDC3 & $T_{30}$ & EZTC3 & $T_{57}$ & OIBR3 \\
$T_{4}$ & BBSE3 & $T_{31}$ & FIBR3 & $T_{58}$ & PCAR4 \\
$T_{5}$ & BEEF3 & $T_{32}$ & GFSA3 & $T_{59}$ & PDGR3 \\
$T_{6}$ & BRAP4 & $T_{33}$ & GGBR4 & $T_{60}$ & PETR3 \\
$T_{7}$ & BRFS3 & $T_{34}$ & GOAU4 & $T_{61}$ & POMO4 \\
$T_{8}$ & BRKM5 & $T_{35}$ & GOLL4 & $T_{62}$ & PSSA3 \\
$T_{9}$ & BRML3 & $T_{36}$ & HGTX3 & $T_{63}$ & QGEP3 \\
$T_{10}$ & BRPR3 & $T_{37}$ & HYPE3 & $T_{64}$ & QUAL3 \\
$T_{11}$ & BRSR6 & $T_{38}$ & IGTA3 & $T_{65}$ & RADL3 \\
$T_{12}$ & BTOW3 & $T_{39}$ & ITSA4 & $T_{66}$ & RAPT4 \\
$T_{13}$ & CCRO3 & $T_{40}$ & ITUB4 & $T_{67}$ & RENT3 \\
$T_{14}$ & CESP6 & $T_{41}$ & JBSS3 & $T_{68}$ & RSID3 \\
$T_{15}$ & CIEL3 & $T_{42}$ & KLBN11 & $T_{69}$ & SANB11 \\
$T_{16}$ & CMIG4 & $T_{43}$ & KROT3 & $T_{70}$ & SBSP3 \\
$T_{17}$ & CPFE3 & $T_{44}$ & LAME4 & $T_{71}$ & SULA11 \\
$T_{18}$ & CPLE6 & $T_{45}$ & LIGT3 & $T_{72}$ & TAEE11 \\
$T_{19}$ & CSAN3 & $T_{46}$ & LREN3 & $T_{73}$ & TIMP3 \\
$T_{20}$ & CSNA3 & $T_{47}$ & MDIA3 & $T_{74}$ & TOTS3 \\
$T_{21}$ & CYRE3 & $T_{48}$ & MGLU3 & $T_{75}$ & UGPA3 \\
$T_{22}$ & DTEX3 & $T_{49}$ & MILS3 & $T_{76}$ & USIM5 \\
$T_{23}$ & ECOR3 & $T_{50}$ & MMXM3 & $T_{77}$ & VALE3 \\
$T_{24}$ & ELET3 & $T_{51}$ & MPLU3 & $T_{78}$ & VIVT4 \\
$T_{25}$ & EMBR3 & $T_{52}$ & MRFG3 & $T_{79}$ & VLID3 \\
$T_{26}$ & ENBR3 & $T_{53}$ & MRVE3 & $T_{80}$ & VVAR11 \\
$T_{27}$ & EQTL3 & $T_{54}$ & MULT3 & $T_{81}$ & WEGE3 \\
\hline & & & &
\end{tabular}

combinations of $(C, \gamma)$ through a grid search, the final model is chosen based on the best mean accuracy of all 6 folds. A similar approach was used in (REIS; CASTRO; SICHMAN, 2016)

Figure 19 - 6-Fold Time Series Cross Validation

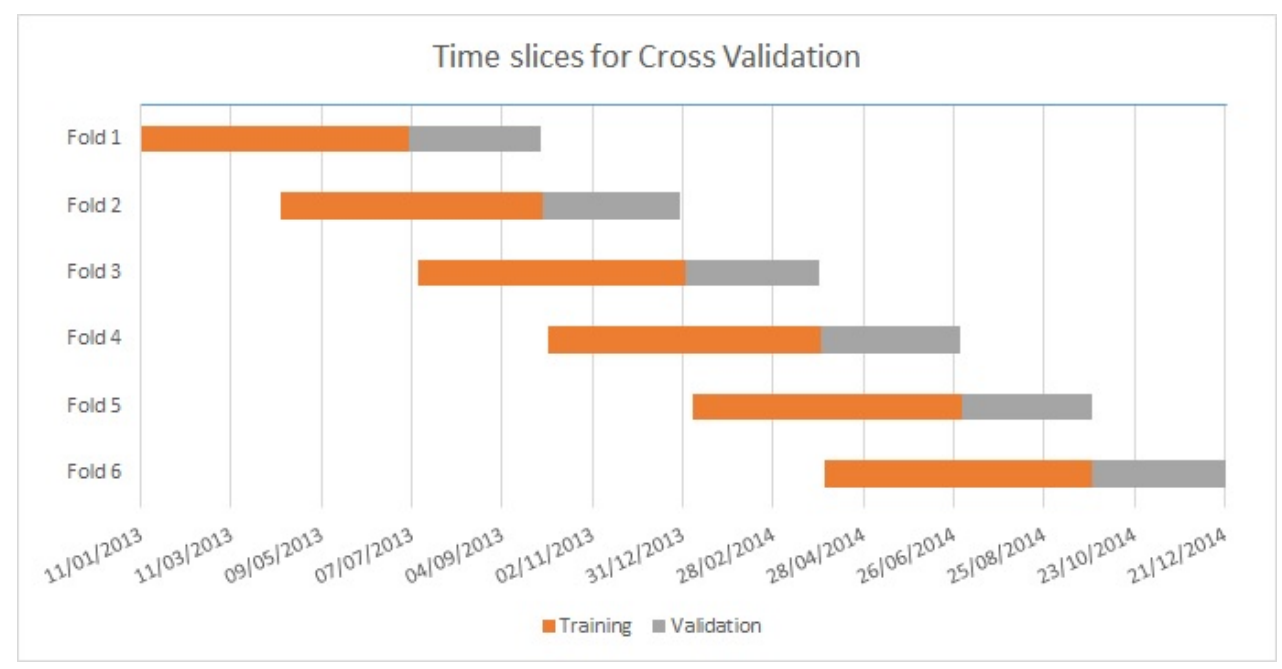

The problem was transformed into a binary classification problem (see subsection 3.2.2), it tries to predict if the stock is in a high or low trend, generating a buy or sell recommendation. 
To create the labels for supervised learning, i.e. if a stock is in a buy or sell movement, it was used the ZigZag indicator. Instead of using a fixed \% of price's changes, it was used the standard deviation of monthly returns, because each stock has its own volatility, and for some stocks, a movement of $6 \%$, for example, can be too high or too small. In Figure 20, some stocks's prices with ZigZag indicator applied to them are presented, for the year of 2015.

Figure 20 - Creating labels for 2015 with ZigZag indicator.

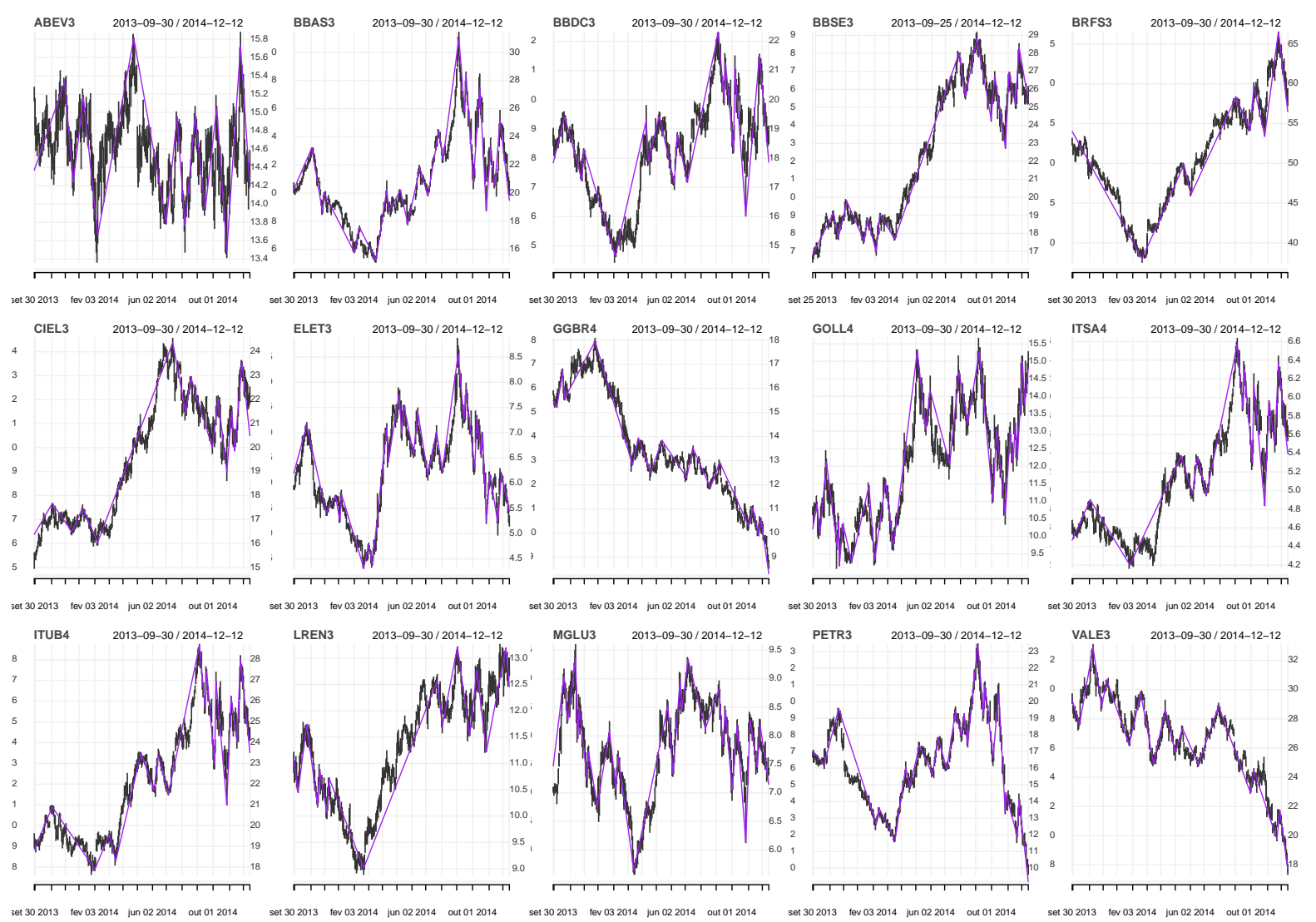

The best fifteen models, in terms of higher accuracy and lower standard deviation, of each year was selected to create the technical agents. They are presented in Table 8.

The complete results for each stock with the selected features and optimized hyperparameters are presented in Appendix A. In general, the models had a good accuracy results, even for some imbalanced datasets.

\subsection{FINANCIAL DISTRESS PREDICTION MODEL}

As explained in subsection 5.3.2, the fundamentalist agent uses an unsupervised learning method, called Partitioning Around Medoids (PAM) to cluster similar companies and perform relative valuation. Once each multiple is calculated, and target prices are defined to evaluate which 
Table 8 - Technical agent's selected stocks for each year.

\begin{tabular}{l|l|l|l|l|l}
\hline \multicolumn{2}{|c|}{2015} & \multicolumn{2}{|c|}{2016} & \multicolumn{2}{c}{2017} \\
\hline Ticker & Accuracy & Ticker & Accuracy & Ticker & Accuracy \\
\hline BRFS3 & $84.72 \% \pm 10.19 \%$ & ABEV3 & $74.72 \% \pm 06.62 \%$ & BRPR3 & $85.00 \% \pm 15.18 \%$ \\
BTOW3 & $91.25 \% \pm 10.66 \%$ & BEEF3 & $81.39 \% \pm 05.42 \%$ & CSNA3 & $87.00 \% \pm 01,83 \%$ \\
CPFE3 & $73.61 \% \pm 04.88 \%$ & BTOW3 & $83.75 \% \pm 07.74 \%$ & ECOR3 & $84.00 \% \pm 14.80 \%$ \\
CSAN3 & $80.23 \% \pm 10.40 \%$ & CMIG4 & $84.58 \% \pm 16.74 \%$ & ENBR3 & $76.67 \% \pm 07.60 \%$ \\
EZTC3 & $83.33 \% \pm 11.88 \%$ & ENBR3 & $76.33 \% \pm 06.81 \%$ & EVEN3 & $78.33 \% \pm 07.73 \%$ \\
HYPE3 & $82.78 \% \pm 10.89 \%$ & GGBR4 & $79.44 \% \pm 06.72 \%$ & ITSA4 & $80.67 \% \pm 11.52 \%$ \\
MDIA3 & $86.67 \% \pm 05.14 \%$ & GOAU4 & $80.83 \% \pm 07.66 \%$ & LAME4 & $81.11 \% \pm 08.34 \%$ \\
MGLU3 & $86.67 \% \pm 11.49 \%$ & GOLL4 & $80.00 \% \pm 09.94 \%$ & LIGT3 & $78.06 \% \pm 04.14 \%$ \\
MILS3 & $76.11 \% \pm 07.43 \%$ & KROT3 & $73.75 \% \pm 06.29 \%$ & MDIA3 & $94.58 \% \pm 07.12 \%$ \\
PDGR3 & $84.72 \% \pm 11.03 \%$ & MGLU3 & $87.33 \% \pm 14.56 \%$ & MGLU3 & $92.92 \% \pm 05.67 \%$ \\
SBSP3 & $78.33 \% \pm 08.50 \%$ & MMXM3 & $96.25 \% \pm 04.39 \%$ & MPLU3 & $88.33 \% \pm 04.08 \%$ \\
SULA11 & $78.61 \% \pm 07.78 \%$ & RSID3 & $79.17 \% \pm 08.87 \%$ & NATU3 & $79.00 \% \pm 10.04 \%$ \\
UGPA3 & $76.67 \% \pm 06.91 \%$ & SBSP3 & $74.67 \% \pm 05.82 \%$ & SBSP3 & $82.92 \% \pm 12.05 \%$ \\
VIVT4 & $75.56 \% \pm 07.12 \%$ & SULA11 & $79.67 \% \pm 12.55 \%$ & UGPA3 & $76.33 \% \pm 07.21 \%$ \\
VLID3 & $81.67 \% \pm 10.38 \%$ & TIMP3 & $80.33 \% \pm 03.21 \%$ & VIVT4 & $79.33 \% \pm 09.32 \%$ \\
\hline
\end{tabular}

company is over/undervalued, the potential undervalued companies are filtered out by a financial distress prediction model (FDP), i.e. companies that have a high probability of bankrupting in the next year are not considered as an investment opportunity. In this section, the results and resources regarding the FDP model are presented.

The problem of predicting if a company will have some financial distress in the next year or not is a classification problem, so it is necessary to provide some positive (unhealthy companies) and negative (healthy companies) examples to train the model.

Real-world problem of FDP consists of imbalanced datasets, as there are fewer companies in the stock market that went bankrupt than those that did not. This modelling problem should be considered, so it was created a dataset with companies that entered court-supervised reorganization or bankrupted in the period of 1998 to 2013. This period precedes the period of backtesting, so no future information is added.

Data was retrieved from Economatica database, and the final unbalanced dataset is composed of 39 unhealthy and 110 healthy companies, resulting in a dataset of 149 companies. The distribution of companies by sector is given in Table 9 . These sectors division are defined by Economatica.

The dataset was divided using $60 \%$ of the companies for training and $40 \%$ for testing in a stratified way, so class imbalance was respected. The quantities are presented in Table 10.

Initially, there were 25 features to predict companies' health, all of them are presented in Table 11, then the CFS filter was applied to filter them out, and the selected features are presented in Table 12.

It is interesting to note that at least one feature of each kind was selected, where EPS 
Table 9 - Companies by sector for FDP modelling.

\begin{tabular}{l|cc|c|c|}
\cline { 2 - 5 } \multicolumn{1}{c|}{} & \multicolumn{2}{c|}{ Quantity } & \multicolumn{2}{c|}{ Class Balance } \\
\hline Sector & Healthy & Unhealthy & Healthy & Unhealthy \\
\hline Agriculture and fishing & 2 & 1 & $67 \%$ & $33 \%$ \\
Food and beverage & 15 & 4 & $79 \%$ & $21 \%$ \\
Contruction & 10 & 2 & $83 \%$ & $17 \%$ \\
Electroelectronic & 4 & 2 & $67 \%$ & $33 \%$ \\
Energy & 15 & 3 & $83 \%$ & $17 \%$ \\
Mining & 2 & 1 & $67 \%$ & $33 \%$ \\
Non-Metalic Minerals & 2 & 1 & $67 \%$ & $33 \%$ \\
Others & 28 & 7 & $80 \%$ & $20 \%$ \\
Gas \& Oil & 4 & 2 & $67 \%$ & $33 \%$ \\
Chemistry & 3 & 1 & $75 \%$ & $25 \%$ \\
Materials & 6 & 3 & $67 \%$ & $33 \%$ \\
Textil & 9 & 7 & $56 \%$ & $44 \%$ \\
Transportation & 3 & 3 & $50 \%$ & $50 \%$ \\
Auto Manufacurers and Parts & 7 & 2 & $78 \%$ & $22 \%$ \\
\hline Total/Avg & 110 & 39 & $70 \%$ & $30 \%$ \\
\hline
\end{tabular}

Table 10 - Train and test dataset for FDP modelling.

\begin{tabular}{l|c|c|c|c}
\cline { 2 - 5 } \multicolumn{2}{c|}{ Quantity } & \multicolumn{2}{c}{ Class Balance } \\
\hline Dataset & Healthy & Unhealthy & Healthy & Unhealthy \\
\hline Train & 66 & 24 & $73 \%$ & $27 \%$ \\
\hline Test & 44 & 15 & $75 \%$ & $25 \%$ \\
\hline
\end{tabular}

represents a measure of profitability, Total Liabilities to Equity ratio is a degree of indebtedness, measuring the capital of third parties in relation to Shareholders' Equity, Quick ratio is an indicator of a company's short term liquidity, EBT plus Debt Financing is another measure of indebtedness that measure payment capabilities, and finally, ROA is an indicator of how profitable a company is relative to its total assets.

The algorithm used was a Random Forest, and it has a hyper-parameter to be optimized called mtry, that is the number of variables considered for splitting at each tree node. To select this hyper-parameter, a 3 times 10-fold cross-validation was used, and the metric to be optimized was the Area Under ROC Curve (AUC). This is a better metric than accuracy when evaluating an imbalanced dataset, a similar approach was used in (REIS; SICHMAN, 2018).

The results obtained from cross-validation are presented in Table 13. Based on crossvalidation results, it was chosen mtry $=2$.

The selected model was used to make prediction on the unseen data from the test set. The confusion matrix of predictions are presented in Table 14 and the model's metrics in Table 15.

It can be seen that the model can accurately separate health from unhealthy companies using the selected five features. This model is used to filter out undervalued companies after calculating their fair value using relative analysis, and a hypotheses test has being performed to verify if its use reduces risk and potentially improves performance. 
Table 11 - Financial Indicators

\begin{tabular}{|c|c|}
\hline Type of Indicator & Description (unit) \\
\hline \multirow{3}{*}{ Values per Share } & EPS - Earnings per Share $(\$)$ \\
\hline & BVES - Book Value of Equity per Share (\$) \\
\hline & Sales per Share $(\$)$ \\
\hline \multirow{10}{*}{ Capital Structure } & Net Debt $(\$)$ \\
\hline & Total Debt (\$) \\
\hline & Total Debt to Total Assets (\%) \\
\hline & D/E - Total Debt to Equity (\%) \\
\hline & Net Debt to Equity (a.k.a. Gearing) (\%) \\
\hline & (D/D+E) - Capital Structure (\%) \\
\hline & EBIT to Net Debt (\%) \\
\hline & Total Liabilities to Total Assets (\%) \\
\hline & Total Liabilities to Equity (\%) \\
\hline & Fixed Asset to Equity (\%) \\
\hline \multirow{5}{*}{ Liquidity } & Liquidity Ratio (x) \\
\hline & Current Ratio (x) \\
\hline & Quick Ratio (x) \\
\hline & Working Capital (\$) \\
\hline & Capital Employed (\$) \\
\hline \multirow{7}{*}{ Profitability } & EBT + Debt Financing $(\$)$ \\
\hline & Asset Turnover Ratio (x) \\
\hline & Equity Turnover Ratio (x) \\
\hline & ROA - Return on Assets (\%) \\
\hline & Invested Capital (\$) \\
\hline & Financial Leverage Ratio (x) \\
\hline & Operating Leverage Ratio (x) \\
\hline
\end{tabular}

Table 12 - Selected Financial Indicators

\begin{tabular}{c|l}
\hline Type of Indicator & \multicolumn{1}{c}{ Description (unit) } \\
\hline Values per Share & EPS - Earnings per Share (\$) \\
\hline Capital Structure & Total Liabilities to Equity (\%) \\
\hline Liquidity & Quick Ratio (x) \\
\hline Profitability & EBT + Debt Financing (\$) \\
& ROA - Return on Assets (\%) \\
\hline
\end{tabular}

Table 13 - Training set Results

\begin{tabular}{c|c|c|c}
\hline mtry & AUC & Sensibility & Specificity \\
\hline 2 & $98.69 \% \pm 3.13 \%$ & $88.33 \% \pm 24.43 \%$ & $95.40 \% \pm 7.18 \%$ \\
3 & $97.82 \% \pm 5.72 \%$ & $83.89 \% \pm 26.07 \%$ & $94.92 \% \pm 7.34 \%$ \\
4 & $97.46 \% \pm 5.83 \%$ & $83.89 \% \pm 26.07 \%$ & $94.44 \% \pm 8.35 \%$ \\
5 & $97.13 \% \pm 6.06 \%$ & $82.22 \% \pm 26.60 \%$ & $93.97 \% \pm 8.43 \%$ \\
\hline
\end{tabular}

\subsection{EXPERIMENTS CONFIGURATION}

The period chosen for backtesting was limited due to availability of web information. The information agent scraps fundamental data from a website ${ }^{1}$, and in the moment of scraping, there were four years available, i.e. 2014, 2015, 2016 and 2017, however, as some indicators 
Table 14 - Confusion Matrix

\begin{tabular}{c|c|c}
\cline { 2 - 3 } & \multicolumn{2}{c}{ Reference } \\
\hline Prediction & Unhealthy & Healthy \\
\hline Unhealthy & 13 & 1 \\
\hline Healthy & 2 & 43 \\
\hline
\end{tabular}

Table 15 - Test set results

\begin{tabular}{c|c|c|c}
\hline Accuracy & Sensitivity & Specificity & AUC \\
\hline $94,92 \%$ & $86,67 \%$ & $97,73 \%$ & $92,20 \%$ \\
\hline
\end{tabular}

calculation need the variation between one year to another (YoY), it was just possible to use the years of 2015, 2016 and 2017 for backtesting. Each experiment has the duration of one year starting 01/jan and ending 31/dec.

There are three different years, four investors profiles and the possibility of using or not the Technical agent with two or three top recommendations, and using or not the FDP model. Combining all possibilities there are a total of 72 experiments that are described in Table 16.

Table 16 - Experiments description.

\begin{tabular}{|c|c|c|c|c|c|c|c|c|c|c|c|}
\hline ID & Abreviation & Profile & Year & FDP Model & $\#$ of Tech. Recom & ID & Abreviation & Profile & Year & FDP Model & \# of Tech. Recom \\
\hline 1 & MAR & I1 & 2015 & $\mathrm{~N}$ & 0 & 37 & LRR & $\mathrm{I} 3$ & 2015 & $\mathrm{~N}$ & 0 \\
\hline 2 & MAR_FDP & I1 & 2015 & $\mathrm{Y}$ & 0 & 38 & LRR_FDP & I3 & 2015 & $\mathrm{Y}$ & 0 \\
\hline 3 & MAR_T2 & I1 & 2015 & $\mathrm{~N}$ & 2 & 39 & LRR_T2 & I3 & 2015 & $\mathrm{~N}$ & 2 \\
\hline 4 & MAR_T2_FDP & I1 & 2015 & $\mathrm{Y}$ & 2 & 40 & LRR_T2_FDP & I3 & 2015 & $\mathrm{Y}$ & 2 \\
\hline 5 & MAR_T3 & I1 & 2015 & $\mathrm{~N}$ & 3 & 41 & LRR_T3 & I3 & 2015 & $\mathrm{~N}$ & 3 \\
\hline 6 & MAR_T3_FDP & I1 & 2015 & $\mathrm{Y}$ & 3 & 42 & LRR_T3_FDP & I3 & 2015 & $\mathrm{Y}$ & 3 \\
\hline 7 & MAR & I1 & 2016 & $\mathrm{~N}$ & 0 & 43 & LRR & I3 & 2016 & $\mathrm{~N}$ & 0 \\
\hline 8 & MAR_FDP & I1 & 2016 & $\mathrm{Y}$ & 0 & 44 & LRR_FDP & I3 & 2016 & $\mathrm{Y}$ & 0 \\
\hline 9 & MAR_T2 & I1 & 2016 & $\mathrm{~N}$ & 2 & 45 & LRR_T2 & I3 & 2016 & $\mathrm{~N}$ & 2 \\
\hline 10 & MAR_T2_FDP & I1 & 2016 & $\mathrm{Y}$ & 2 & 46 & LRR_T2_FDP & $\mathrm{I} 3$ & 2016 & $\mathrm{Y}$ & 2 \\
\hline 11 & MAR_T3 & I1 & 2016 & $\mathrm{~N}$ & 3 & 47 & LRR_T3 & I3 & 2016 & $\mathrm{~N}$ & 3 \\
\hline 12 & MAR_T3_FDP & I1 & 2016 & $\mathrm{Y}$ & 3 & 48 & LRR_T3_FDP & I3 & 2016 & $\mathrm{Y}$ & 3 \\
\hline 13 & MAR & I1 & 2017 & $\mathrm{~N}$ & 0 & 49 & LRR & I3 & 2017 & $\mathrm{~N}$ & 0 \\
\hline 14 & MAR_FDP & I1 & 2017 & $\mathrm{Y}$ & 0 & 50 & LRR_FDP & I3 & 2017 & $\mathrm{Y}$ & 0 \\
\hline 15 & MAR_T2 & I1 & 2017 & $\mathrm{~N}$ & 2 & 51 & LRR_T2 & I3 & 2017 & $\mathrm{~N}$ & 2 \\
\hline 16 & MAR_T2_FDP & I1 & 2017 & $\mathrm{Y}$ & 2 & 52 & LRR_T2_FDP & I3 & 2017 & $\mathrm{Y}$ & 2 \\
\hline 17 & MAR_T3 & I1 & 2017 & $\mathrm{~N}$ & 3 & 53 & LRR_T3 & I3 & 2017 & $\mathrm{~N}$ & 3 \\
\hline 18 & MAR_T3_FDP & I1 & 2017 & $\mathrm{Y}$ & 3 & 54 & LRR_T3_FDP & I3 & 2017 & $\mathrm{Y}$ & 3 \\
\hline 19 & DTR & I2 & 2015 & $\mathrm{~N}$ & 0 & 55 & FRR & I4 & 2015 & $\mathrm{~N}$ & 0 \\
\hline 20 & DTR_FDP & I2 & 2015 & $\mathrm{Y}$ & 0 & 56 & FRR_FDP & I4 & 2015 & $\mathrm{Y}$ & 0 \\
\hline 21 & DTR_T2 & I2 & 2015 & $\mathrm{~N}$ & 2 & 57 & FRR_T2 & I4 & 2015 & $\mathrm{~N}$ & 2 \\
\hline 22 & DTR_T2_FDP & I2 & 2015 & $\mathrm{Y}$ & 2 & 58 & FRR_T2_FDP & I4 & 2015 & $\mathrm{Y}$ & 2 \\
\hline 23 & DTR_T3 & I2 & 2015 & $\mathrm{~N}$ & 3 & 59 & FRR_T3 & I4 & 2015 & $\mathrm{~N}$ & 3 \\
\hline 24 & DTR_T3_FDP & I2 & 2015 & $\mathrm{Y}$ & 3 & 60 & FRR_T3_FDP & I4 & 2015 & $\mathrm{Y}$ & 3 \\
\hline 25 & DTR & I2 & 2016 & $\mathrm{~N}$ & 0 & 61 & FRR & I4 & 2016 & $\mathrm{~N}$ & 0 \\
\hline 26 & DTR_FDP & I2 & 2016 & Y & 0 & 62 & FRR_FDP & I4 & 2016 & Y & 0 \\
\hline 27 & DTR_T2 & I2 & 2016 & $\mathrm{~N}$ & 2 & 63 & FRR_T2 & I4 & 2016 & $\mathrm{~N}$ & 2 \\
\hline 28 & DTR_T2_FDP & I2 & 2016 & Y & 2 & 64 & FRR_T2_FDP & I4 & 2016 & Y & 2 \\
\hline 29 & DTR_T3 & $\mathrm{I} 2$ & 2016 & $\mathrm{~N}$ & 3 & 65 & FRR_T3 & I4 & 2016 & $\mathrm{~N}$ & 3 \\
\hline 30 & DTR_T3_FDP & $\mathrm{I} 2$ & 2016 & Y & 3 & 66 & FRR_T3_FDP & I4 & 2016 & $\mathrm{Y}$ & 3 \\
\hline 31 & DTR & I2 & 2017 & $\mathrm{~N}$ & 0 & 67 & FRR & I4 & 2017 & $\mathrm{~N}$ & 0 \\
\hline 32 & DTR_FDP & I2 & 2017 & $\mathrm{Y}$ & 0 & 68 & FRR_FDP & I4 & 2017 & $\mathrm{Y}$ & 0 \\
\hline 33 & DTR_T2 & I2 & 2017 & $\mathrm{~N}$ & 2 & 69 & FRR_T2 & I4 & 2017 & $\mathrm{~N}$ & 2 \\
\hline 34 & DTR_T2_FDP & I2 & 2017 & Y & 2 & 70 & FRR_T2_FDP & I4 & 2017 & $\mathrm{Y}$ & 2 \\
\hline 35 & DTR_T3 & I2 & 2017 & $\mathrm{~N}$ & 3 & 71 & FRR_T3 & I4 & 2017 & $\mathrm{~N}$ & 3 \\
\hline 36 & DTR_T3_FDP & I2 & 2017 & $\mathrm{Y}$ & 3 & 72 & FRR_T3_FDP & I4 & 2017 & $\mathrm{Y}$ & 3 \\
\hline
\end{tabular}


considering three technical recommendations and using the financial distress prediction model it is named as $L R R \_T 3 \_F D P$, if not using FDP model and just considering two recommendations it is named as $L R R \_T 2$ and so on.

There are also some parameters regarding investor's profile, technical and fundamentalist agent and about trading and simulation that are better detailed in Appendix B.

These experiments would allow the verification of the following hypotheses:

1. Has Financial Distress Prediction model reduced risk?

2. Has Technical Agent improved results of each investor profile?

The list of assets used for backtesting by fundamentalist agent is the same one used by technical agent, presented in Table 7.

\subsection{PROFTS RESULTS}

The time to run each experiment is presented in Table 17, and its total time was of 1698.04 minutes. In Appendix C it is presented the detailed backtesting's results for each investor profile for each year. In the next sections are presented the summarized results.

Table 17 - Experiments duration in minutes.

\begin{tabular}{c|c|c|c|c|c} 
Experiment ID & Time (min) & Experiment ID & Time $(\min )$ & Experiment ID & Time (min) \\
\hline 1 & 21,49 & 25 & 22,16 & 49 & 21,75 \\
2 & 21,53 & 26 & 22,08 & 50 & 21,61 \\
3 & 23,46 & 27 & 23,94 & 51 & 24,12 \\
4 & 23,31 & 28 & 24,01 & 52 & 22,77 \\
5 & 22,80 & 29 & 25,24 & 53 & 25,22 \\
6 & 23,25 & 30 & 25,03 & 54 & 24,88 \\
7 & 22,15 & 31 & 21,47 & 55 & 21,58 \\
8 & 22,31 & 32 & 25,65 & 56 & 21,50 \\
9 & 24,07 & 33 & 24,93 & 57 & 23,35 \\
10 & 23,84 & 34 & 23,31 & 58 & 23,30 \\
11 & 25,32 & 35 & 26,01 & 59 & 23,16 \\
12 & 25,00 & 36 & 24,62 & 60 & 23,35 \\
13 & 22,53 & 37 & 21,58 & 61 & 22,45 \\
14 & 21,58 & 38 & 21,50 & 62 & 22,23 \\
15 & 25,04 & 39 & 23,28 & 63 & 24,10 \\
16 & 23,50 & 40 & 23,75 & 64 & 24,07 \\
17 & 26,86 & 41 & 23,32 & 65 & 25,43 \\
18 & 26,27 & 42 & 23,23 & 66 & 25,34 \\
19 & 21,53 & 43 & 22,25 & 67 & 21,62 \\
20 & 21,64 & 44 & 22,07 & 68 & 21,45 \\
21 & 23,49 & 45 & 30,30 & 69 & 22,84 \\
22 & 23,45 & 46 & 24,60 & 70 & 23,12 \\
23 & 23,42 & 47 & 25,52 & 71 & 25,85 \\
24 & 23,47 & 48 & 25,32 & 72 & 26,47 \\
\hline Total & & & & & 1698,04 \\
\hline & & & & &
\end{tabular}




\subsubsection{BACKTEST FOR 2015}

The benchmark used for comparison was the IBrX 100 Index, it is an Index composed of the 100 most negotiated stocks in the Brazilian stock market. In the year of 2015 the Index had an annualized return of $-10.2 \%$, this is an interesting period to see how portfolios will behave, as all portfolios are long only.

In Table 18, all portfolios with different investor profile are compared. It was created a simple ranking that is the average of its ranking position when comparing each portfolio in terms of (i) Sharpe ratio, (ii) annualized return, (iii) Standard Deviation and (iv) maximum drawdown.

For 2015, portfolios with investor profiles I2 and I4 were, in general, better than the benchmark. In terms of risk (standard deviation), almost all of them had a lower risk than the benchmark.

Table 18 - Portfolios comparison for 2015.

\begin{tabular}{|c|c|c|c|c|c|c|c|c|c|c|c|c|c|c|}
\hline \multicolumn{15}{|c|}{2015} \\
\hline Exp. ID & Sharpe & Rank & Exp. ID & Return & Rank & Exp. ID & StdDev & Rank & Exp. ID & Drawdown & Rank & Exp. ID & Exp. Description & Final Score \\
\hline 60 & 0,8081 & 1 & 60 & 0,1470 & 1 & 59 & 0,1802 & 1 & 60 & 0,1167 & 1 & 60 & FRR_T3_FDP & 1,25 \\
\hline 59 & 0,7698 & 2 & 59 & 0,1387 & 2 & 60 & 0,1819 & 2 & 59 & 0,1169 & 2 & 59 & FRR_T3 & 1,75 \\
\hline 56 & 0,4383 & 3 & 56 & 0,0861 & 3 & 6 & 0,1861 & 3 & 56 & 0,1429 & 3 & 56 & FRR_FDP & 5 \\
\hline 55 & 0,3890 & 4 & 55 & 0,0757 & 4 & 42 & 0,1861 & 3 & 55 & 0,1433 & 4 & 55 & FRR & 5,25 \\
\hline 58 & 0,0873 & 5 & 58 & 0,0168 & 5 & 41 & 0,1898 & 4 & 58 & 0,1815 & 5 & 58 & FRR_T2_FDP & 5,5 \\
\hline 23 & 0,0633 & 6 & 23 & 0,0122 & 6 & 57 & 0,1915 & 5 & 57 & 0,1820 & 6 & 57 & FRR_T2 & 6,25 \\
\hline 57 & 0,0465 & 7 & 57 & 0,0089 & 7 & 3 & 0,1926 & 6 & 23 & 0,1879 & 7 & 23 & DTR_T3 & 6,75 \\
\hline 24 & $-0,0874$ & 8 & 24 & $-0,0181$ & 8 & 39 & 0,1926 & 6 & 41 & 0,2115 & 8 & 6 & MAR_T3_FDP & 8,5 \\
\hline 5 & $-0,2576$ & 9 & 5 & $-0,0554$ & 9 & 58 & 0,1927 & 7 & 24 & 0,2127 & 9 & 42 & LRR_T3_FDP & 8,5 \\
\hline 19 & $-0,3201$ & 10 & 6 & $-0,0610$ & 10 & 23 & 0,1932 & 8 & 6 & 0,2131 & 10 & 41 & LRR_T3 & 9,75 \\
\hline 6 & $-0,3276$ & 11 & 42 & $-0,0610$ & 10 & 55 & 0,1947 & 9 & 42 & 0,2131 & 10 & 24 & DTR_T3_FDP & 10 \\
\hline 42 & $-0,3276$ & 11 & 19 & $-0,0677$ & 11 & 4 & 0,1961 & 10 & 19 & 0,2240 & 11 & 19 & DTR & 12 \\
\hline 20 & $-0,4477$ & 12 & 41 & $-0,0928$ & 12 & 40 & 0,1961 & 10 & bench. & 0,2415 & 12 & 5 & MAR_T3 & 12 \\
\hline bench. & $-0,4653$ & 13 & 21 & $-0,0973$ & 13 & 56 & 0,1965 & 11 & 5 & 0,2532 & 13 & 21 & DTR_T2 & 13,25 \\
\hline 21 & $-0,4839$ & 14 & bench. & $-0,1017$ & 14 & 21 & 0,2011 & 12 & 21 & 0,2536 & 14 & bench. & IBrX 100 & 14,5 \\
\hline 41 & $-0,4888$ & 15 & 20 & $-0,1036$ & 15 & 1 & 0,2060 & 13 & 20 & 0,2567 & 15 & 20 & DTR_FDP & 15,5 \\
\hline 22 & $-0,5850$ & 16 & 22 & $-0,1264$ & 16 & 37 & 0,2060 & 13 & 1 & 0,2613 & 16 & 4 & MAR_T2_FDP & 16 \\
\hline 2 & $-0,7543$ & 17 & 2 & $-0,1556$ & 17 & 2 & 0,2063 & 14 & 37 & 0,2613 & 16 & 40 & LRR_T2_FDP & 16 \\
\hline 38 & $-0,7543$ & 17 & 38 & $-0,1556$ & 17 & 38 & 0,2063 & 14 & 2 & 0,2641 & 17 & 2 & MAR_FDP & 16,25 \\
\hline 4 & $-0,8376$ & 18 & 4 & $-0,1642$ & 18 & 24 & 0,2068 & 15 & 38 & 0,2641 & 17 & 38 & LRR_FDP & 16,25 \\
\hline 40 & $-0,8376$ & 18 & 40 & $-0,1642$ & 18 & 19 & 0,2115 & 16 & 4 & 0,2815 & 18 & 3 & MAR_T2 & 16,5 \\
\hline 1 & $-0,8812$ & 19 & 1 & $-0,1815$ & 19 & 5 & 0,2149 & 17 & 40 & 0,2815 & 18 & 39 & LRR_T2 & 16,5 \\
\hline 37 & $-0,8812$ & 19 & 37 & $-0,1815$ & 19 & 22 & 0,2161 & 18 & 22 & 0,2848 & 19 & 1 & MAR & 16,75 \\
\hline 3 & $-1,3436$ & 20 & 3 & $-0,2588$ & 20 & bench. & 0,2185 & 19 & 3 & 0,3001 & 20 & 37 & LRR & 16,75 \\
\hline 39 & $-1,3436$ & 20 & 39 & $-0,2588$ & 20 & 20 & 0,2315 & 20 & 39 & 0,3001 & 20 & 22 & DTR_T2_FDP & 17,25 \\
\hline
\end{tabular}

\subsubsection{BACKTEST FOR 2016}

Contrary to 2015, the year of 2016 had a high annualized return of $41,3 \%$, this is a completely different trend compared to 2015 and could favour all portfolios.

In Table 19, it is possible to compare all portfolios with different investor profiles. Despite the fact that 2016 was a great year, in terms or return, half of the portfolios managed by PROFTS still had a better result than the benchmark. It is also important to note that almost all portfolios had a lower standard deviation. 
Table 19 - Portfolios comparison for 2016.

\begin{tabular}{|c|c|c|c|c|c|c|c|c|c|c|c|c|c|c|}
\hline \multicolumn{15}{|c|}{2016} \\
\hline Exp. ID & Sharpe & Rank & Exp. ID & Return & Rank & Exp. ID & StdDev & Rank & Exp. ID & Drawdown & Rank & Exp. ID & Exp. Desc. & Final Score \\
\hline 63 & 2,7870 & 1 & 27 & 0,7322 & 1 & 48 & 0,1631 & 1 & 48 & 0,1020 & 1 & 63 & FRR_T2 & 6,25 \\
\hline 27 & 2,7652 & 2 & 63 & 0,7252 & 2 & 12 & 0,1641 & 2 & 12 & 0,1020 & 1 & 27 & DTR_T2 & 6,5 \\
\hline 25 & 1,7953 & 3 & 25 & 0,4884 & 3 & 47 & 0,1740 & 3 & 47 & 0,1022 & 2 & 11 & MAR_T3 & 7 \\
\hline 61 & 1,7563 & 4 & 61 & 0,4766 & 4 & 11 & 0,1756 & 4 & 11 & 0,1022 & 2 & 29 & DTR_T3 & 7,25 \\
\hline 29 & 1,6692 & 5 & bench. & 0,4132 & 5 & 8 & 0,1760 & 5 & 63 & 0,1117 & 3 & 45 & LRR_T2 & 7,25 \\
\hline bench. & 1,6407 & 6 & 29 & 0,3940 & 6 & 44 & 0,1760 & 5 & 27 & 0,1117 & 3 & 47 & LRR_T3 & 7,5 \\
\hline 65 & 1,5829 & 7 & 65 & 0,3832 & 7 & 10 & 0,1827 & 6 & 29 & 0,1143 & 4 & 12 & MAR_T3_FDP & 7,75 \\
\hline 45 & 1,1370 & 8 & 45 & 0,2185 & 8 & 46 & 0,1827 & 6 & 45 & 0,1145 & 5 & 48 & LRR_T3_FDP & 8,25 \\
\hline 9 & 1,0190 & 9 & 9 & 0,1968 & 9 & 7 & 0,1875 & 7 & 9 & 0,1156 & 6 & 9 & MAR_T2 & 8,25 \\
\hline 11 & 0,9191 & 10 & 28 & 0,1967 & 10 & 43 & 0,1875 & 7 & 7 & 0,1202 & 7 & 7 & MAR & 9 \\
\hline 7 & 0,8962 & 11 & 7 & 0,1680 & 11 & 45 & 0,1921 & 8 & 43 & 0,1202 & 7 & 43 & LRR & 9 \\
\hline 43 & 0,8962 & 11 & 43 & 0,1680 & 11 & 9 & 0,1931 & 9 & bench. & 0,1204 & 8 & bench. & IBrX 100 & 9,25 \\
\hline 47 & 0,8696 & 12 & 11 & 0,1614 & 12 & 66 & 0,2055 & 10 & 62 & 0,1255 & 9 & 25 & DTR & 9,5 \\
\hline 28 & 0,8296 & 13 & 47 & 0,1513 & 13 & 30 & 0,2110 & 11 & 25 & 0,1315 & 10 & 61 & FRR & 10 \\
\hline 12 & 0,7149 & 14 & 12 & 0,1173 & 14 & 62 & 0,2250 & 12 & 61 & 0,1333 & 11 & 65 & FRR_T3 & 11,5 \\
\hline 48 & 0,6636 & 15 & 10 & 0,1133 & 15 & 64 & 0,2274 & 13 & 8 & 0,1344 & 12 & 8 & MAR_FDP & 12,75 \\
\hline 10 & 0,6200 & 16 & 46 & 0,1133 & 15 & 29 & 0,2361 & 14 & 44 & 0,1344 & 12 & 44 & LRR_FDP & 12,75 \\
\hline 46 & 0,6200 & 16 & 48 & 0,1082 & 16 & 26 & 0,2362 & 15 & 66 & 0,1371 & 13 & 10 & MAR_T2_FDP & 12,75 \\
\hline 8 & 0,5648 & 17 & 8 & 0,0994 & 17 & 28 & 0,2371 & 16 & 10 & 0,1379 & 14 & 46 & LRR_T2_FDP & 12,75 \\
\hline 44 & 0,5648 & 17 & 44 & 0,0994 & 17 & 65 & 0,2421 & 17 & 46 & 0,1379 & 14 & 28 & DTR_T2_FDP & 14,25 \\
\hline 64 & 0,0972 & 18 & 64 & 0,0221 & 18 & bench. & 0,2518 & 18 & 65 & 0,1382 & 15 & 62 & FRR_FDP & 15,25 \\
\hline 66 & $-0,0842$ & 19 & 66 & $-0,0173$ & 19 & 63 & 0,2602 & 19 & 64 & 0,1546 & 16 & 66 & FRR_T3_FDP & 15,25 \\
\hline 62 & $-0,1269$ & 20 & 62 & $-0,0285$ & 20 & 27 & 0,2648 & 20 & 30 & 0,1587 & 17 & 64 & FRR_T2_FDP & 16,25 \\
\hline 30 & $-0,1666$ & 21 & 30 & $-0,0351$ & 21 & 61 & 0,2713 & 21 & 28 & 0,1745 & 18 & 30 & DTR_T3_FDP & 17,5 \\
\hline 26 & $-0,2457$ & 22 & 26 & $-0,0580$ & 22 & 25 & 0,2721 & 22 & 26 & 0,1794 & 19 & 26 & DTR_FDP & 19,5 \\
\hline
\end{tabular}

\subsubsection{BACKTEST FOR 2017}

The year of 2017 was similar to 2016, the index had an annualized return of $29,6 \%$. In Table 20, it is possible to compare all portfolios with different investor profiles. With exception of portfolios with investor profile I4, that used FDP model, all of them were better than the benchmark.

Table 20 - Portfolios comparison for 2017.

\begin{tabular}{|c|c|c|c|c|c|c|c|c|c|c|c|c|c|c|}
\hline \multicolumn{15}{|c|}{2017} \\
\hline Exp. ID & Sharpe & Rank & Exp. ID & Return & Rank & Exp. ID & StdDev & Rank & Exp. ID & Drawdown & Rank & Exp. ID & Exp. Desc. & Final Score \\
\hline 16 & 3,3627 & 1 & 35 & 0,5429 & 1 & 51 & 0,1355 & 1 & 16 & 0,0694 & 1 & 16 & MAR_T2_FDP & 3,75 \\
\hline 15 & 3,3460 & 2 & 31 & 0,5382 & 2 & 52 & 0,1378 & 2 & 52 & 0,0700 & 2 & 15 & MAR_T2 & 4,75 \\
\hline 14 & 3,0961 & 3 & 16 & 0,5352 & 3 & 53 & 0,1384 & 3 & 15 & 0,0768 & 3 & 14 & MAR_FDP & 5,25 \\
\hline 50 & 3,0961 & 3 & 33 & 0,5326 & 4 & 54 & 0,1386 & 4 & 14 & 0,0855 & 4 & 50 & LRR_FDP & 5,25 \\
\hline 13 & 3,0188 & 4 & 15 & 0,5323 & 5 & 14 & 0,1427 & 5 & 50 & 0,0855 & 4 & 52 & LRR_T2_FDP & 5,75 \\
\hline 49 & 3,0188 & 4 & 36 & 0,5225 & 6 & 50 & 0,1427 & 5 & 18 & 0,0865 & 5 & 13 & MAR & 7,5 \\
\hline 52 & 2,7923 & 5 & 69 & 0,5092 & 7 & 18 & 0,1437 & 6 & 32 & 0,0877 & 6 & 49 & LRR & 7,5 \\
\hline 18 & 2,6350 & 6 & 34 & 0,5075 & 8 & 13 & 0,1448 & 7 & 54 & 0,0906 & 7 & 18 & MAR_T3_FDP & 8 \\
\hline 35 & 2,6336 & 7 & 14 & 0,4418 & 9 & 49 & 0,1448 & 7 & 17 & 0,0960 & 8 & 35 & DTR_T3 & 9,25 \\
\hline 17 & 2,5753 & 8 & 50 & 0,4418 & 9 & 17 & 0,1450 & 8 & 13 & 0,0975 & 9 & 17 & MAR_T3 & 10 \\
\hline 33 & 2,5701 & 9 & 13 & 0,4370 & 10 & 15 & 0,1591 & 9 & 49 & 0,0975 & 9 & 54 & LRR_T3_FDP & 11 \\
\hline 69 & 2,5693 & 10 & 49 & 0,4337 & 10 & 16 & 0,1592 & 10 & 36 & 0,0990 & 10 & 36 & DTR_T3_FDP & 11 \\
\hline 36 & 2,5113 & 11 & 67 & 0,4282 & 11 & 71 & 0,1853 & 11 & 53 & 0,0991 & 11 & 33 & DTR_T2 & 11,25 \\
\hline 31 & 2,4675 & 12 & 32 & 0,4135 & 12 & 69 & 0,1982 & 12 & 34 & 0,1011 & 12 & 69 & FRR_T2 & 11,5 \\
\hline 34 & 2,4305 & 13 & bench. & 0,4132 & 13 & 72 & 0,1999 & 13 & 51 & 0,1043 & 13 & 51 & LRR_T2 & 11,75 \\
\hline 51 & 2,4288 & 14 & 52 & 0,3847 & 14 & 67 & 0,2033 & 14 & 35 & 0,1162 & 14 & 53 & LRR_T3 & 12,5 \\
\hline 54 & 2,4058 & 15 & 18 & 0,3786 & 15 & 35 & 0,2062 & 15 & 71 & 0,1164 & 15 & 34 & DTR_T2_FDP & 12,75 \\
\hline 53 & 2,3671 & 16 & 17 & 0,3733 & 16 & 33 & 0,2072 & 16 & 33 & 0,1165 & 16 & 32 & DTR_FDP & 13,75 \\
\hline 67 & 2,1065 & 17 & 71 & 0,3564 & 17 & 36 & 0,2080 & 17 & 69 & 0,1188 & 17 & 31 & DTR & 13,75 \\
\hline 32 & 1,9237 & 18 & 54 & 0,3334 & 18 & 34 & 0,2088 & 18 & bench. & 0,1204 & 18 & 67 & FRR & 15,25 \\
\hline 71 & 1,9228 & 19 & 51 & 0,3291 & 19 & 32 & 0,2150 & 19 & 67 & 0,1207 & 19 & 71 & FRR_T3 & 15,5 \\
\hline bench. & 1,6407 & 20 & 53 & 0,3277 & 20 & 70 & 0,2174 & 20 & 31 & 0,1289 & 20 & bench. & IBrX 100 & 18,5 \\
\hline 70 & 1,5013 & 21 & 70 & 0,3263 & 21 & 31 & 0,2181 & 21 & 72 & 0,1585 & 21 & 72 & FRR_T3_FDP & 20 \\
\hline 68 & 1,0267 & 22 & 68 & 0,2302 & 22 & 68 & 0,2243 & 22 & 70 & 0,1845 & 22 & 70 & FRR_T2_FDP & 21 \\
\hline 72 & 0,9382 & 23 & 72 & 0,1876 & 23 & bench. & 0,2518 & 23 & 68 & 0,2056 & 23 & 68 & FRR_FDP & 22,25 \\
\hline
\end{tabular}




\subsection{RESULTS ANALYSIS}

Table 21 - Final Result

\begin{tabular}{l|c|c}
\hline Exp. Description. & Final Score & Rank \\
\hline DTR_T3 & 7,8 & 1 \\
FRR_T2 & 8,0 & 2 \\
MAR_T3_FDP & 8,1 & 3 \\
LRR_T3_FDP & 9,3 & 4 \\
FRR_T3 & 9,6 & 5 \\
MAR_T3 & 9,7 & 6 \\
MAR_T2 & 9,8 & 7 \\
LRR_T3 & 9,9 & 8 \\
FRR & 10,2 & 9 \\
DTR_T2 & 10,3 & 10 \\
MAR_T2_FDP & 10,8 & 11 \\
MAR & 11,1 & 12 \\
LRR & 11,1 & 12 \\
MAR_FDP & 11,4 & 13 \\
LRR_FDP & 11,4 & 13 \\
LRR_T2_FDP & 11,5 & 14 \\
DTR & 11,8 & 15 \\
LRR_T2 & 11,8 & 15 \\
FRR_T3_FDP & 12,2 & 16 \\
DTR_T3_FDP & 12,8 & 17 \\
IBrX 100 & 14,1 & 18 \\
FRR_FDP & 14,2 & 19 \\
FRR_T2_FDP & 14,3 & 20 \\
DTR_T2_FDP & 14,8 & 21 \\
DTR_FDP & 16,3 & 22 \\
\hline & &
\end{tabular}

In Table 21 all portfolios were compared between all years, and a final rank was created averaging the final scores of each year. The best portfolio was DTR_T3, it was the most consistent portfolio considering sharpe ratio, return, standard deviation and maximum drawdown along these three years.

All experiments were conducted in pairs, where the first experiment had some feature and the second one had not. The resulting data follows a normal distribution, thus to these characteristics, to validate each hypotheses it was performed a paired t-test (KANJI, 2006).

\subsubsection{FINANCIAL DISTRESS PREDICTION HYPOTHESES}

The first hypothesis is that FDP model reduced risk. Two different risk measure were used, i.e. Standard Deviation, a measure of volatility, and the Maximum Drawdown, a measure of downside risk over a specified time period, to verify this hypothesis. Considering that a smaller value of risk means a better portfolio in terms of risk, the general form of the hypothesis is:

H1: The portfolio that used the FDP model is better that the one that did not use it.

This hypothesis can be mathematically formulated as $M_{F D P}^{X}<M^{X}$ where $\mathrm{X}$ is the Standard Deviation or Max Drawdown metric, and $M$ is the portfolio being analysed. In order to 
validate this hypothesis using a paired t-test the following test was performed:

$$
\begin{aligned}
& H 0: M_{F D P}^{X} \geq M^{X} \\
& H 1: M_{F D P}^{X}<M^{X}
\end{aligned}
$$

In Table 22, considering a confidence level of $95 \%$ and the degree of freedom of 35, it is possible to see that for standard deviation, the hypothesis of $\mathrm{H} 0$ was rejected, which confirms the alternative hypothesis, while for maximum drawdown, it was not possible to reject H0. Something to point out, is that neither fundamentalist agent nor technical agent tried to reduce drawdown during their decisions, but only standard deviation, where they were successful. More details about the differences between each pair can be find in section D.1.

Table 22 - Hypotheses test results for FDP model.

\begin{tabular}{l|c|c|c|c|c}
\hline Metric & hipótese & $\mathrm{t}$ & $\mathrm{df}$ & $\mathrm{p}$-value & Reject H0 \\
\hline StdDev & 1 - FDP x NFDP & $-1,8917$ & 35 & 0,033410 & $\mathrm{Y}$ \\
DD & 1 - FDP x NFDP & 1,7674 & 35 & 0,957100 & $\mathrm{~N}$ \\
\hline
\end{tabular}

\subsubsection{TECHNICAL AGENT HYPOTHESES}

The second hypothesis is that Technical agent improved results of each investor profile. For investors I1 and I3 it was tested standard deviation and maximum drawdown and these metrics were called risk metrics, while for I 2 and I4 it was tested return and sharpe ratio and these metrics were called performance metrics. Both hypotheses were tested for portfolios that used two technical recommendations (T2) and three technical recommendations (T3) separately.

When the metric is related to risk, a smaller value means a better portfolio, however, when the metric is related to return and sharpe ratio, a higher value means a better portfolio. The general form of the hypotheses is:

H1: The portfolio that used technical agent recommendations is better than the one that did not use it.

In terms of risk, this hypothesis can be mathematically formulated as $M_{T}^{X}<M^{X}$ where $\mathrm{X}$ is the Standard Deviation or Max Drawdown metric and T can refer to T2 or T3. In order to validate this hypothesis using a paired t-test the following test was performed:

$$
\begin{aligned}
& H 0: M_{T}^{X} \geq M^{X} \\
& H 1: M_{T}^{X}<M^{X}
\end{aligned}
$$

In terms of performance, this hypothesis can be mathematically formulated as $M_{T}^{X}>M^{X}$ where $\mathrm{X}$ is the return or sharpe ratio metric and $\mathrm{T}$ can refer to T2 or T3. In order to validate this 
hypothesis using a paired t-test the following test was performed:

$$
\begin{aligned}
& H 0: M_{T}^{X} \leq M^{X} \\
& H 1: M_{T}^{X}>M^{X}
\end{aligned}
$$

The hypothesis testing results are presented in Table 23 for risk metrics and in Table 24 for performance metrics.

Table 23 - Hypothesis test results for risk metrics using technical agent recommendation.

\begin{tabular}{l|c|r|c|c|c}
\hline Metric & hipótese & $\mathrm{t}$ & $\mathrm{df}$ & $\mathrm{p}$-value & Reject H0 \\
\hline StdDev & $2-\mathrm{T} 2 \times \mathrm{NT}$ & $-0,181$ & 11 & 0,429900 & $\mathrm{~N}$ \\
DD & $2-\mathrm{T} 2 \times \mathrm{NT}$ & 0,922 & 11 & 0,811800 & $\mathrm{~N}$ \\
\hline StdDev & $2-\mathrm{T} 3 \times \mathrm{NT}$ & $-3,429$ & 11 & 0,002817 & $\mathrm{Y}$ \\
DD & $2-\mathrm{T} 3 \times \mathrm{NT}$ & $-3,404$ & 11 & 0,002944 & $\mathrm{Y}$ \\
\hline
\end{tabular}

Table 24 - Hypothesis test results for performance metrics using technical agent recommendation.

\begin{tabular}{l|c|c|c|c|c}
\hline Metric & hipótese & $\mathrm{t}$ & $\mathrm{df}$ & $\mathrm{p}$-value & Reject H0 \\
\hline Return & 2 - NT x T2 & 2,093 & 11 & 0,030190 & $\mathrm{Y}$ \\
Sharpe & 2 - NT x T2 & 2,142 & 11 & 0,027720 & $\mathrm{Y}$ \\
\hline Return & 2 - NT x T3 & 0,542 & 11 & 0,299400 & $\mathrm{~N}$ \\
Sharpe & 2 - NT x T3 & 1,978 & 11 & 0,036770 & $\mathrm{Y}$ \\
\hline
\end{tabular}

For investors I1 and I3, when using three technical agent recommendation's, it was possible to reduce risk and the $\mathrm{H} 0$ hypothesis was reject, the same did not happen when having just two technical agent recommendations. When using three recommendations, the system has more options to choose and generally will trade less, because all three recommendations should have at least $70 \%$ of confidence (see Table 30), these facts may have caused this difference in the results.

For investors $\mathrm{I} 2$ and $\mathrm{I} 4$, both hypotheses $\mathrm{H} 0$ were rejected for $\mathrm{T} 2$ and the one related to sharpe ratio was rejected for $\mathrm{T} 3$, probably because of its superior results regarding risk. The machine learning model from each technical agent was used to predict an upward movement in prices, if the models are accurate in their predictions, the more you trade, the better results you get. This can explain the results obtained by $\mathrm{T} 2$ portfolios. Improving these models would increase even more the return and sharpe ratio, while having more options to choose, would have reduced risk.

More details about the hypothesis testing can be found in section D.2. 


\section{CONCLUSIONS}

\section{CONCLUSIONS}

The use of a multi-agent systems approach to deal with the problem of autonomous portfolio management has great relevance and is very suitable for this kind of problem. However, most studies using MAS are used as recommendation systems. When trying to find studies that used MAS for ATS, the number of studies, which are already few, become fewer.

In this work, we proposed a multi-agent system architecture called PROFTS to perform automated portfolio management. We combined the use of fundamental and technical analysis. It is worth mentioning that fundamental analysis are rarely implemented in studies of computational finance, given its complexity. Different investor's profile were also considered.

PROFTS's results were very impressive, outperforming the benchmark in almost all scenarios. From our final ranking, the benchmark was positioned at $18^{\text {th }}$ place out of 22 . It is important to highlight that these results considered costs, so the proposed system can really be profitable, as its name suggests.

From our initial hypothesis, FDP model proved to reduce risk. In a real-world scenario, we believe it would have been even more important, as our experiments suffers from survivorship bias, because companies that go bankrupt are delisted and their information could not be found in the internet by information agent, so in our simulation there was not companies that went bankrupt between 2015 and 2017, just some companies that were under court-supervised reorganization.

The use of technical analysis to controls PROFTS's goals also proved its value, showing statistically significant difference in means for portfolios that use them, compared with those that did not. There is an indication that portfolios that traded more following technical agent recommendation had better results in terms of return and sharpe ratio, while portfolios that had more options to choose in between had better results in terms of risk, but it needs better investigation.

The system has a lot of parameters that were defined based on expertise. In future work, some of these parameters could be changed to see how this affects the system. There are a lot of improvements that can be also done for future work, some of them are: (i) deal with class imbalance to train technical agent models; (ii) use more accurate models for prediction, e.g. ensembles of classifiers; (iii) use stop loss to avoid bad portfolio formation; (iv) add short positions for long and short portfolios; (v) add more stocks, from different countries or even different assets, like fixed income, currencies, etc. 


\section{A TECHNICAL AGENTS RESULTS}

In Table 25 it is presented, for each stock and year, the standard deviation of monthly returns that was used as input for the ZiZag indicator to create the labels, and the \% of buy/sell signal, to verify the class imbalance. For the year of 2015, it did not have sufficient data for KLBN11 and VVAR11, that is why these were just used on 2016 and 2017.

Table 25 - ZigZag parameters for each year and stock and class balance.

\begin{tabular}{|c|c|c|c|c|c|c|c|c|c|}
\hline & \multicolumn{3}{|c|}{2015} & \multicolumn{3}{|c|}{2016} & & 117 & \\
\hline & ZigZag Inpu & Class & Salance & ZigZag Inpu & Class & Balance & ZigZag Input & \begin{tabular}{|l|l|} 
Class \\
\end{tabular} & Balance \\
\hline & SD Return & Buy & Sell & SD Return & Buy & Sell & SD Return & \begin{tabular}{|l|l|} 
Buy \\
\end{tabular} & Sell \\
\hline ABEV3 & $4,57 \%$ & $46 \%$ & $54 \%$ & $3,76 \%$ & $52 \%$ & $48 \%$ & $3,72 \%$ & $50 \%$ & $50 \%$ \\
\hline BBAS3 & $10,89 \%$ & $55 \%$ & $45 \%$ & $11,48 \%$ & $47 \%$ & $53 \%$ & $17,01 \%$ & $57 \%$ & $43 \%$ \\
\hline BBDC3 & $8,24 \%$ & $57 \%$ & $43 \%$ & $7,49 \%$ & $49 \%$ & $51 \%$ & $10,95 \%$ & $57 \%$ & $43 \%$ \\
\hline BBSE3 & $6,21 \%$ & $58 \%$ & $42 \%$ & $8,32 \%$ & $61 \%$ & $39 \%$ & $9,92 \%$ & $58 \%$ & $42 \%$ \\
\hline BEEF3 & $9,27 \%$ & $44 \%$ & $56 \%$ & $10,51 \%$ & $49 \%$ & $51 \%$ & $10,14 \%$ & $52 \%$ & $48 \%$ \\
\hline BRAP4 & $7,77 \%$ & $35 \%$ & $65 \%$ & $10,33 \%$ & $34 \%$ & $66 \%$ & $22,92 \%$ & $49 \%$ & $51 \%$ \\
\hline BRFS3 & $5,95 \%$ & $57 \%$ & $43 \%$ & $6,26 \%$ & $66 \%$ & $34 \%$ & $7,62 \%$ & $59 \%$ & $41 \%$ \\
\hline BRKM5 & $7,92 \%$ & $59 \%$ & $41 \%$ & $13,90 \%$ & $56 \%$ & $44 \%$ & $15,22 \%$ & $66 \%$ & $34 \%$ \\
\hline BRML3 & $9,12 \%$ & $42 \%$ & $58 \%$ & $9,46 \%$ & $45 \%$ & $55 \%$ & $10,44 \%$ & $51 \%$ & $49 \%$ \\
\hline BRPR3 & $6,54 \%$ & $43 \%$ & $57 \%$ & $10,74 \%$ & $53 \%$ & $47 \%$ & $11,95 \%$ & $44 \%$ & $56 \%$ \\
\hline BRSR6 & $10,26 \%$ & $42 \%$ & $58 \%$ & $12,10 \%$ & $42 \%$ & $58 \%$ & $18,35 \%$ & $39 \%$ & $61 \%$ \\
\hline BTOW3 & $21,33 \%$ & $62 \%$ & $38 \%$ & $20,56 \%$ & $48 \%$ & $52 \%$ & $20,36 \%$ & $49 \%$ & $51 \%$ \\
\hline CCRO3 & $6,16 \%$ & $57 \%$ & $43 \%$ & $7,69 \%$ & $53 \%$ & $47 \%$ & $9,03 \%$ & $51 \%$ & $49 \%$ \\
\hline CESP6 & $7,16 \%$ & $59 \%$ & $41 \%$ & $7,82 \%$ & $51 \%$ & $49 \%$ & $9,14 \%$ & $42 \%$ & $58 \%$ \\
\hline CIEL3 & $5,91 \%$ & $66 \%$ & $34 \%$ & $6,99 \%$ & $62 \%$ & $38 \%$ & $7,79 \%$ & $57 \%$ & $43 \%$ \\
\hline CMIG4 & $8,90 \%$ & $57 \%$ & $43 \%$ & $11,30 \%$ & $55 \%$ & $45 \%$ & $17,28 \%$ & $51 \%$ & $49 \%$ \\
\hline CPFE3 & $6,59 \%$ & $46 \%$ & $54 \%$ & $7,11 \%$ & $48 \%$ & $52 \%$ & $7,36 \%$ & $67 \%$ & $33 \%$ \\
\hline $\begin{array}{l}\text { CPLE6 } \\
\end{array}$ & $9,30 \%$ & $59 \%$ & $41 \%$ & $8,14 \%$ & $50 \%$ & $50 \%$ & $12,51 \%$ & $66 \%$ & $34 \%$ \\
\hline CSAN3 & $7,43 \%$ & $49 \%$ & $51 \%$ & $9,62 \%$ & $45 \%$ & $55 \%$ & $9,58 \%$ & $55 \%$ & $45 \%$ \\
\hline CSNA3 & $14,64 \%$ & $40 \%$ & $60 \%$ & $18,69 \%$ & $45 \%$ & $55 \%$ & $30,55 \%$ & $59 \%$ & $41 \%$ \\
\hline CYRE3 & $6,07 \%$ & $43 \%$ & $57 \%$ & $7,76 \%$ & $45 \%$ & $55 \%$ & $11,73 \%$ & $54 \%$ & $46 \%$ \\
\hline DTEX3 & $8,50 \%$ & $48 \%$ & $52 \%$ & $8,28 \%$ & $40 \%$ & $60 \%$ & $13,47 \%$ & $47 \%$ & $53 \%$ \\
\hline ECOR3 & $6,66 \%$ & $50 \%$ & $50 \%$ & $7,60 \%$ & $44 \%$ & $56 \%$ & $13,35 \%$ & $53 \%$ & $47 \%$ \\
\hline ELET3 & $14,90 \%$ & $45 \%$ & $55 \%$ & $14,71 \%$ & $40 \%$ & $60 \%$ & $19,32 \%$ & \begin{tabular}{|l}
$67 \%$ \\
\end{tabular} & $33 \%$ \\
\hline EMBR3 & $7,49 \%$ & $72 \%$ & $28 \%$ & $7,03 \%$ & 60 & $39 \%$ & $9,32 \%$ & $\begin{array}{l}33 \% \\
\end{array}$ & $57 \%$ \\
\hline ENBR3 & $8,41 \%$ & $52 \%$ & $48 \%$ & $7,86 \%$ & $51 \%$ & $49 \%$ & $6,84 \%$ & $56 \%$ & $44 \%$ \\
\hline EQTL3 & $6,09 \%$ & $64 \%$ & $36 \%$ & $5,57 \%$ & $64 \%$ & $36 \%$ & $5,45 \%$ & $66 \%$ & $34 \%$ \\
\hline ESTC3 & $9,26 \%$ & $66 \%$ & $34 \%$ & $12,63 \%$ & $53 \%$ & $47 \%$ & $14,24 \%$ & $46 \%$ & $54 \%$ \\
\hline EVEN3 & $6,26 \%$ & $44 \%$ & $56 \%$ & $10,00 \%$ & $39 \%$ & $\begin{array}{l}11 \% \\
61 \%\end{array}$ & $11,05 \%$ & $\begin{array}{l}46 \% \\
\end{array}$ & $54 \%$ \\
\hline EZTC3 & $7,21 \%$ & $48 \%$ & $52 \%$ & $8,33 \%$ & $29 \%$ & $71 \%$ & $10,13 \%$ & $48 \%$ & $52 \%$ \\
\hline FIBR3 & $7,21 \%$ & $55 \%$ & $45 \%$ & $8,58 \%$ & $56 \%$ & $44 \%$ & $13,79 \%$ & $68 \%$ & $32 \%$ \\
\hline GFSA3 & $12,41 \%$ & $45 \%$ & $55 \%$ & $12,78 \%$ & $42 \%$ & $58 \%$ & $13,71 \%$ & $40 \%$ & $60 \%$ \\
\hline GGBR4 & $7,96 \%$ & $38 \%$ & $62 \%$ & $9,29 \%$ & $31 \%$ & $69 \%$ & $25,84 \%$ & $40 \%$ & $60 \%$ \\
\hline GOAU4 & $7,73 \%$ & $45 \%$ & $55 \%$ & $11,98 \%$ & $24 \%$ & $\begin{array}{l}76 \% \\
\end{array}$ & $33,43 \%$ & \begin{tabular}{|l}
$41 \%$ \\
\end{tabular} & $59 \%$ \\
\hline GOLL4 & $13,45 \%$ & $53 \%$ & $47 \%$ & $14,24 \%$ & $33 \%$ & $67 \%$ & $29,74 \%$ & $32 \%$ & $68 \%$ \\
\hline HGTX3 & $10,14 \%$ & $35 \%$ & $65 \%$ & $10,90 \%$ & $41 \%$ & $59 \%$ & $10,64 \%$ & \begin{tabular}{|l}
$47 \%$ \\
\end{tabular} & $53 \%$ \\
\hline HYPE3 & $7,88 \%$ & $56 \%$ & $44 \%$ & $10,38 \%$ & $63 \%$ & $37 \%$ & $12,39 \%$ & $67 \%$ & $33 \%$ \\
\hline IGTA3 & $7,26 \%$ & $45 \%$ & $55 \%$ & $6,52 \%$ & \begin{tabular}{|l}
$43 \%$ \\
\end{tabular} & $57 \%$ & $7,28 \%$ & \begin{tabular}{|l}
$57 \%$ \\
\end{tabular} & $43 \%$ \\
\hline ITSA4 & $7,14 \%$ & $50 \%$ & $50 \%$ & $7,03 \%$ & $52 \%$ & $48 \%$ & $8,35 \%$ & $54 \%$ & $46 \%$ \\
\hline ITUB4 & $7,64 \%$ & $41 \%$ & $59 \%$ & $7,56 \%$ & $53 \%$ & $\begin{array}{l}47 \% \\
\end{array}$ & $9,75 \%$ & $50 \%$ & $50 \%$ \\
\hline JBSS3 & $10,01 \%$ & $56 \%$ & $44 \%$ & $9,92 \%$ & $51 \%$ & $49 \%$ & $12,86 \%$ & $44 \%$ & $56 \%$ \\
\hline KLBN11 & & & & $7,20 \%$ & $73 \%$ & $27 \%$ & $8,54 \%$ & \begin{tabular}{|l}
$56 \%$ \\
\end{tabular} & $44 \%$ \\
\hline KROT3 & $8,81 \%$ & $72 \%$ & $28 \%$ & $12,71 \%$ & $66 \%$ & $34 \%$ & $13,62 \%$ & $53 \%$ & $47 \%$ \\
\hline LAME4 & $7,35 \%$ & $47 \%$ & $53 \%$ & $6,60 \%$ & $51 \%$ & \begin{tabular}{|l}
$49 \%$ \\
\end{tabular} & $7,54 \%$ & $50 \%$ & $50 \%$ \\
\hline LIGT3 & $9,69 \%$ & $61 \%$ & $39 \%$ & $12,30 \%$ & $53 \%$ & $47 \%$ & $15,55 \%$ & $62 \%$ & $38 \%$ \\
\hline LREN3 & $6,78 \%$ & $50 \%$ & $50 \%$ & $6,65 \%$ & $59 \%$ & $41 \%$ & $9,60 \%$ & $55 \%$ & $45 \%$ \\
\hline MDIA3 & $7,17 \%$ & $49 \%$ & $51 \%$ & $8,38 \%$ & $38 \%$ & $62 \%$ & $10,48 \%$ & \begin{tabular}{|l}
$48 \%$ \\
\end{tabular} & $52 \%$ \\
\hline MGLU3 & $15,43 \%$ & $38 \%$ & $62 \%$ & $21,58 \%$ & \begin{tabular}{|l}
$20 \%$ \\
\end{tabular} & \begin{tabular}{|l|}
$80 \%$ \\
\end{tabular} & $28,41 \%$ & \begin{tabular}{|l}
$49 \%$ \\
\end{tabular} & $51 \%$ \\
\hline MILS3 & $9,98 \%$ & $45 \%$ & $55 \%$ & $15,12 \%$ & $36 \%$ & \begin{tabular}{|l|}
$64 \%$ \\
\end{tabular} & $21,32 \%$ & $48 \%$ & $52 \%$ \\
\hline MMXM3 & $26,18 \%$ & $27 \%$ & $73 \%$ & $21,12 \%$ & $15 \%$ & $85 \%$ & $26,05 \%$ & $17 \%$ & $83 \%$ \\
\hline MPLU3 & $10,84 \%$ & $46 \%$ & $54 \%$ & $9,69 \%$ & $55 \%$ & $45 \%$ & $12,49 \%$ & $70 \%$ & $30 \%$ \\
\hline MRFG3 & $13,25 \%$ & $48 \%$ & $52 \%$ & $13,07 \%$ & $51 \%$ & $49 \%$ & $10,83 \%$ & $40 \%$ & $60 \%$ \\
\hline MRVE3 & $12,18 \%$ & $50 \%$ & $50 \%$ & $9,31 \%$ & $48 \%$ & $52 \%$ & $10,64 \%$ & $61 \%$ & $39 \%$ \\
\hline MULT3 & $6,36 \%$ & $50 \%$ & $50 \%$ & $6,15 \%$ & $52 \%$ & $48 \%$ & $7,95 \%$ & $52 \%$ & $48 \%$ \\
\hline NATU3 & $6,84 \%$ & $46 \%$ & $54 \%$ & $8,47 \%$ & $42 \%$ & $58 \%$ & $11,26 \%$ & \begin{tabular}{|l}
$42 \%$ \\
\end{tabular} & $58 \%$ \\
\hline ODPV3 & $7,13 \%$ & $50 \%$ & $50 \%$ & $5,42 \%$ & $54 \%$ & $46 \%$ & $7,42 \%$ & $49 \%$ & $51 \%$ \\
\hline OIBR3 & $17,39 \%$ & $25 \%$ & $75 \%$ & $18,92 \%$ & \begin{tabular}{|l}
$34 \%$ \\
\end{tabular} & \begin{tabular}{|l|l}
$66 \% \%$ \\
\end{tabular} & $31,22 \%$ & $32 \%$ & $68 \%$ \\
\hline PCAR4 & $5,75 \%$ & $59 \%$ & $41 \%$ & $8,23 \%$ & $61 \%$ & $39 \%$ & $12,02 \%$ & $42 \%$ & $58 \%$ \\
\hline PDGR3 & $11,74 \%$ & $32 \%$ & $68 \%$ & $18,64 \%$ & $26 \%$ & $\begin{array}{l}74 \% \\
\end{array}$ & $65,78 \%$ & $\begin{array}{l}16 \% \\
\end{array}$ & $84 \%$ \\
\hline PETR3 & $12,91 \%$ & $51 \%$ & $49 \%$ & $15,76 \%$ & $43 \%$ & $57 \%$ & $20,08 \%$ & $58 \%$ & $42 \%$ \\
\hline POMO4 & $6,82 \%$ & $44 \%$ & $56 \%$ & $12,28 \%$ & $30 \%$ & \begin{tabular}{|l}
$70 \%$ \\
\end{tabular} & $14,57 \%$ & \begin{tabular}{|l}
$52 \%$ \\
\end{tabular} & $48 \%$ \\
\hline PSSA3 & $6,35 \%$ & $58 \%$ & $42 \%$ & $7,74 \%$ & $55 \%$ & $45 \%$ & $9,17 \%$ & $51 \%$ & $49 \%$ \\
\hline QGEP3 & $5,75 \%$ & $47 \%$ & $53 \%$ & $8,23 \%$ & $48 \%$ & $52 \%$ & $13,32 \%$ & $40 \%$ & $60 \%$ \\
\hline QUAL3 & $7,45 \%$ & $52 \%$ & $48 \%$ & $9,38 \%$ & $57 \%$ & $43 \%$ & $11,47 \%$ & $46 \%$ & $54 \%$ \\
\hline RADL3 & $8,47 \%$ & $53 \%$ & $47 \%$ & $7,39 \%$ & $60 \%$ & $40 \%$ & $8,05 \%$ & $71 \%$ & $29 \%$ \\
\hline RAPT4 & $7,18 \%$ & $46 \%$ & $54 \%$ & $8,15 \%$ & $35 \%$ & \begin{tabular}{|l|}
$65 \%$ \\
\end{tabular} & $18,91 \%$ & $35 \%$ & $65 \%$ \\
\hline RENT3 & $5,20 \%$ & $48 \%$ & $52 \%$ & $6,39 \%$ & $49 \%$ & $51 \%$ & $10,95 \%$ & $41 \%$ & $59 \%$ \\
\hline RSID3 & $11,01 \%$ & $37 \%$ & $63 \%$ & $17,01 \%$ & $24 \%$ & $76 \%$ & $32,82 \%$ & $\begin{array}{l}19 \% \\
\end{array}$ & $81 \%$ \\
\hline SANB3 & $7,78 \%$ & $47 \%$ & $53 \%$ & $7,53 \%$ & $59 \%$ & $41 \%$ & $9,18 \%$ & $66 \%$ & $34 \%$ \\
\hline SBSP3 & $8,97 \%$ & $48 \%$ & $52 \%$ & $10,69 \%$ & $\begin{array}{l}9 \% \\
\end{array}$ & $51 \%$ & $10,19 \%$ & $\begin{array}{l}69 \% \\
\end{array}$ & $31 \%$ \\
\hline SULA11 & $7,75 \%$ & $58 \%$ & $42 \%$ & $8,38 \%$ & $58 \%$ & $42 \%$ & $8,29 \%$ & $57 \%$ & $43 \%$ \\
\hline TAEE11 & $5,92 \%$ & $47 \%$ & $53 \%$ & $5,91 \%$ & \begin{tabular}{|l}
$45 \%$ \\
\end{tabular} & $\begin{array}{l}55 \% \\
\end{array}$ & $8,14 \%$ & \begin{tabular}{|l}
$44 \%$ \\
\end{tabular} & $56 \%$ \\
\hline TIMP3 & $6,75 \%$ & $51 \%$ & $49 \%$ & $6,85 \%$ & $37 \%$ & $63 \%$ & $10,20 \%$ & $52 \%$ & $48 \%$ \\
\hline TOTS3 & $6,28 \%$ & $50 \%$ & $50 \%$ & $7,97 \%$ & $51 \%$ & $49 \%$ & $8,31 \%$ & $46 \%$ & $54 \%$ \\
\hline UGPA3 & $4,19 \%$ & $56 \%$ & $44 \%$ & $5,15 \%$ & $51 \%$ & $49 \%$ & $6,23 \%$ & $51 \%$ & $49 \%$ \\
\hline USIM5 & $11,01 \%$ & $46 \%$ & $54 \%$ & $15,62 \%$ & $26 \%$ & \begin{tabular}{|l|}
$74 \%$ \\
\end{tabular} & $34,03 \%$ & \begin{tabular}{|l}
$54 \%$ \\
\end{tabular} & $46 \%$ \\
\hline VALE3 & $5,94 \%$ & $42 \%$ & $58 \%$ & $8,76 \%$ & $39 \%$ & \begin{tabular}{|l|}
$61 \%$ \\
\end{tabular} & $18,55 \%$ & $51 \%$ & $49 \%$ \\
\hline VIVT4 & $6,06 \%$ & $53 \%$ & $47 \%$ & $6,55 \%$ & $45 \%$ & $55 \%$ & $8,46 \%$ & $47 \%$ & $53 \%$ \\
\hline VLID3 & $8,18 \%$ & $55 \%$ & $45 \%$ & $5,45 \%$ & $54 \%$ & $46 \%$ & $7,04 \%$ & $47 \%$ & $53 \%$ \\
\hline VVAR11 & & & & $12.03 \%$ & $29 \%$ & $71 \%$ & $21.16 \%$ & $35 \%$ & $65 \%$ \\
\hline & $6,13 c^{\circ}$ & & & & $60 \%$ & $40 \%$ & $7,40 \%$ & $50 \%$ & $50 \%$ \\
\hline
\end{tabular}


Model's results for each year are presented in Table 26, Table 27 and Table 28. Each table presents the selected features by CFS filter, model's hyper-parameters chosen through grid-search with cross-validation and its accuracy results with standard deviation.

Table 26 - SVM model's results and picked stocks for 2015.

\begin{tabular}{|c|c|c|c|c|c|c|}
\hline & \multicolumn{6}{|l|}{2015} \\
\hline & \multirow[b]{2}{*}{ Selected Features } & \multirow[b]{2}{*}{ \# } & \multicolumn{2}{|c|}{ Selected Hyper-Parameters } & CrossVal. Results & \\
\hline & & & & $\mathrm{C}$ & Accuracy \pm StdDev & Selected \\
\hline ABEV3 & ama50, ma50, SAR, Chaikin3L, CCI, Force13E, WPR & 7 & 0.0004882812 & 128 & $72.78 \% \pm 12.94 \%$ & \\
\hline BBAS3 & ama50, ma50S, sd50L, Chaikin3L, CCI, Force 13E, Trix, WPR & 8 & 0.0078125 & 0.5 & $76.94 \% \pm 18.84 \%$ & \\
\hline BBDC3 & ama50, ma21, ma50s, sd50S, BearsP, Chaikin5, Chaikin5S, Chaikin3L, CCI, Force13L, RSIv & 11 & 0.0001220703 & 32 & $75.28 \% \pm 16.55 \%$ & \\
\hline BBSE3 & ama21, ama50, adx14, sd50, sd5E, sd21S, sd50S, BearsP, BullsP, Chaikin3L, CCI, DeMarker, Force13E, Force13S, RSIv, Trix, WPR & 17 & 0.03125 & 0.125 & $78.33 \% \pm 17.56 \%$ & \\
\hline BEEF3 & ama50, WPR & 2 & 0,03125 & 512 & $65.56 \% \pm 26.37 \%$ & \\
\hline BRAP4 & ama50, ma50, sd50E, BearsP, CCI, WPR & 6 & 0,000030517578125 & 128 & $71,67 \% \pm 15,13 \%$ & \\
\hline BRFS3 & ama21, ama50, ma21, ma50S, sd50E, sd50S, BearsP, BullsP, Chaikin3E, Chaikin3S, Chaikin5S, Chaikin3L, CCI, WPR & 14 & 0.00003051758 & 128 & $84.72 \% \pm 10.19 \%$ & $\checkmark$ \\
\hline BRKM5 & $\mathrm{ama50, \textrm {CCI }}$ & 2 & 0.125 & 32768 & $72.22 \% \pm 22.94 \%$ & \\
\hline BRML3 & ama21, ama50, ma50, SAR, sd50, sd50S, BearsP, Chaikin3, Chaikin3L, CCI, Force 13E, WPR & 12 & 0,0078125 & 2 & $72.22 \% \pm 13.89 \%$ & \\
\hline BRPR3 & ma50, SAR, sd21E, sd5S, sd50S, sd50L, ATR14, BearsP, Chaikin3, Chaikin3L, CCI, Force13E, Force13L, WPR, AD, MFI & 16 & 0,000030517578125 & 0.125 & $71.39 \% \pm 8.97 \%$ & \\
\hline BRSR6 & ama50, Force 13L & 2 & 0.000488 & 0.03125 & $69.97 \% \pm 18.46 \%$ & \\
\hline BTOW3 & ama21, ama50, Force13S & 3 & 0.000122 & 32768 & $91.25 \% \pm 10.66 \%$ & $\checkmark$ \\
\hline CCRO3 & ama50, Chaikin3E, Chaikin5S, Force 13S & 4 & 0.007813 & 0.5 & $73.33 \% \pm 9.89 \%$ & \\
\hline CESP6 & ama21, ama50, ma50, SAR, sd21, sd50S, Chaikin5, Chaikin3L, CCI, Force 13, Force13E, WPR, AD & 13 & 0.03125 & 0.5 & $70.00 \% \pm 11.01 \%$ & \\
\hline CIEL3 & ama9, ama21, ama50, ma21, sd21, BearsP, Chaikin3L, CCI, Force 13E, OsMa & 10 & 0.0078125 & 128 & $72.67 \% \pm 12.34 \%$ & \\
\hline CMIG4 & ama21, ama50, ma50, sd50S, Chaikin5S, Chaikin3L, CCI, Force13S, RSIv, WPR, MFI, OBV & 12 & 0.001953 & 2 & $84.58 \% \pm 16.74 \%$ & \\
\hline CPFE3 & ama21, ama50, ma50E, sd50E, BullsP, CCI, Force13L, Trix, WPR & 9 & 0.001953 & 0.5 & $73.61 \% \pm 4.88 \%$ & $\checkmark$ \\
\hline CPLE6 & ama50, ma50S, SAR, Chaikin3E, Chaikin3L, WPR & 6 & 0.001953 & 128 & $77.78 \% \pm 10.83 \%$ & \\
\hline CSAN3 & ama21, ama50, ma50, SAR, sd50S, BullsP, CCI, Force13E, Force13S, OsMa, WPR & 11 & 0.007813 & 0.03125 & $80.23 \% \pm 10.40 \%$ & $\checkmark$ \\
\hline CSNA3 & ama50, Froce13E, Force13S & 3 & 0.03125 & 0.125 & $64.72 \% \pm 30.90 \%$ & \\
\hline CYRE3 & am50, SAR, sd50S, BullsP, Chaikin3L, CCI, Force13E, WPR & 8 & 0.03125 & 0.03125 & $74.17 \% \pm 15.66 \%$ & \\
\hline DTEX3 & ama50, ma50S, sd50E, Chaikin3L, CCI, Force 13L & 6 & 0.5 & 0.5 & $72.22 \% \pm 19.31 \%$ & \\
\hline ECOR3 & ama50, ma50, ma50L, BearsP, CCI, MACD & 6 & 0.007813 & 2 & $66.39 \% \pm 28.02 \%$ & \\
\hline ELET3 & ama50, ma50S, SAR, sd21, BullsP, CCI, Force13E, MFI & 8 & 2 & 0.125 & $71.67 \% \pm 15.88 \%$ & \\
\hline EMBR3 & ama21, ama50, adx14, ma50E, sd50E, sd50L, BearsP, BullsP, Chaikin3E, Chaikin3L, CCI, Force13E, OsMa, WPR & 14 & 2 & 2048 & $69.72 \% \pm 19.02 \%$ & \\
\hline ENBR3 & ama50, ma50, ma21S, SAR, sd50, sd50E, sd50S, BearsP, Chaikin5E, Chaikin3L, CCI, Force13E, WPR, AD & 14 & 0.03125 & 0.5 & $74.72 \% \pm 8.97 \%$ & \\
\hline EQTL3 & ma50E, ma50S, ma50L, SAR, sd50, BearsP, BullsP, Chaikin5, CCI, Forcel3E, RSIv, WPR & 12 & 0.007813 & 0.03125 & $74.72 \% \pm 13.88 \%$ & \\
\hline ESTC3 & ama50, ma50, SAR, sd50, Chaikin3E, CCI, RSIv, WPR & 8 & 0.03125 & 0.5 & $70.56 \% \pm 18.91 \%$ & \\
\hline EVEN3 & ama50, sd50, sd21S, BullsP, Chaikin3, Chaikin5E, Chaikin3L, CCI, Force13E, WPR & 10 & 0.007813 & 32 & $72.50 \% \pm 10.53 \%$ & \\
\hline EZTC3 & ama50, ma50, sd50S, BearsP, Chaikin3E, Force 13E, Force13S, WPR & 8 & 0.000488 & $\frac{3}{8}$ & $83.33 \% \pm 11.88 \%$ & $\checkmark$ \\
\hline FIBR3 & ama21, ama50, ma21, ma21L, sd50E, BullsP, Chaikin3L, CCI, Force13E, Momentum, WPR, MFI & 12 & 0,000030517578125 & 0.125 & $73.89 \% \pm 5.64 \%$ & \\
\hline GFSA3 & ma50, ma50S, sd50E, Chaikin5S, Chaikin3L, CCI, Force13E, WPR & 8 & 0.000488 & 2 & $71.39 \% \pm 12.40 \%$ & \\
\hline GGBR4 & ama21, ama50, sd50S, BullsP, Chaikin3E, Chaikin3S, Chaikin5S, Chaikin5L, Force13E, Force13L, WPR & 11 & 0.0004882812 & 512 & $73.89 \% \pm 12.72 \%$ & \\
\hline GOAU4 & ama50, ma50, ma50S, sd50S, sd50L, BullsP, Chaikin3S, Chaikin5S, Chaikin3L, CCI, Force13E, Force13L, OsMa, Trix & 14 & 0.000488 & 2 & $72.78 \% \pm 23.16 \%$ & \\
\hline GOLL4 & ama50, ma50E, ma50S, BearsP, Chaikin3L, CCI, OsMa, WPR & 8 & 0.00003051758 & 128 & $73.06 \% \pm 16.91 \%$ & \\
\hline HGTX3 & ama50, ma50S, SAR, BullsP, Chaikin3, CCI, Force13S, OsMa & 8 & 0.001953 & 8 & $73.67 \% \pm 18.61 \%$ & \\
\hline HYPE3 & ama21, ama50, ma50E, sd50S, sd50L, VIDya, ATR14, BearsP, & 12 & 0,000030517578125 & 128 & $82.78 \% \pm 10.89 \%$ & $\checkmark$ \\
\hline IGTA3 & am21, ama50, ma50, SAR, sd50, ATR14, Chaikin3L, CCI, Force13E, WPR, MFI & 11 & 0.007813 & 0.5 & $66.34 \% \pm 14.04 \%$ & \\
\hline ITSA4 & ma50, ma21S, ma50S, sd50L, CCI, Force13S, WPR, AD, MFI & 9 & 0.0004882812 & 32 & $73.33 \% \pm 14.10 \%$ & \\
\hline ITUB4 & ama50, Force13E & 2 & 8 & 2048 & $68,75 \% \pm 12,20 \%$ & \\
\hline JBSS3 & ama21, ama50, ma21E, sd21E, sd50E, BullsP, Chaikin3E, CCI, Force13E, Trix & 10 & 0.125 & 0.125 & $63.06 \% \pm 9.45 \%$ & \\
\hline KROT3 & ama21, ama50, ma21E, sd21E, sd50S, TEMA14, BearsP, CCI, Force13L, WPR & 10 & 0.125 & 8192 & $68.33 \% \pm 9.60 \%$ & \\
\hline LAME4 & ama21, ama50, ma50, ma50S, ATR14, BearsP, BullsP, Chaikin3L, CCI, Trix, WPR & 11 & 0.000488 & 8 & $70.83 \% \pm 22.22 \%$ & \\
\hline LIGT3 & ama21, ama50, ma50, ma50S, SAR, sd50E, sd21L, BearsP, BullsP, Chaikin3E, Chaikin3L, CCI, Fo & 15 & 0,000030517578125 & 128 & $80.00 \% \pm 35.69 \%$ & \\
\hline LREN3 & ama21, ama50, ma50, ma50L, SAR, sd21S, sd50S, BearsP, Chaikin5, Chaikin3S, Chaikin3L, CCI, Force 13E, Forcel3S, WPR & 15 & 0.5 & 0.5 & $66.94 \% \pm 15.18 \%$ & \\
\hline MDIA3 & ama50, FrAMA14, ma50S, ma50L, SAR, Chaikin3L, CCI, Force13L, OsMa, WPR & 10 & 0.125 & 0.125 & $86.67 \% \pm 5.14 \%$ & \\
\hline MGLU3 & ama21, ama50, adx14, ma21S, ma50L, sd50E, BullsP, Force13, Force13E, RSIv, WPR & 11 & 0.00003051758 & 512 & $86.67 \% \pm 11.49 \%$ & $\checkmark$ \\
\hline MILS3 & ama21, ama50, sd50L, Chaikin3E, Chaikin3L, CCI, Force 13L, WPR, AD & 9 & 0,000030517578125 & 32 & $76.11 \% \pm 7.43 \%$ & $\checkmark$ \\
\hline MMXM3 & ama21, ama50, ma50, sd50E, sd5S, BullsP, Chaikin3S, Chaikin5S, Chaikin3L, CCI, Force13E, OsMa, WPR & 13 & 0,000030517578125 & 0.03125 & $73.89 \% \pm 20.97 \%$ & \\
\hline MPLU3 & ama21, ama50, ma21, ma50, ma50S, SAR, BearsP, Chaikin5S, Chaikin3L, CCI, Force 13, Force 13E, Force13L, OsM & 15 & 2 & 0.5 & $66.33 \% \pm 26.10 \%$ & \\
\hline MRFG3 & ama50, ma21, SAR, sd50S, Chaikin3L, CCI, Force13E, OsMa, Trix, WPR & 10 & 0.125 & 0.5 & $67.78 \% \pm 15.23 \%$ & \\
\hline MRVE3 & ama21, ama50, Chaikin3, Force13E, WPR & 5 & 0.000122 & 0.03125 & $70.28 \% \pm 12.04 \%$ & \\
\hline MULT3 & ama50, m21, ma50, ma21E, ma50S, SAR, sd21S, BullsP, Chaikin3, Chaikin5S, CCI, Force13E, Force13S, Force13L, Trix, WPR & 16 & 0,000030517578125 & 32 & $76.39 \% \pm 12.36 \%$ & \\
\hline NATU3 & ama50, adx 14, ma21S, ma50S, SAR, sd50E, VIDya, BearsP, Chaikin3, Chaikin3L, CCI, Force13E, Force13S, Oss & 17 & 0,000030517578125 & 512 & $73.61 \% \pm 12.76 \%$ & \\
\hline ODPV3 & ama21, ama50, ma50, SAR, sd21S, BearsP, BullsP, Chaikin3L, Force13E, Force13S, OsMa, WPR & 12 & 0.5 & 0.03125 & $76.00 \% \pm 14.56 \%$ & \\
\hline OIBR3 & ama21, ama50, ma50S, ma21L, sd21L, BearsP, Chaikin5S, Chaikin3L, CCI, Force13E, Forcel3L, Momentum, WPR, Vol & 14 & 0.000488 & 8 & $68.89 \% \pm 16.25 \%$ & \\
\hline PCAR4 & ama50, Force13L, WPR & 3 & 0.000122 & 0.03125 & $74.33 \% \pm 18.92 \%$ & \\
\hline PDGR3 & ma21, sd21S, VIDya, BullsP, Chaikin3, Chaikin3L, CCI, Force13E, Trix, WPR & 10 & 0.000488 & 2048 & $84.72 \% \pm 11.03 \%$ & $\checkmark$ \\
\hline PETR3 & ama21, ama50, ma50S, sd50L, CCI, Force13S, MACD, RSIv, WPR, MFI & 10 & 0.03125 & 0.03125 & $73.61 \% \pm 13.43 \%$ & \\
\hline POMO4 & ama50, ma50, sd50S, BullsP, Chaikin3E, Chaikin3L, CCI, DeMarker, Trix, WPR & 10 & 0.000030517578125 & 128 & $77.78 \% \pm 9.35 \%$ & \\
\hline PSSA3 & ama21, ama50, SAR, BearsP, Chaikin3E, Chaikin3L, Force13E, Force13L, WPR & 9 & 0.007813 & 0.5 & $73.89 \% \pm 10.78 \%$ & \\
\hline QGEP3 & ama50, ma50, sd50S, BearsP, Chaikin3L, CCI, Force 13E, WPR & 8 & 0.03125 & 0.5 & $74.44 \% \pm 11.43 \%$ & \\
\hline QUAL3 & ama21, ama50, ma50, ma50S, ma21L, sd50, sd21S, ATR14, BearsP, Chaikin3E, Chaikin5S, Chaikin3L, CCI, RSIv, Trix, WPR & 16 & 0.03125 & 0.03125 & $64.67 \% \pm 19.49 \%$ & \\
\hline RADL3 & ama21, ama50, BullsP, Chaikin5L, CCI, Force13E & 6 & 0.000030517578125 & 0.03125 & $68.61 \% \pm 22.45 \%$ & \\
\hline RAPT4 & ama50, adx 14, ma21, ma50S, sd21E, sd50S, VIDya, ATR14, BullsP, Chaikin3E, Chaikin5E, Chaikin3L, CCI, Force13E, WPR, MFI & 16 & 0.5 & 32 & $68.61 \% \pm 8.66 \%$ & \\
\hline RENT3 & ama21, ma50L, sd21S, BullsP, Chaikin3E, Chaikin5S, Chaikin3L, CCI, Force13E, Force13L, WPR & 11 & 0.000122 & 0.125 & $71.11 \% \pm 11.09 \%$ & \\
\hline RSID3 & ama50, ma50L, sd21L, BearsP, BullsP, Chaikin3, Chaikin3L, CCI, Force13E, WPR & 10 & 0.000030517578125 & 0.5 & $69.17 \% \pm 18.18 \%$ & \\
\hline SANB11 & ama50, ma50E, sd21S, sd50L, Chaikin3L & 7 & 0.03125 & 0.03125 & $67.22 \% \pm 23.44 \%$ & \\
\hline SBSP3 & ma21, ma50, BullsP, Chaikin5S, Chaikin3L, CCI, Force13E, Trix, WPR & 9 & 0.125 & 8 & $78.33 \% \pm 8.50 \%$ & $\checkmark$ \\
\hline SULA11 & ama21, ama50, ma50S, BearsP, BullsP, Chaikin3S, Forcel3E, Force13S, Force13L, Trix, WPR, MFI & 12 & 0.03125 & 0.5 & $78.61 \% \pm 7.78 \%$ & $\checkmark$ \\
\hline TAEE11 & ma50, ma21E, ma21S, sd50L, ATR14, BearsP, BullsP, Chaikin5S, Chaikin3L, CCI, Forcel3E, WPR, AD & 13 & 0.007813 & 0.03125 & $74.44 \% \pm 10.99 \%$ & \\
\hline TIMP3 & ama50, ma50L, SAR, BullsP, Chaikin3L, CCI, OsMa, WPR & 8 & 0.007813 & 0.125 & $74.67 \% \pm 16.93 \%$ & \\
\hline TOTS3 & ama50, ma50S, ma50L, sd50S, CCI, DeMarker, Forcel3L, WPR & 8 & 0.001953 & 0.5 & $68.33 \% \pm 9.66 \%$ & \\
\hline UGPA3 & ama50, adx 14, ma50E, ma50S, BearsP, BullsP, Chaikin3L, CCI, F & 11 & 0.007813 & 2 & $76.67 \% \pm 6.91 \%$ & $\checkmark$ \\
\hline USIM5 & ama50, ma50, BullsP, Force 13E, WPR & 5 & 0.125 & 32 & $63.61 \% \pm 28.10 \%$ & \\
\hline VALE3 & ma50, ma50S, SAR, sd21E, sd50L, BearsP, BullsP, Chaikin3, Chaikin3L, CCI, Force13E, WPR & 12 & 0.0001220703 & 32 & $70.83 \% \pm 19.91 \%$ & \\
\hline VIVT4 & ama21, ama50, adx14, ma50, ma50E, sd50, Chaikin3E, Chaikin3L, CCI, Force13E, OsMa, WPR & 12 & 0.001953 & 0.125 & $75.56 \% \pm 7.12 \%$ & \\
\hline VLID3 & ama50, ma50, SAR, BullsP, CCI, Force13S, Force13L & 7 & 0.125 & 0.125 & $81.67 \% \pm 10.38 \%$ & $\checkmark$ \\
\hline WEGE3 & ama50, Chaikin3L, CCI & 3 & 0.000030517578125 & 32768 & $75.00 \% \pm 17.42 \%$ & \\
\hline
\end{tabular}


Table 27 - SVM model's results and picked stocks for 2016.

\begin{tabular}{|c|c|c|c|c|c|c|}
\hline & \multicolumn{6}{|l|}{2015} \\
\hline & \multirow[b]{2}{*}{ Selected Features } & \multirow[b]{2}{*}{ \# } & Selected Hyper-Par & meters & CrossVal. Results & \\
\hline & & & & C & Accuracy \pm StdDev & Selected \\
\hline ABEV3 & ama50, ma50, SAR, sd21, ATR14, BearsP, BullsP, Chaikin3L, CCI, Force13E, WPR, MFI & 12 & 0.0004882812 & 0.125 & $74.72 \% \pm 6.62 \%$ & $\checkmark$ \\
\hline BBAS3 & ama21, ama50, ma50, sd50, Chaikin3L, Force13E, Force13L, RSIv, WPR & 9 & 0.125 & 0.125 & $70.56 \% \pm 12.00 \%$ & \\
\hline BBDC3 & ama21, ama50, ma50, ma50E, SAR, sd50S, sd21L, BearsP, Chaikin5, Chaikin3E, Chaikin3L, CCI, Force13E, Force13S, Force13L, WPR & 16 & 0.0001220703 & 32 & $75.33 \% \pm 17.77 \%$ & \\
\hline BBSE3 & ama21, ama50, ma21, ma50, SAR, BearsP, Chaikin3L, CCI, Force13E, Forcel3S, Trix, MFI & 12 & 0.03125 & 0.5 & $71.00 \% \pm 8.79 \%$ & \\
\hline BEEF3 & ama50, ma50, ma50S, sd50S, sd21L, BearsP, Chaikin3E, Chaikin3L, CCI, DeMarker, Force13E, Force13S, WPR, AD & 14 & 0.00003051758 & 0.5 & $81.39 \% \pm 5.42 \%$ & $\checkmark$ \\
\hline BRAP4 & ama50, ma50, ma50L, sd50E, BearsP, CCI, WPR & 7 & 0.00003051758 & 128 & $71.67 \% \pm 15.13 \%$ & \\
\hline BRFS3 & ama50, ma50, SAR, VIDya, BearsP, Chaikin3, Chaikin3S, Chaikin5S, CCI, Force13L, WPR & 11 & 0.00003051758 & 512 & $76.00 \% \pm 17.46 \%$ & \\
\hline BRKM5 & ama9, ama21, ama50, ma50S, sd50, sd50S, ATR14, Chaikin5L, CCI, Force13E, Force13L, Momentum, RSIv, MFI & 14 & 0.001953 & 128 & $68.33 \% \pm 29.78 \%$ & \\
\hline BRML3 & ama50, sd50S, Chaikin3L, CCI, Force13E, WPR & 6 & 8 & 0.125 & $70.33 \% \pm 15.25 \%$ & \\
\hline BRPR3 & ama50, ma50S, sd21, sd50, ATR14, Chaikin5L, Force13E, Force13S, OsMa & 9 & 8 & 128 & $66.67 \% \pm 24.69 \%$ & \\
\hline BRSR6 & ama50, Force 13L & 2 & 0.000488 & 0.03125 & $69.67 \% \pm 18.46 \%$ & \\
\hline BTOW3 & ama50, Chaikin3E, Chaikin5S, Forcel3S & 4 & 0.00003051758 & 32768 & $83.75 \% \pm 7.74 \%$ & $\checkmark$ \\
\hline CCRO3 & ama21, ama50, adx14, ma21, ma50, SAR, sd50S, BearsP, Chaikin3E, Chaikin3L, CCI, DeMarker, Force13E, Force13S, WPR, AD & 16 & 0.000122 & 32 & $66.00 \% \pm 13.92 \%$ & \\
\hline CESP6 & ama50, ma21, ma50, sd21S, Chaikin5E, Chaikin3L, CCI, Force13E, Force13L, WPR & 10 & 0.03125 & 0.125 & $67.33 \% \pm 13.72 \%$ & \\
\hline CIEL3 & ama21, ama50, adx14, ma50L, sd50, BullsP, Chaikin5, Chaikin3L, CCI, Force13E, Force13L, Momentum, WPR, MFI & 14 & 0.00003051758 & 2 & $72.67 \% \pm 14.18 \%$ & \\
\hline CMIG4 & ama50, ma50, ma50S, sd21, sd50E, sd50S, BearsP, Chaikin3E, Chaikin5E, Chaikin5S, Chaikin3L, CCI, Force13E, Force13L, RSIv, Trix, WPR, MFI & 18 & 0.001953 & 2 & $84.58 \% \pm 16.74 \%$ & $\checkmark$ \\
\hline CPFE3 & ama50, ma50, ma50S, ma50L, sd50S, ATR14, BearsP, BullsP, Chaikin3L, CCI, Force13E, Force13S, Trix, WPR, MFI & 15 & 0.03125 & 0.125 & $68.67 \% \pm 9.16 \%$ & \\
\hline CPLE6 & ma50S, ma50L, SAR, sd21, sd50L, BearsP, Chaikin5, Chaikin3E, Chaikin3L, Chaikin5L, CCI, Force13E, WPR & 13 & 0.007813 & 2 & $75.56 \% \pm 9.87 \%$ & \\
\hline CSAN3 & ama21, ama50, FrAMA14, ma50S, sd21E, BullsP, Chaikin3L, CCI, Force13E, Force13S, RSIv, WPR & 12 & 0.001953 & 0.03125 & $74.33 \% \pm 12.94 \%$ & \\
\hline CSNA3 & ama50, sd50L, BearsP, WPR & 4 & 0.125 & 0.125 & $70.00 \% \pm 24.47 \%$ & \\
\hline CYRE3 & ama21, ama50, sd21S, BearsP, Force13E, WPR & 6 & 0.001953 & 0.03125 & $67.00 \% \pm 16.60 \%$ & \\
\hline DTEX3 & ama21, ma50S, sd50E, sd50L, Chaikin3L, CCI, Force13E, Force13S, MFI & 9 & 0.125 & 0.03125 & $69.67 \% \pm 10.76 \%$ & \\
\hline ECOR3 & ama21, adx14, ma50, sd21E, sd50S, ATR14, BearsP, BullsP, Chaikin3L, CCI, Force13E, Force13S, MACD, WPR, AD, MFI & 16 & 0.000122 & 0.5 & $73.33 \% \pm 13.04 \%$ & \\
\hline ELET3 & ama21, ama50, ma50, ma21L, BearsP, Chaikin3E, Chaikin3L, CCI, Force13E, MFI, OBV & 11 & 0.0078125 & 8192 & $74.72 \% \pm 18.60 \%$ & \\
\hline EMBR3 & ama50, ma21, Chaikin3E, Chaikin3L, Force13E, WPR & 6 & 0.125 & 0.5 & $73.00 \% \pm 10.10 \%$ & \\
\hline ENBR3 & ama50, ma21S, ma50S, sd21S, BullsP, Chaikin3E, Chaikin3L, CCI, Force13E, Force13S, WPR, AD & 12 & 0.000488 & 8 & $76.33 \% \pm 6.81 \%$ & $\checkmark$ \\
\hline EQTL3 & ama50, ma21E, sd50E, BearsP, BullsP, Chaikin5S, CCI, WPR & 8 & 0.03125 & 32 & $68.89 \% \pm 17.79 \%$ & \\
\hline ESTC3 & ama50, ma50, ma50E, sd21E, sd50E, ATR14, BearsP, Chaikin5S, Chaikin3L, Force13L, WPR, MFI & 12 & 0.007813 & 0.5 & $74.58 \% \pm 11.17 \%$ & \\
\hline EVEN3 & ama21, ama50, sd50S, CCI, Force13E, Trix, WPR & 7 & 0.125 & 8192 & $66.67 \% \pm 21.89 \%$ & \\
\hline EZTC3 & ama21, ama50, ma21S, ma50S, sd50S, BearsP, BullsP, Chaikin3L, Force13E, Force13L, WPR & 11 & 0.000488 & 32 & $74.44 \% \pm 14.36 \%$ & \\
\hline FIBR3 & ama21, ama50, ma21, ma50S, sd21L, BullsP, CCI, DeMarker, Force13E, Momentum, OsMa, WPR & 12 & 0.007813 & 2 & $76.00 \% \pm 19.57 \%$ & \\
\hline GFSA3 & ama21, ama50, ma50L, sd50L, BullsP, Chaikin5S, CCI, Force13E, WPR, MFI & 10 & 0.03125 & 0.5 & $75.33 \% \pm 14.45 \%$ & \\
\hline GGBR4 & ma21E, sd50S, sd50L, BullsP, Chaikin3, Chaikin3L, CCI, Force13S, RSIv, WPR & 10 & 0.03125 & 0.5 & $79.44 \% \pm 6.72 \%$ & $\checkmark$ \\
\hline GOAU4 & ama21, ma50, ma21L, SAR, sd50S, BearsP, BullsP, Chaikin3S, Chaikin3L, CCI, Force13E, Force13L, OsMa, WPR & 14 & 0.03125 & 0.5 & $80.83 \% \pm 7.66 \%$ & $\checkmark$ \\
\hline GOLL4 & ma50, sd21E, ATR14, BullsP, Chaikin3L, Chaikin5L, Forcel3E, Force13L, WPR & 9 & 0.125 & 0.03125 & $80.00 \% \pm 9.94 \%$ & $\checkmark$ \\
\hline HGTX3 & ama21, ama50, CCI & 3 & 0.000122 & 128 & $75.67 \% \pm 9.90 \%$ & \\
\hline HYPE3 & ama50, Force13L & 2 & 0.125 & 32768 & $73.33 \% \pm 23.48 \%$ & \\
\hline IGTA3 & ama50, ma21, ma50, ma21S, sd21E, BullsP, Chaikin3L, CCI, Force13E, Force13S, Momentum, WPR & 12 & 0.007813 & 0.125 & $70.00 \% \pm 17.16 \%$ & \\
\hline ITSA4 & ama9, ama21, ama50, Chaikin3L, Forcel3E, WPR & 6 & 0.125 & 0.125 & $62.50 \% \pm 21.31 \%$ & \\
\hline ITUB4 & ama21, ama50, ma21, ma50L, SAR, Chaikin3L, Force13E, WPR, MFI & 9 & 0.00003051758 & 0.03125 & $70.00 \% \pm 15.52 \%$ & \\
\hline JBSS3 & ama50, ma50S, CCI & 3 & 0.007813 & 0.03125 & $80.00 \% \pm 15.94 \%$ & \\
\hline KLBN11 & ama50, ma50S, ma50L, sd50S, BearsP, Chaikin3, Chaikin3L, CCI, OsMa, WPR & 10 & 0.03125 & 0.03125 & $76.25 \% \pm 9.47 \%$ & \\
\hline KROT3 & ama21, ama50, SAR, VIDya, ATR14, BearsP, CCI, Force13E, Force13S, OsMa, AD & 11 & 0.03125 & 0.03125 & $73.75 \% \pm 6.29 \%$ & $\checkmark$ \\
\hline LAME4 & ma50, ma50S, SAR, sd50S, Chaikin3L, CCI, Force13E, RSIv, Trix, WPR, OBV & 11 & 0.03125 & 0.03125 & $66.94 \% \pm 15.00 \%$ & \\
\hline LIGT3 & ama21, ama50, FrAMA14, sd50S, ATR14, BearsP, BullsP, Chaikin3, CCI, DeMarker, Force13E, MACD, RSIv, WPR & 14 & 0.007813 & 0.03125 & $74.33 \% \pm 12.83 \%$ & \\
\hline LREN3 & ama50, ma50L, sd21S, sd21L, BullsP, Chaikin5E, Chaikin3L, CCI, Force13E, Force13S, WPR & 11 & 0.03125 & 8 & $70.67 \% \pm 10.51 \%$ & \\
\hline MDIA3 & ama50, SAR, sd50S, Force13S, WPR, MFI & 6 & 0.000030517578125 & 128 & $73.33 \% \pm 9.78 \%$ & \\
\hline MGLU3 & ama50 & 1 & 0.125 & 32768 & $87.33 \% \pm 14.56 \%$ & $\checkmark$ \\
\hline MILS3 & ama21, ama50, ma21S, ma50S, BearsP, Chaikin3E, Chaikin3L, CCI, Force13E, Force13L, Momentum, OsMa, WPR & 13 & 0.000030517578125 & 128 & $75.00 \% \pm 13.74 \%$ & \\
\hline MMXM3 & ama50, ma50S, WPR, OBV & 4 & 8 & 512 & $96.25 \% \pm 4.39 \%$ & $\checkmark$ \\
\hline MPLU3 & ama50, CCI, OsMa & 3 & 0.5 & 0.125 & $71.67 \% \pm 10.07 \%$ & \\
\hline MRFG3 & ama50, ma21S, SAR, sd50S, CCI, WPR & 6 & 0.000030517578125 & 0.5 & $53.06 \% \pm 12.88 \%$ & \\
\hline MRVE3 & ama21, ama50, ma50L, SAR, sd21L, Chaikin5E, Chaikin3L, CCI, Force13E, WPR & 10 & 0.007813 & 0.5 & $71.00 \% \pm 7.69 \%$ & \\
\hline MULT3 & ama50, sd21, BullsP, Chaikin3E, Force13E, RSIv, WPR & 7 & 0.007813 & 0.125 & $71.39 \% \pm 6.09 \%$ & \\
\hline NATU3 & ama21, ama50, ma21S, sd50E, BearsP, CCI, WPR, AD & 8 & 0.000030517578125 & 512 & $73.61 \% \pm 12.76 \%$ & \\
\hline ODPV3 & ama50, ma50, SAR, BullsP, Chaikin3L, CCI, Force13E, Force13S, WPR, MFI, OBV & 11 & 0.007813 & 0.03125 & $75.33 \% \pm 12.88 \%$ & \\
\hline OIBR3 & ama21, ama50, ma50S, SAR, sd50E, sd50S, Chaikin5S, Chaikin3L, CCI, Force13L, OsMa, WPR & 12 & 0.125 & 2 & $65.33 \% \pm 26.34 \%$ & \\
\hline PCAR4 & ama21, ama50, BearsP, CCI, Force13S, MACD, OBV & 7 & 0.03125 & 0.03125 & $75.12 \% \pm 14.10 \%$ & \\
\hline PDGR3 & ama21, SAR, sd21, sd50, VIDya, BearsP, Chaikin3E, Chaikin3L, CCI, Force13E, Force13L, Trix, Vol & 13 & 0.125 & 2 & $76.33 \% \pm 13.96 \%$ & \\
\hline PETR3 & ama50, DEMA14, ma21, BearsP, Chaikin5, Chaikin3E, Chaikin5S, Forcel3E, WPR & 9 & 0.001953125 & 2 & $73.33 \% \pm 8.98 \%$ & \\
\hline POMO4 & ama50, ma50, ma50E, ma50L, sd50L, BullsP, Chaikin5E, Chaikin3L, Chaikin5L, CCI, Force13E, Momentum, WPR, Vol & 14 & 0.03125 & 2 & $79.44 \% \pm 13.69 \%$ & \\
\hline PSSA3 & ama50, ma50, ma50L, BearsP, Chaikin3L, CCI, WPR & 7 & 0.001953 & 8 & $74.17 \% \pm 8.55 \%$ & \\
\hline QGEP3 & ama50, ma21S, ma50S, SAR, sd21E, sd21S, BearsP, BullsP, Chaikin3S, Chaikin3L, CCI, Force13E, WPR & 13 & 0.001953 & 8 & $70.56 \% \pm 17.82 \%$ & \\
\hline QUAL3 & ama50, ma50E, ma21L, ma50L, sd50S, VIDya, ATR14, BullsP, DeMarker, Force13E, WPR & 11 & 0.125 & 2 & $72.67 \% \pm 15.12 \%$ & \\
\hline RADL3 & ama9, ama21, ama50, ma50S, sd50, BearsP, Chaikin3, Chaikin5, Chaikin3E, CCI, Force13E, WPR, AD & 13 & 0.007813 & 2 & $66.33 \% \pm 11.75 \%$ & \\
\hline RAPT4 & ma21L, SAR, BullsP, Chaikin3E, Chaikin3L, CCI, Force13E, Force13L, WPR & 9 & 0.03125 & 0.03125 & $73.61 \% \pm 9.57 \%$ & \\
\hline RENT3 & ama21, ama50, sd50, sd50E, BearsP, CCI, AD & 7 & 0.03125 & 0.5 & $76.39 \% \pm 19.25 \%$ & \\
\hline RSID3 & ma50, ma5S, sd50E, VIDya, Chaikin3, Chaikin3E, Chaikin3L, CCI, Force13E, Force13S, Trix, WPR, Vol & 13 & 0.000122 & 128 & $79.17 \% \pm 8.87 \%$ & $\checkmark$ \\
\hline SANB11 & ama21, ma50, sd50, sd50S, BearsP, BullsP, Chaikin3L, Force13E, Force13L, RSIv, WPR, AD & 12 & 0.03125 & 0.125 & $70.00 \% \pm 22.04 \%$ & \\
\hline SBSP3 & ama21,VIDya, Chaikin3L, CCI, WPR & 5 & 0.001953 & 128 & $74.67 \% \pm 5.82 \%$ & $\checkmark$ \\
\hline SULA11 & ama21, ama50, sd50, sd21L, ATR14, BullsP, Chaikin5S, CCI, Force13E, Force13L, WPR, AD & 12 & 0.000488 & 32 & $79.67 \% \pm 12.55 \%$ & $\checkmark$ \\
\hline TAEE11 & ama50, ma50S, ma21L, ma50L, SAR, sd50E, sd50S, BullsP, Chaikin3E, Chaikin3L, CCI, Force13E, WPR & 13 & 0.007813 & 2 & $73.89 \% \pm 11.04 \%$ & \\
\hline TIMP3 & ama50, CCI, WPR & 3 & 0.000488 & 2048 & $80.33 \% \pm 3.21 \%$ & $\checkmark$ \\
\hline TOTS3 & ama50, ma21, ma50E, SAR, sd50L, Chaikin3L, CCI, Forcel3E, OsMa, WPR, MFI & 11 & 0.000488 & 32 & $74.67 \% \pm 13.51 \%$ & \\
\hline UGPA3 & ama50, ma50S, Chaikin3L, Force13E, RSIv, WPR & 6 & 0.000030517578125 & 0.125 & $72.33 \% \pm 23.41 \%$ & \\
\hline USIM5 & ama50, Force 13L & 2 & 8 & 2 & $69.00 \% \pm 25.84 \%$ & \\
\hline VALE3 & ama50, ma50, SAR, sd50, sd50S, VIDya, BullsP, Chaikin3L, CCI, Force13L, WPR & 11 & 0.00003051758 & 0.03125 & $66.67 \% \pm 10.54 \%$ & \\
\hline VIVT4 & ama50, Chaikin3L, CCI & 3 & 0.007813 & 32 & $70.33 \% \pm 19.13 \%$ & \\
\hline VLID3 & ama50, ma50E, ma21S, ma50L, sd21, sd50E, BearsP, BullsP, Chaikin3L, CCI, Force13E, Force13S, WPR, OBV & 14 & 0.007813 & 32 & $65.00 \% \pm 11.30 \%$ & \\
\hline VVAR11 & adx 14, ma50, ma21S, sd50, sd50S, Chaikin5S, DeMarker, OsMa, Trix, WPR & 10 & 0.001953 & 2048 & $75.00 \% \pm 8.28 \%$ & \\
\hline WEGE3 & ama50, CCI & 2 & 2 & 0.5 & $65.33 \% \pm 22.65 \%$ & \\
\hline
\end{tabular}


Table 28 - SVM model's results and picked stocks for 2017.

\begin{tabular}{|c|c|c|c|c|c|c|}
\hline & \multicolumn{6}{|l|}{2017} \\
\hline & \multirow[b]{2}{*}{ Selected Features } & \multirow[b]{2}{*}{ \# } & Selected Hyper-1 & arameters & CrossVal. Results & \\
\hline & & & $\gamma$ & $\mathrm{C}$ & Accuracy \pm StdDev & Selected \\
\hline ABEV3 & ama9, ma50S, SAR, BearsP, BullsP, Chaikin3L, CCI, Force13E & 8 & 0.001953125 & 128 & $77.66 \% \pm 14.90 \%$ & \\
\hline BBAS3 & ama50, RSIv & 2 & 0.0004882812 & 8 & $69.00 \% \pm 28.18 \%$ & \\
\hline BBDC3 & ama21, ama50, ma50, ma50S, sd50E, sd50S, sd21L, BearsP, Chaikin5, Chaikin3E, CCI, DeMarker, Force13L, WPR & 14 & 0.03125 & 128 & $70.33 \% \pm 27.19 \%$ & \\
\hline BBSE3 & ama21, ama50, ma50S, Chaikin5E, Force13E, MFI & 6 & 0.001953125 & 2048 & $79.00 \% \pm 18.17 \%$ & \\
\hline BEEF3 & ama21, ama50, ma50E, sd50, sd50L, Chaikin3L, CCI, Forcel3E, RSIv, WPR, AD & 11 & 0.125 & 8192 & $61.33 \% \pm 20.32 \%$ & \\
\hline BRAP4 & ama50 & 1 & 0.00003051758 & 0.5 & $75.67 \% \pm 29.36 \%$ & \\
\hline BRFS3 & ama21, ama50, ma50E, sd50S, BullsP, Chaikin3E, Chaikin3L, CCI, Force13E, Force13L, RSIv, Trix, WPR & 13 & 0.00003051758 & 0.5 & $72.67 \% \pm 21.20 \%$ & \\
\hline BRKM5 & ama50, ma50E, sd21S, ATR14, BearsP, Chaikin5S, Chaikin5L, CCI, Force13E & 9 & 0.001953125 & 0.5 & $64.00 \% \pm 20.97 \%$ & \\
\hline BRML3 & ama21, ama50, ma50L, SAR, BearsP, Chaikin5, Chaikin5S, CCI, Force 13L, OsMa & 10 & 0.03125 & 0.5 & $71.94 \% \pm 8.19 \%$ & \\
\hline BRPR3 & ama50, ma50, ma50S, sd50L, CCI,Force13S, RSIV, OBV & 8 & 0.0001220703 & 512 & $85.00 \% \pm 15.18 \%$ & $\checkmark$ \\
\hline BRSR6 & ama21, ama50, Chaikin3S, Chaikin5S, WPR, MFI & 6 & 0.125 & 128 & $65.00 \% \pm 31,12 \%$ & \\
\hline BTOW3 & ama21, ama50, ma21E, ma50S, sd21, sd50S, sd50L, ATR14, Chaikin5, Chaikin3S, Chaikin3L, CCI, DeMarker, Forcel3E, MACD, WPR, AD & 17 & 0.0001220703 & 128 & $79.00 \% \pm 12.17 \%$ & \\
\hline CCRO3 & ama21, ama50, ma21, ma50, ma50S, SAR, sd21S, sd50S, BearsP, BullsP, Chaikin5E, Chaikin3L, CCI, Force13L, Trix, WPR & 16 & 0.001953125 & 2 & $61.94 \% \pm 16.07 \%$ & \\
\hline CESP6 & ama21, ma21E, sd50S, BullsP, CCI, Force13E, WPR, AD & 8 & 0.0004882812 & 0.125 & $77.33 \% \pm 11.88 \%$ & \\
\hline CIEL3 & ama50, sd50S, VIDya, Chaikin5, DeMarker, Force13, Force13E, Force13L, WPR, AD & 10 & 0.03125 & 0.125 & $76.67 \% \pm 9.19 \%$ & \\
\hline CMIG4 & ama21, ama50, Chaikin5E, DeMarker, Force13L & 5 & 0.03125 & 0.125 & $73.00 \% \pm 17.22 \%$ & \\
\hline CPFE3 & ama50, ma21E, VIDya, BearsP, Chaikin5E, Chaikin3L, Force13E, Force13S, WPR & 9 & 0.00003051758 & 0.125 & $78.06 \% \pm 22.84 \%$ & \\
\hline CPLE6 & ama50, ma50S, sd21S, BullsP, Chaikin3S, CCI, MACD, RSIv & 8 & 8 & 0.125 & $67.92 \% \pm 24.85 \%$ & \\
\hline CSAN3 & ama21, ma50, ma50E, ma21S, ma50S, sd21E, sd50E, ATR14, BearsP, BullsP, CCI, Force13E, Force13S, RSIv, Trix, WPR, MFI & 17 & 0.00003051758 & 0.125 & $71.39 \% \pm 26.17 \%$ & \\
\hline CSNA3 & ama21, ama50, adx14, SAR, BearsP, BullsP, CCI, DeMarker, OsMa, MFI & 10 & 0.0078125 & 0.03125 & $87.00 \% \pm 1,83 \%$ & $\checkmark$ \\
\hline CYRE3 & ama50, BearsP & 2 & 0.00003051758 & 8192 & $66.67 \% \pm 17.26 \%$ & \\
\hline DTEX3 & ama50, ma50S, BullsP, Chaikin3S, Force13E, AD, MFI & 7 & 0.0078125 & 0.5 & $79.33 \% \pm 20.70 \%$ & \\
\hline ECOR3 & ama21, ama50, ma50S, SAR, sd50E, Chaikin5S, Chaikin3L, Force13S, WPR, AD, Vol & 11 & 0.001953125 & 32 & $84.00 \% \pm 14.80 \%$ & $\checkmark$ \\
\hline ELET3 & ama50, Chaikin5S, Momentum, AD & 4 & 2 & 2048 & $72.33 \% \pm 28.39 \%$ & \\
\hline EMBR3 & ama50, ma21, ma50L, sd5S, sd21S, sd50S, VIDya, BullsP, Chaikin5, Chaikin3E, Chaikin3L, Force13L, RSIv, WPR & 14 & 0.5 & 32768 & $82.33 \% \pm 14.37 \%$ & \\
\hline ENBR3 & ama50, ma50, SAR, sd21S, ATR14, BullsP, Chaikin3E, Chaikin3L, CCI, Forcel3E, WPR & 11 & 0.0001220703 & 8 & $76.67 \% \pm 7.60 \%$ & $\checkmark$ \\
\hline EQTL3 & High, ama50, ma50E, sd50, sd21E, sd50S, BearsP, BullsP, Chaikin5S, CCI, Force13E, Momentum, MFI & 13 & 0.001953125 & 128 & $66.67 \% \pm 18.47 \%$ & \\
\hline ESTC3 & ama9, ama21, SAR, sd50, sd50E, sd50S, VIDya, BearsP, Chaikin3E, Chaikin3L, CCI, Force13E, Force13L, Trix, WPR, AD & 16 & 0.00003051758 & 0.03125 & $68.61 \% \pm 10.30 \%$ & \\
\hline EVEN3 & ama50, ma21, Force13E, WPR & 4 & 0.0004882812 & 8 & $78.33 \% \pm 7.73 \%$ & $\checkmark$ \\
\hline EZTC3 & ama21, ama50, ma50, ma50S, ma50L, sd5E, sd50L, ATR14, BearsP, BullsP, CCI, DeMarker, Forcel3E, Force13L, Momentum, OsMa, AD, MFI, OBV & 19 & 0.5 & 512 & $65.28 \% \pm 23.67 \%$ & \\
\hline FIBR3 & ama21, ama50, ma21, ma50S, sd50, BullsP, Chaikin3L, Force13, Force13S, RSIv, WPR & 11 & 0.0004882812 & 2 & $76.67 \% \pm 9.21 \%$ & \\
\hline GFSA3 & ama21, ama50, ma50, ma21E, ma21S, ma50S, sd50S, BearsP, BullsP, Chaikin5, Chaikin5S, CCI, Force13E, WPR & 14 & 0.00003051758 & 32 & $78.61 \% \pm 10.92 \%$ & \\
\hline GGBR4 & ama21, ama50, Chaikin3L, CCI, AD, MFI, OBV & 7 & 0.125 & 8192 & $71.67 \% \pm 29.34 \%$ & \\
\hline GOAU4 & ama50, sd50S, BearsP, Force13L, AD, OBV & 6 & 0.00003051758 & 0.03125 & $72.08 \% \pm 36.45 \%$ & \\
\hline GOLL4 & ama21, ama50, ma50S, ma50L, Chaikin5S, CCI, MACD, RSIv & 8 & 0.0004882812 & 32768 & $78.33 \% \pm 21.81 \%$ & \\
\hline HGTX3 & ama21, ama50, adx14, ma50, sd50S, ATR14, Chaikin5S, CCI, Force13E, WPR & 10 & 0.125 & 0.03125 & $64.67 \% \pm 8.03 \%$ & \\
\hline HYPE3 & ama21, ama50, CCI, DeMarker, MACD & 5 & 2 & 2 & $63.67 \% \pm 37.26 \%$ & \\
\hline IGTA3 & ama9, adx14, ma21, ma50L, sd21S, sd50S, BearsP, BullsP, Chaikin5S, CCI, Force13E, OsMa, WPR & 13 & 0.03125 & 0.5 & $70.33 \% \pm 26.52 \%$ & \\
\hline ITSA4 & ama21, ama50, ma50S, sd50E, BullsP, Chaikin5E, Force13E, RSIv, WPR, MFI & 10 & 0.03125 & 0.5 & $80.67 \% \pm 11.52 \%$ & $\checkmark$ \\
\hline ITUB4 & ama50, ma50E, ma50L, sd21S, ATR14, Chaikin3, Chaikin5E, Force13E, WPR, MFI & 10 & 0.0001220703 & 512 & $66.67 \% \pm 25.98 \%$ & \\
\hline JBSS3 & ama50, ma50, ma21S, sd50S, Chaikin5L, Forcel3S, WPR & 7 & 0.03125 & 8 & $77.67 \% \pm 17.62 \%$ & \\
\hline KLBN11 & ama50, ma50, ma50S, sd50, sd21S, sd50L, BearsP, Chaikin3S, Chaikin3L, CCI, Force13E, OsMa, WPR, AD & 14 & 0.03125 & 0.5 & $75.33 \% \pm 12.77 \%$ & \\
\hline KROT3 & ama21, ama50, ma50, ma50S, sd50S, BearsP, BullsP, CCI, Momentum, OsMa, WPR & 11 & 0.007813 & 0.5 & $72.67 \% \pm 11.64 \%$ & \\
\hline LAME4 & ama21, ama50, sdSE, sd50E, sd21L, BullsP, Chaikin3L, CCI, Force13E, Force13S, Force13L, WPR & 12 & 0.00003051758 & 0.5 & $81.11 \% \pm 8.34 \%$ & $\checkmark$ \\
\hline LIGT3 & ama50, ma50L, Chaikin5, DeMarker, Forcel3L, WPR & 6 & 0.00012207 & 0.03125 & $78.06 \% \pm 4.14 \%$ & $\checkmark$ \\
\hline LREN3 & ama50, ma50L, WPR & 3 & 0.5 & 512 & $58.33 \% \pm 27.36 \%$ & \\
\hline MDIA3 & ama50, sd50S, Chaikin5L, Forcel3S, Trix, WPR, OBV & 7 & 0.007813 & 0.125 & $94.58 \% \pm 7.12 \%$ & $\checkmark$ \\
\hline MGLU3 & ama50, CCI, Forcel3S, MACD, OBV & 5 & 0.00003051758 & 8192 & $92.92 \% \pm 5.67 \%$ & $\checkmark$ \\
\hline MILS3 & ama21, ama50, ma50, Force13L, Momentum, OsMa, WPR & 7 & 0.000488 & 32 & $76.00 \% \pm 14.75 \%$ & \\
\hline MMXM3 & ama50, ma50, ma50L, SAR, sd50S, BearsP, CCI, Momentum & 8 & 0.007813 & 2 & $87.92 \% \pm 10.13 \%$ & \\
\hline MPLU3 & ama50, sd21S, BearsP, Momentum & 4 & 0.125 & 0.5 & $88.33 \% \pm 4.08 \%$ & $\checkmark$ \\
\hline MRFG3 & ama50, ma50E, Force13, WPR, AD & 5 & 0.125 & 0.125 & $74.33 \% \pm 26.42 \%$ & \\
\hline MRVE3 & ama21, ama50, ma50, ma21S, sd50S, Chaikin3, CCI, OsMa, AD, MFI & 10 & 2 & 0.5 & $66.00 \% \pm 19.42 \%$ & \\
\hline MULT3 & ama21, ama50, ma50S, ma50L, SAR, sd21, BullsP, Chaikin3L, CCI, Force13E, RSIv, WPR, MFI & 13 & 0.03125 & 0.125 & $66.33 \% \pm 20.60 \%$ & \\
\hline NATU3 & ama50, WPR & 2 & 0.001953 & 0.125 & $79.00 \% \pm 10.04 \%$ & $\checkmark$ \\
\hline ODPV3 & ama21, ama50, SAR, BearsP, Chaikin3L, Force13E, WPR & 7 & 0.00003051758 & 0.125 & $66.67 \% \pm 11.11 \%$ & \\
\hline OIBR3 & ama50, ma21 & 2 & 0.5 & 32 & $60.83 \% \pm 20.66 \%$ & \\
\hline PCAR4 & ama21, ama50, SAR, BearsP & 4 & 0.5 & 2048 & $72.92 \% \pm 16.80 \%$ & \\
\hline PDGR3 & ama50, ma50E, sd21, sd21L, BearsP, Chaikin5E, Force13L & 7 & 0.000122 & 8 & $82.33 \% \pm 14.56 \%$ & \\
\hline PETR3 & ama50, Chaikin5 & 2 & 0.00003051758 & 0.125 & $72.67 \% \pm 26.94 \%$ & \\
\hline POMO4 & ama21, ama50, ma50E, SAR, BearsP, BullsP, Chaikin3E, Chaikin3S, CCI, Force13E, Force13L, OsMa, MFI & 13 & 0.000488 & 2048 & $78.61 \% \pm 11.32 \%$ & \\
\hline PSSA3 & ama50, BullsP, Chaikin5S, Force13E, WPR & 5 & 0.000122 & 8 & $69.00 \% \pm 14.42 \%$ & \\
\hline QGEP3 & ama9, ama50, ma50S, sd5S, BullsP, Chaikin3, Chaikin3S, Chaikin3L, OsMa, WPR & 10 & 0.00003051758 & 2 & $76.33 \% \pm 15.16 \%$ & \\
\hline QUAL3 & ama9, ama21, ama50, ma50S, SAR, Chaikin3L, Force13E, Force13L, Momentum, OsMa, WPR & 11 & 0.000122 & 2048 & $76.00 \% \pm 13.47 \%$ & \\
\hline RADL3 & ama21, ama50, ma50S, ATR14, BullsP, Chaikin5, Chaikin3L, CCI, Force13E, Momentum, OsMa, WPR & 12 & 0.000122 & 2048 & $86.26 \% \pm 18.17 \%$ & \\
\hline RAPT4 & ama50, Force13, Force13S & 3 & 0.000122 & 8 & $73.33 \% \pm 20.85 \%$ & \\
\hline RENT3 & ama50, sd50S, VIDya, BearsP, Force13E, WPR & 6 & 0.000122 & 8 & $71.63 \% \pm 11.30 \%$ & \\
\hline RSID3 & ama50, VIDya, Force13S & 3 & 0.00003051758 & 0.03125 & $75.00 \% \pm 29.42 \%$ & \\
\hline SANB11 & ama50, ma50S, ma50L, sd50S, BearsP, CCI, Momentum, WPR & 8 & 0.000122 & 0.5 & $71.94 \% \pm 6.36 \%$ & \\
\hline SBSP3 & ama50, ma50E, ma50L, sd21L, BearsP, Chaikin3E, Chaikin5S, Chaikin3L, CCI, DeMarker, WPR, MFI & 12 & 0.125 & 0.125 & $82.92 \% \pm 12.05 \%$ & $\checkmark$ \\
\hline SULA11 & ama21, ama50, sd21S, sd21L, VIDya, BullsP, CCI, Force13E, Trix, WPR & 10 & 0.007813 & 0.5 & $72.67 \% \pm 12.17 \%$ & \\
\hline TAEE11 & ama21, ama50, ma50, ma50S, sd50E, BullsP, Chaikin5E, CCI, Force13, Force13S, OsMa, WPR & 12 & 0.00003051758 & 0.5 & $75.67 \% \pm 10.58 \%$ & \\
\hline TIMP3 & ama21, ama50, ma21S, ma50L, sd50E, sd5L, ATR14, BearsP, BullsP, Chaikin3S, CCI, Force13E, Momentum, OsMa, RSIv, WPR, OBV & 17 & 0.001953 & 2 & $67.33 \% \pm 6.08 \%$ & \\
\hline TOTS3 & ama9, ama21, ama50, sd50E, sd50L, Chaikin5E, CCI, Force13L, RSIV, WPR & 10 & 0.125 & 0.125 & $75.67 \% \pm 9.97 \%$ & \\
\hline UGPA3 & ama50, adx14, ma21, ma50, ma50S, SAR, sd50, sd21E, BullsP, Chaikin3E, Chaikin5S, Chaikin3L, CCI, Force13E, Force13S, Force13L, WPR & 17 & 0.00003051758 & 0.03125 & $76.33 \% \pm 7.21 \%$ & $\checkmark$ \\
\hline USIM5 & ama50 & 1 & 0.03125 & 32768 & $77.00 \% \pm 24.16 \%$ & \\
\hline VALE3 & ama21, ama50, ma50L, sd50, BearsP, Chaikin5E, Chaikin3L, CCI, WPR, AD, OBV & 11 & 0.00003051758 & 8192 & $80.55 \% \pm 15.33 \%$ & \\
\hline VIVT4 & ama21, ama50, adx14, ma50, ma50S, SAR, sd21E, sd21S, ATR14, BullsP, Chaikin3, Chaikin3E, Chaikin3L, CCI, Force13E, Force13L, OsMa, WI & 19 & 0.00003051758 & 0.125 & $79.33 \% \pm 9.32 \%$ & $\checkmark$ \\
\hline VLID3 & ama50, ma21S, sd50, VIDya, Chaikin3E, CCI, WPR & 7 & 0.000488 & 32768 & $66.67 \% \pm 19.41 \%$ & \\
\hline VVAR11 & ama50, ma50E, ChaikinsE, Force13L & 4 & 0.001953 & 0.5 & $68.75 \% \pm 17.29 \%$ & \\
\hline WEGE3 & ama21, ama50, ma21E, sd50L, Chaikin3L, CCI, Force13L, WPR & 8 & 0.000488 & 0.5 & $69.33 \% \pm 12.62 \%$ & \\
\hline
\end{tabular}




\section{B PROFTS PARAMETERS}

This appendix details some parameters that were configured to run the simulations, the first set of parameters are related to Investor's profiles, and they define PROFTS's goal. They can be found in Table 29. The second set of parameters are about technical and fundamentalist agents and they can be found in Table 30. The final set of parameters are about trading and simulation details and they can be found in Table 31.

Table 29 - Investor's profile parameters

\begin{tabular}{l|c|c|c|c} 
Investor Profile & I1 & I2 & I3 & I4 \\
\hline Value & $1 \sigma$ & $2 \%$ p.m & 1 & 1
\end{tabular}

For each Investor Profile, depending on market scenario, PROFTS will have a different objective, as stated in Table 2. The parameters of Table 29 are what define the levels of what is an acceptable/unacceptable return/risk, for example, consider the investor I1 that has a maximum acceptable risk of 1 standard deviation, if current portfolio risk is above this value, coordinator agent will chose technical recommendations that minimize it, otherwise, if it is bellow, it will chose recommendations that would maximize its Sharpe ratio. For I2, the goal selected was to pursue a minimal monthly return of $2 \%$. For investors I3 and I4 the number 1 is just a dummy value indicating that the system should minimize risk (I3) or maximize Sharpe ratio (I4). These parameters are imputed in a configuration file that is read by Coordinator agent when started. It is important to note that just one profile can be used per simulation.

Table 30 - Technical and Fundamentalist Agents parameters

\begin{tabular}{|c|l|c|}
\hline Param ID & \multicolumn{1}{|c|}{ Param. Description } & Value \\
\hline \multicolumn{3}{|c|}{ Fundamentalist Agent } \\
\hline 1 & Number of clusters (k) & {$[2,10]$} \\
\hline 2 & Min. Cluster Size & 10 \\
\hline 3 & Max. Portfolio weight & $20 \%$ \\
\hline 4 & Position Type & Long Only \\
\hline 5 & Min. Prob. Healthy & $85 \%$ \\
\hline 6 & Stop Loss & - \\
\hline 7 & Stop Gain & $80 \%$ of Fair Value \\
\hline 8 & Min. Upside & $10 \%$ \\
\hline \multicolumn{3}{|c|}{ Technical Agent } \\
\hline 9 & Min. Prob. of High & $70 \%$ \\
\hline 10 & Portfolio weight & $20 \%$ \\
\hline 11 & Cash for Technical & $20 \%$ \\
\hline
\end{tabular}

In Table 30 there are the Fundamentalist and Technical Agents parameters. Fundamentalist Agent has eight parameters while for Technical agent there are three.

Parameters 1 and 2 are related to the clustering process. The PAM algorithm will try to cluster companies from 2 to 10 clusters and the number $k$ of cluster will be the one where the 
average silhouette width is maximum, as explained in section 3.2.3. Suppose PAM algorithm clustered similar companies in 3 clusters, as a regression will be performed to chose the multiple used in the relative valuation, each cluster should have at least 10 companies, and this value is given by parameter 2 , it is the minimum cluster size.

Parameters 3 and 4 are related to portfolio optimization. In this study just long positions are allowed, so it is not possible to have negative weights, this constraint is given by parameter 4, and the maximum weight allowed for a single company is $20 \%$, this constraint is important to force diversification and is used to limit the maximum exposure for a given company.

The parameter 5 is related to FDP model prediction. Just companies that are with at least $85 \%$ of probability of being healthy are considered in the experiments that uses the FDP model.

Parameters 6, 7 and 8 are related to the relative valuation and trading. In this study, the parameter 6 (stop loss) was not used, so if Fundamentalist Agent creates a portfolio that never achieve its fair value in none of its selected stocks, it would keep them forever. It is not a desirable situation and this feature will be implemented in future work. Opposite to the stop loss, there is the stop gain, that is the parameter 7 and it is used to close a position at certain level. In this study, if a stock achieves $80 \%$ of its fair value calculated by relative valuation, the position is closed. Finally, there is the parameter 8 that indicates the minimum upside required to a stock be considered undervalued and became a candidate to portfolio's optimization process.

The parameters 9 and 10 are related to Technical agent and Coordinator agent. Parameter 9 indicates the required minimal probability of an upward movement, given by the SVM model prediction. Just recommendations that have a probability of $70 \%$ or more are considered by the Coordination agent. This value can be understood as a recommendation's confidence level. When Coordinator agent checks its goal and analyse if it should minimize risk or maximize return/sharpe ratio according to its investor profile and market scenario, it calculates expected values for the portfolio considering that the stock recommended by the technical agent will have a weight of 20\% (parameter 10), and consequently, current stocks selected by Fundamentalist agent have their weights decreased. Portfolios that use the technical agent in their simulation use $80 \%$ of its cash to buy stocks recommended by the Fundamentalist Agent, and keep $20 \%$ of its cash reserved to trade stocks recommended by Technical agent, its value is given by parameter 11. Portfolios that do not use technical agent recommendation invest $100 \%$ of its cash in fundamentalist agent's portfolio suggestion.

Table 31 - Trading parameters

\begin{tabular}{l|c}
\hline Commission and Fees & $0,12 \%$ \\
Initial Capital & $\mathrm{R} \$ 1.000 .000,00$ \\
Minimal lot size & 100 \\
\hline
\end{tabular}

In Table 31 there are some parameters regarding the trading process, i.e. the initial capital for investment, the minimal lot size of 100 , to be more realistic and avoid the fractional market, and a commission fee of $0,12 \%$ on each trade. 


\section{PROFTS RESULTS}

The results are presented separately for each investor profile. When comparing portfolios, sometimes they are referenced to its peers. Consider an example of portfolio with ID 1, that is the MAR, its peers are MAR_T2 and MAR_T3, while for MAR_FDP, its peers are MAR_FDP_T2 and MAR_FDP_T3.

\section{C.1 BACKTEST FOR 2015}

In this section it is presented the portfolio comparison and results for each investor profile for the year of 2015 .

\section{MAX ACCEPTABLE RISK}

The results obtained for investor profile I1 is presented in Figure 21 and its summary is presented in Table 32.

It is expected from portfolios that use technical agent recommendations that they have a lower standard deviation than those that does not use them, because when the portfolio risk is above the parameter given in Table 29 it would try to minimize portfolio's risk. Only MAR_T3 had a Standard Deviation higher than its comparable portfolio, but all of them had a lower standard deviation than the benchark, and MAR_T3 and MAR_T3_FDP had also a better Sharpe ratio.

Table 32 - Max Acceptable Risk - Portfolio Metrics for 2015

\begin{tabular}{l|c|c|c|c|c|c|c}
\cline { 2 - 9 } & IBrX 100 & MAR & MAR_FDP & MAR_T2 & MAR_T2_FDP & MAR_T3 & MAR_T3_FDP \\
\hline Experiment ID & - & 1 & 2 & 3 & 4 & 5 & 6 \\
\hline Number of Trades & - & 53 & 34 & 70 & 50 & 64 & 49 \\
\hline Annualized Return & $-10,2 \%$ & $-18,2 \%$ & $-15,6 \%$ & $-25,9 \%$ & $-16,4 \%$ & $-5,5 \%$ & $-6,1 \%$ \\
\hline Annualized Std Dev & $21,9 \%$ & $20,6 \%$ & $20,6 \%$ & $19,3 \%$ & $19,6 \%$ & $21,5 \%$ & $18,6 \%$ \\
\hline Max Drawdown & $24,1 \%$ & $26,1 \%$ & $26,4 \%$ & $30,0 \%$ & $28,2 \%$ & $25,3 \%$ & $21,3 \%$ \\
\hline Annualized Alpha & - & $-16,2 \%$ & $-13,4 \%$ & $-25,0 \%$ & $-15,5 \%$ & $-3,2 \%$ & $-4,1 \%$ \\
\hline Active Premium & - & $-8,0 \%$ & $-5,4 \%$ & $-15,7 \%$ & $-6,3 \%$ & $4,6 \%$ & $4,1 \%$ \\
\hline Tracking Error & - & $29,6 \%$ & $29,2 \%$ & $30,5 \%$ & $30,9 \%$ & $30,4 \%$ & $28,0 \%$ \\
\hline Information Ratio & - & $-0,27$ & $-0,18$ & $-0,51$ & $-0,20$ & 0,15 & 0,15 \\
\hline Sharpe Ratio (Rf 0\%) & $-0,47$ & $-0,88$ & $-0,75$ & $-1,34$ & $-0,84$ & $-0,26$ & $-0,33$ \\
\hline
\end{tabular}

\section{DESIRED TARGET RETURN}

The results obtained for investor profile I 2 is presented in Figure 22 and its summary is presented in Table 33. 
Figure 21 - Max Acceptable Risk against Benchmark for 2015.

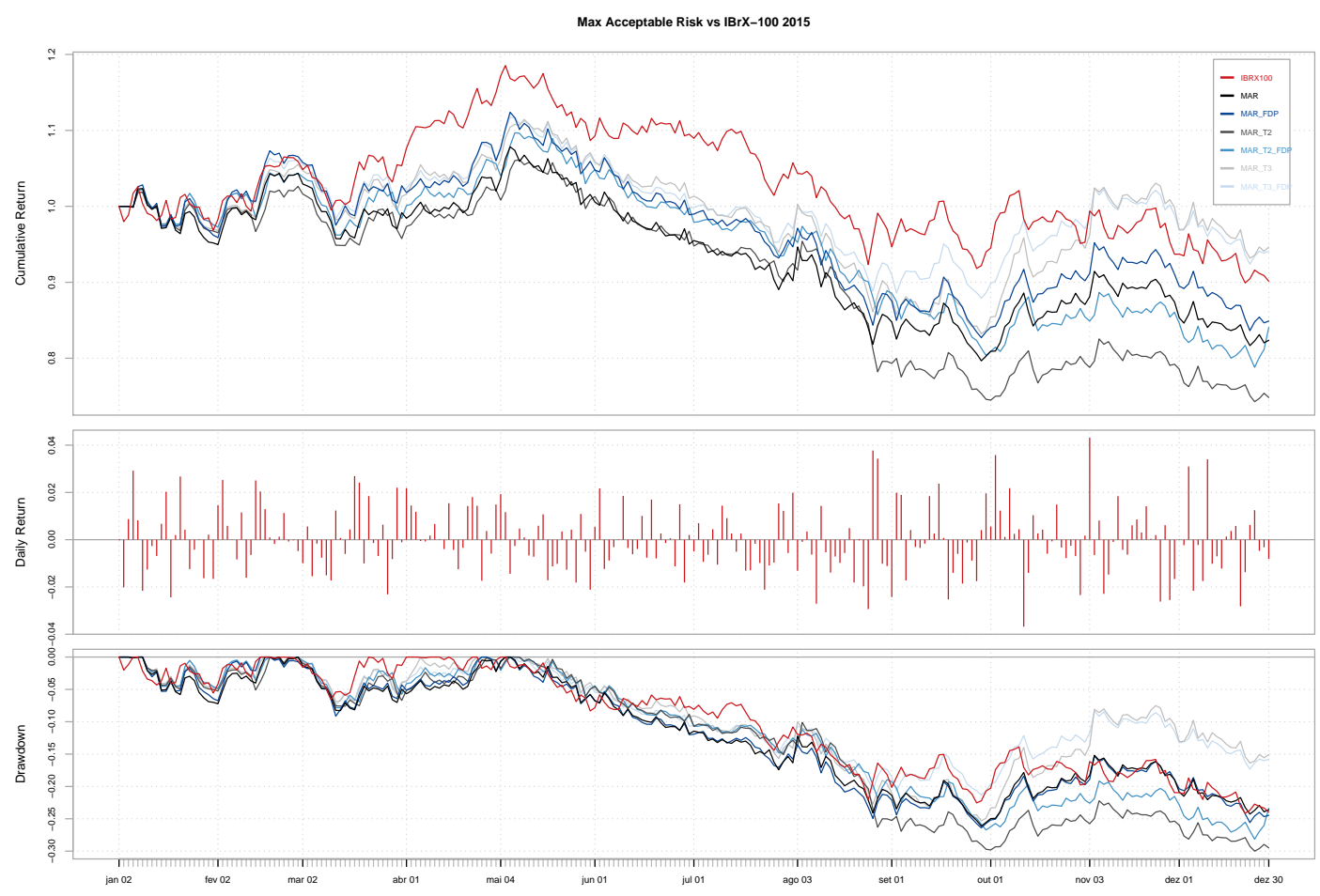

The goal of this type of investor is to maximize return with a target return constraint. Compared with the benchmark, almost all of them achieved a higher return, excluding DTR_FDP and DTR_T2. T3s portfolios had a better result compared to its peers.

Table 33 - Desired Target Return - Portfolio Metrics for 2015

\begin{tabular}{l|c|c|c|c|c|c|c}
\cline { 2 - 8 } & IBrX 100 & DTR & DTR_FDP & DTR_T2 & DTR_T2_FDP & DTR_T3 & DTR_T3_FDP \\
\hline Experiment ID & - & 19 & 20 & 21 & 22 & 23 & 24 \\
\hline Number of Trades & - & 23 & 23 & 43 & 42 & 38 & 38 \\
\hline Annualized Return & $-10,2 \%$ & $-6,8 \%$ & $-10,4 \%$ & $-9,7 \%$ & $-12,6 \%$ & $1,2 \%$ & $-1,8 \%$ \\
\hline Annualized Std Dev & $21,9 \%$ & $21,1 \%$ & $23,1 \%$ & $20,1 \%$ & $21,6 \%$ & $19,3 \%$ & $20,7 \%$ \\
\hline Max Drawdown & $24,1 \%$ & $22,4 \%$ & $25,7 \%$ & $25,4 \%$ & $28,5 \%$ & $18,8 \%$ & $21,3 \%$ \\
\hline Annualized Alpha & - & $-4,9 \%$ & $-8,1 \%$ & $-8,3 \%$ & $-11,0 \%$ & $3,1 \%$ & $0,3 \%$ \\
\hline Active Premium & - & $3,4 \%$ & $-0,2 \%$ & $0,4 \%$ & $-2,5 \%$ & $11,4 \%$ & $8,4 \%$ \\
\hline Tracking Error & - & $30,9 \%$ & $32,2 \%$ & $30,6 \%$ & $31,5 \%$ & $29,3 \%$ & $30,2 \%$ \\
\hline Information Ratio & - & 0,11 & $-0,01$ & 0,01 & $-0,08$ & 0,39 & 0,28 \\
\hline Sharpe Ratio $(\mathrm{Rf}=0 \%)$ & $-0,46$ & $-0,32$ & $-0,45$ & $-0,48$ & $-0,58$ & 0,06 & $-0,09$ \\
\hline
\end{tabular}

\section{LIMITED RISK-RETURN}

The results obtained for investor profile I 3 is presented in Figure 23 and its summary is presented in Table 34.

This type of investor always tries to minimize risk. All portfolios had a smaller Standard Deviation than the benchmark, that was the metric that they were trying to minimize, and those 
Figure 22 - Desired Target Return against Benchmark for 2015.

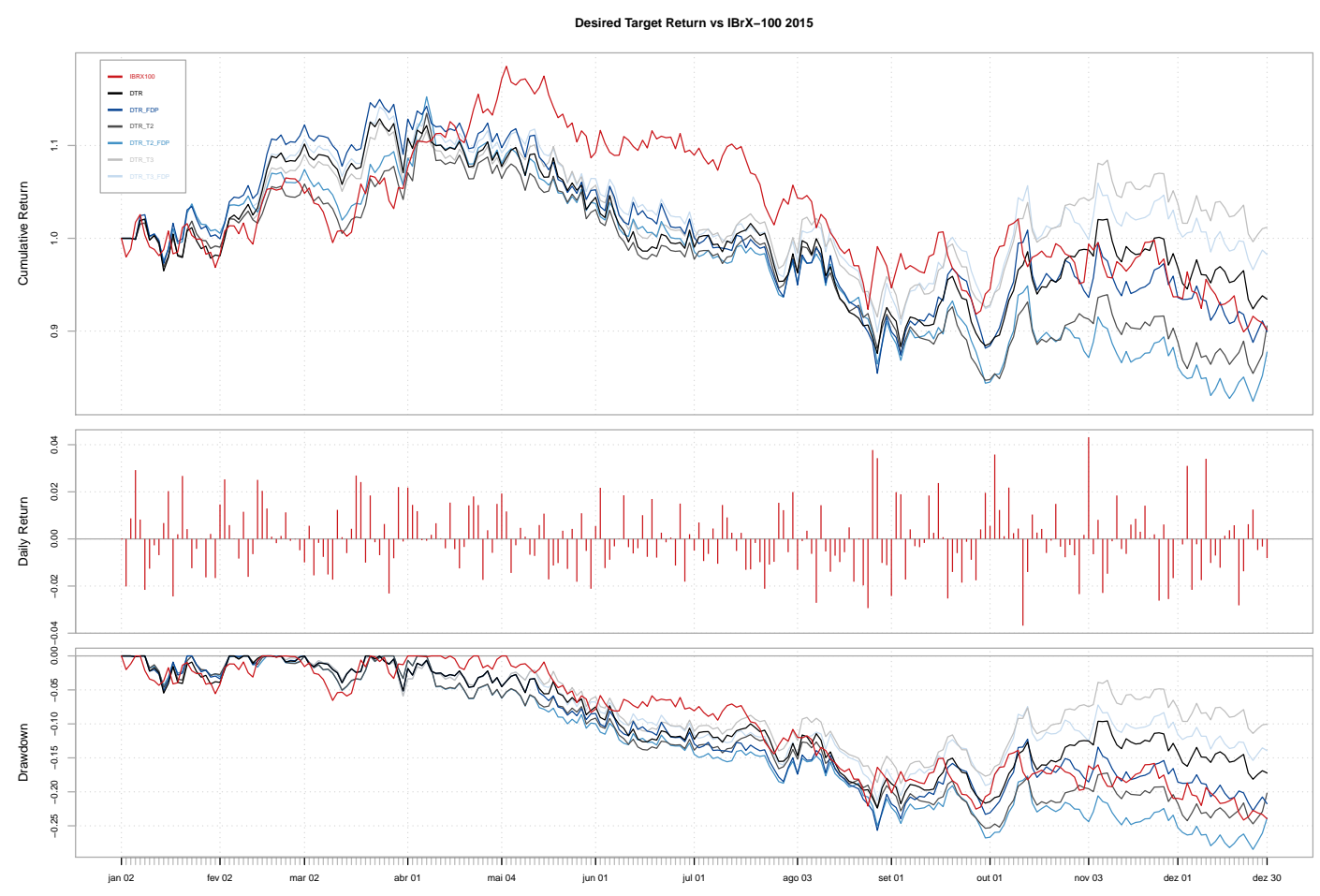

that used technical recommendation had lower standard deviation than its peers.

Table 34 - Limited Risk Return - Portfolio Metrics for 2015

\begin{tabular}{l|c|c|c|c|c|c|c}
\cline { 2 - 9 } & IBrX 100 & DTR & DTR_FDP & DTR_T2 & DTR_T2_FDP & DTR_T3 & DTR_T3_FDP \\
\hline Experiment ID & - & 37 & 38 & 39 & 40 & 41 & 42 \\
\hline Number of Trades & - & 53 & 34 & 70 & 50 & 67 & 49 \\
\hline Annualized Return & $-10,2 \%$ & $-18,2 \%$ & $-15,6 \%$ & $-25,9 \%$ & $-16,4 \%$ & $-9,3 \%$ & $-6,1 \%$ \\
\hline Annualized Std Dev & $21,9 \%$ & $20,6 \%$ & $20,6 \%$ & $19,3 \%$ & $19,6 \%$ & $19,0 \%$ & $18,6 \%$ \\
\hline Max Drawdown & $24,1 \%$ & $26,1 \%$ & $26,4 \%$ & $30,0 \%$ & $28,2 \%$ & $21,2 \%$ & $21,3 \%$ \\
\hline Annualized Alpha & - & $-16,2 \%$ & $-13,4 \%$ & $-25,0 \%$ & $-15,5 \%$ & $-7,5 \%$ & $-4,1 \%$ \\
\hline Active Premium & - & $-8,0 \%$ & $-5,4 \%$ & $-15,7 \%$ & $-6,3 \%$ & $0,9 \%$ & $4,1 \%$ \\
\hline Tracking Error & - & $29,6 \%$ & $29,2 \%$ & $30,5 \%$ & $30,9 \%$ & $28,6 \%$ & $28,0 \%$ \\
\hline Information Ratio & - & $-0,27$ & $-0,18$ & $-0,51$ & $-0,20$ & 0,03 & 0,15 \\
\hline Sharpe Ratio (Rf =0\%) & $-0,46$ & $-0,88$ & $-0,75$ & $-1,34$ & $-0,84$ & $-0,49$ & $-0,33$ \\
\hline
\end{tabular}

\section{FREE RISK-RETURN}

The results obtained for investor profile I4 is presented in Figure 24 and its summary is presented in Table 35.

This type of investor always try to maximize sharpe ratio, and comparing to all others, it achieves better results in terms of risk and return. From all of portfolios, these were the unique that had a positive return (excluding DTR_T3). T3s portfolios were also better than its peers. 
Figure 23 - Limited Risk Return against Benchmark for 2015.

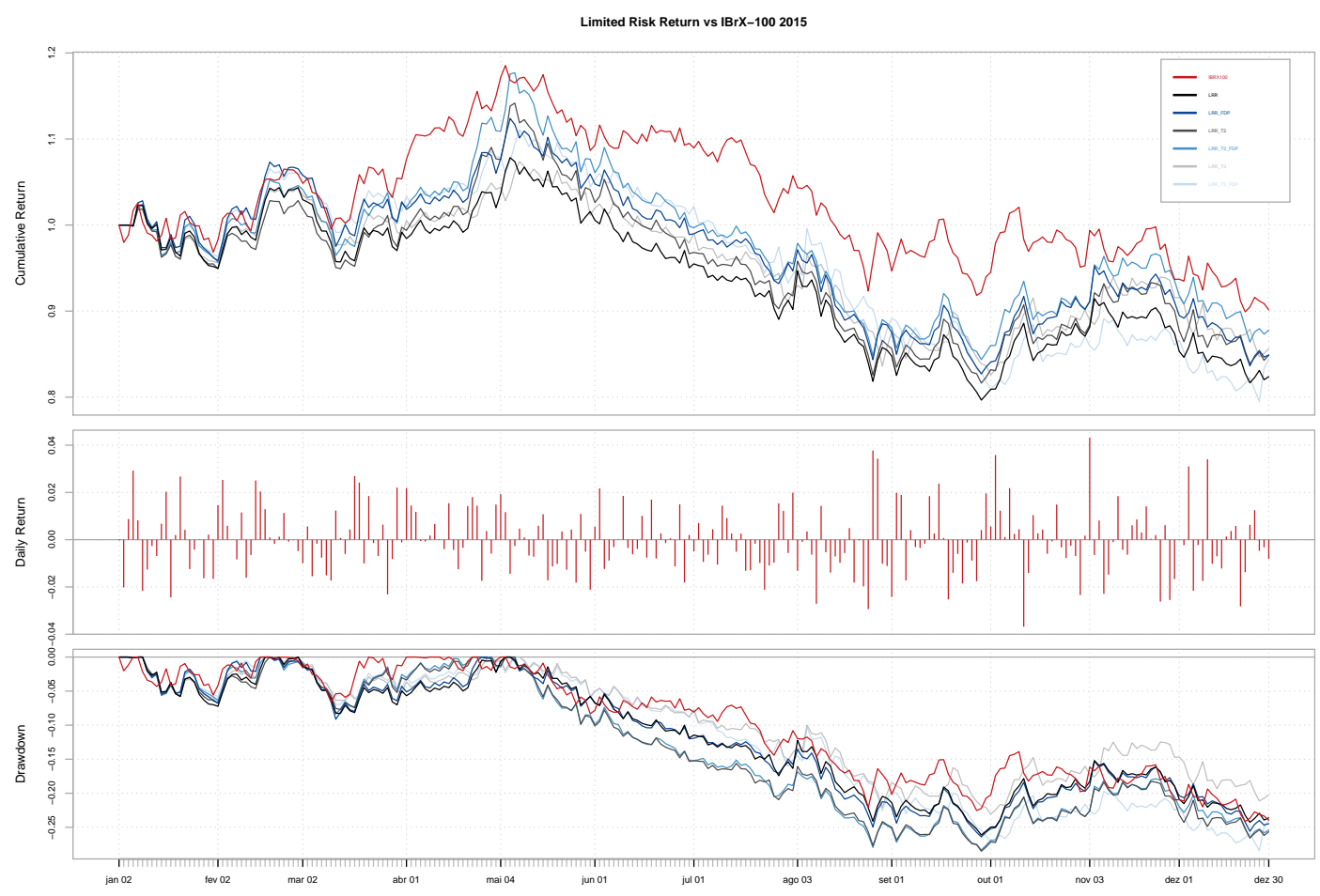

Table 35 - Free Risk Return - Portfolio Metrics for 2015

\begin{tabular}{l|c|c|c|c|c|c|c}
\cline { 2 - 8 } & IBrX 100 & FRR & FRR_FDP & FRR_T2 & FRR_T2_FDP & FRR_T3 & FRR_T3_FDP \\
\hline Experiment ID & - & 55 & 56 & 57 & 58 & 59 & 60 \\
\hline Number of Trades & - & 22 & 20 & 38 & 36 & 37 & 35 \\
\hline Annualized Return & $-10,2 \%$ & $7,6 \%$ & $8,6 \%$ & $0,9 \%$ & $1,7 \%$ & $13,9 \%$ & $14,7 \%$ \\
\hline Annualized Std Dev & $21,9 \%$ & $19,5 \%$ & $19,7 \%$ & $19,1 \%$ & $19,3 \%$ & $18,0 \%$ & $18,2 \%$ \\
\hline Max Drawdown & $24,1 \%$ & $14,3 \%$ & $14,3 \%$ & $18,2 \%$ & $18,2 \%$ & $11,7 \%$ & $11,7 \%$ \\
\hline Annualized Alpha & - & $9,1 \%$ & $10,2 \%$ & $2,0 \%$ & $2,8 \%$ & $15,4 \%$ & $16,3 \%$ \\
\hline Active Premium & - & $17,7 \%$ & $18,7 \%$ & $11,1 \%$ & $11,9 \%$ & $24,0 \%$ & $24,9 \%$ \\
\hline Tracking Error & - & $30,2 \%$ & $30,3 \%$ & $30,6 \%$ & $30,7 \%$ & $28,9 \%$ & $29,0 \%$ \\
\hline Information Ratio & - & 0,59 & 0,62 & 0,36 & 0,39 & 0,83 & 0,86 \\
\hline Sharpe Ratio (Rf =0\%) & $-0,47$ & 0,39 & 0,44 & 0,05 & 0,09 & 0,77 & 0,81 \\
\hline
\end{tabular}

\section{C.2 BACKTEST FOR 2016}

In this section it is presented the portfolio comparison and results for each investor profile for the year of 2016.

\section{MAX ACCEPTABLE RISK}

The results obtained for investor profile I1 for 2016 is presented in Figure 25, and its summary is presented in Table 36.

Compared to the benchmark, all of them had a lower Standard Deviation, on the other hand, they had a lower return and sharpe ratio. Portfolios that used technical agent recommendation 
Figure 24 - Free Risk Return against Benchmark for 2015.

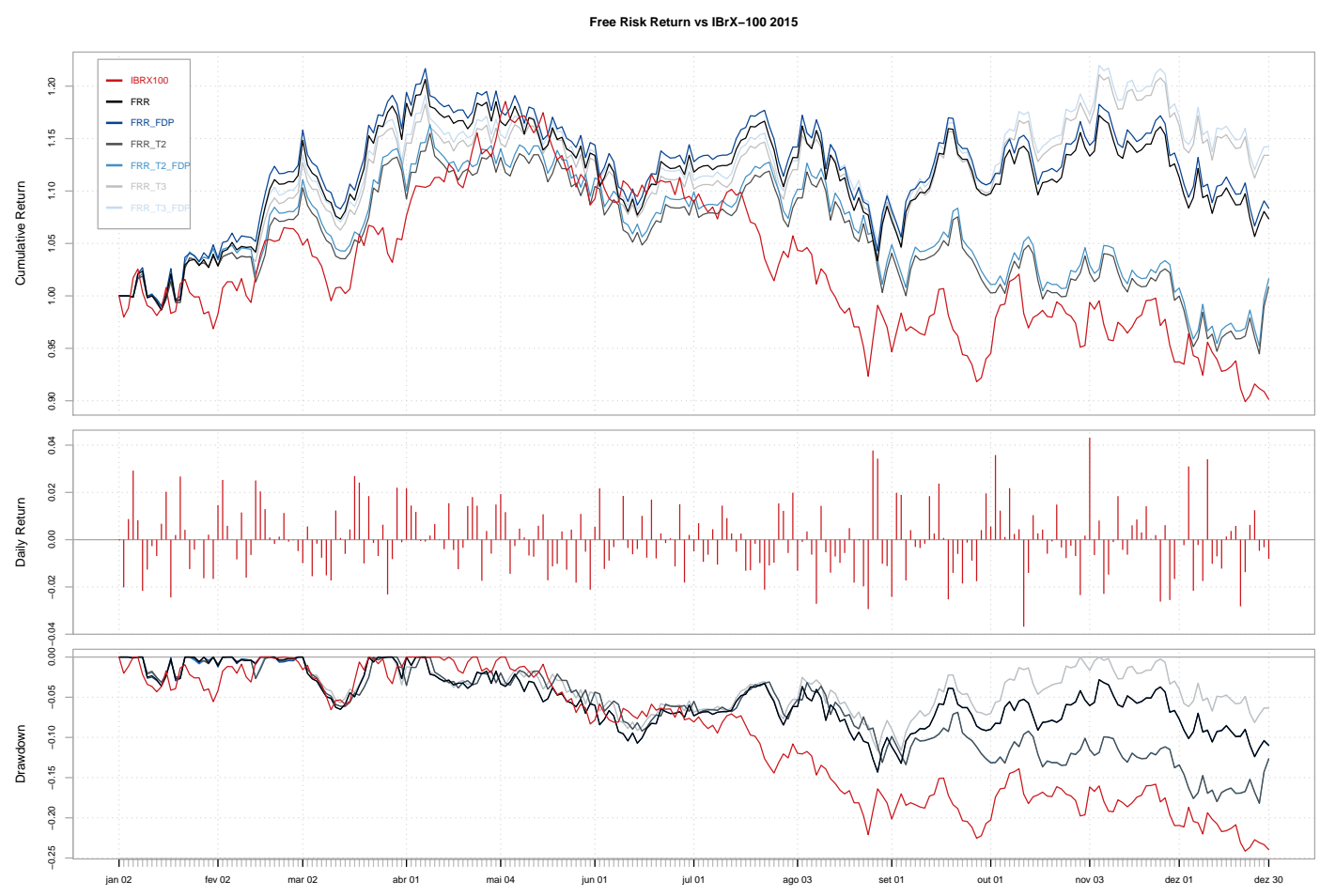

had a better sharpe ratio than its peers that did not used them.

Table 36 - Max Acceptable Risk - Portfolio Metrics for 2016

\begin{tabular}{l|c|c|c|c|c|c|c}
\cline { 2 - 8 } & IBrX 100 & MAR & MAR_FDP & MAR_T2 & MAR_T2_FDP & MAR_T3 & MAR_T3_FDP \\
\hline Experiment ID & - & 7 & 8 & 9 & 10 & 11 & 12 \\
\hline Number of Trades & - & 108 & 107 & 122 & 116 & 127 & 120 \\
\hline Annualized Return & $41,3 \%$ & $16,8 \%$ & $9,9 \%$ & $19,7 \%$ & $11,3 \%$ & $16,1 \%$ & $11,7 \%$ \\
\hline Annualized Std Dev & $25,2 \%$ & $18,8 \%$ & $17,6 \%$ & $19,3 \%$ & $18,3 \%$ & $17,6 \%$ & $16,4 \%$ \\
\hline Max Drawdown & $12,0 \%$ & $12,0 \%$ & $13,4 \%$ & $11,6 \%$ & $13,8 \%$ & $10,2 \%$ & $10,2 \%$ \\
\hline Annualized Alpha & - & $18,2 \%$ & $10,7 \%$ & $20,0 \%$ & $11,2 \%$ & $16,9 \%$ & $12,0 \%$ \\
\hline Active Premium & - & $-24,5 \%$ & $-31,4 \%$ & $-21,6 \%$ & $-30,0 \%$ & $-25,2 \%$ & $-29,6 \%$ \\
\hline Tracking Error & - & $31,1 \%$ & $30,3 \%$ & $30,9 \%$ & $30,1 \%$ & $30,2 \%$ & $29,5 \%$ \\
\hline Information Ratio & - & $-0,79$ & $-1,04$ & $-0,70$ & $-0,99$ & $-0,83$ & $-1,00$ \\
\hline Sharpe Ratio (Rf =0\%) & 1,64 & 0,90 & 0,56 & 1,02 & 0,62 & 0,92 & 0,71 \\
\hline
\end{tabular}

\section{DESIRED TARGET RETURN}

The results obtained for investor profile Desired Target Return is presented in Figure 26 and its summary is presented in Table 37.

It is possible to see that the FDP model here had a highly negative effect, although portfolios with FDP model had a lower standard deviation, compared to its peers, their return were much lower and in some cases negative. Another point to highlight is how portfolios that used technical agent recommendation had a higher return compared to its peers without them. 
Figure 25 - Max Acceptable Risk against Benchmark for 2016.

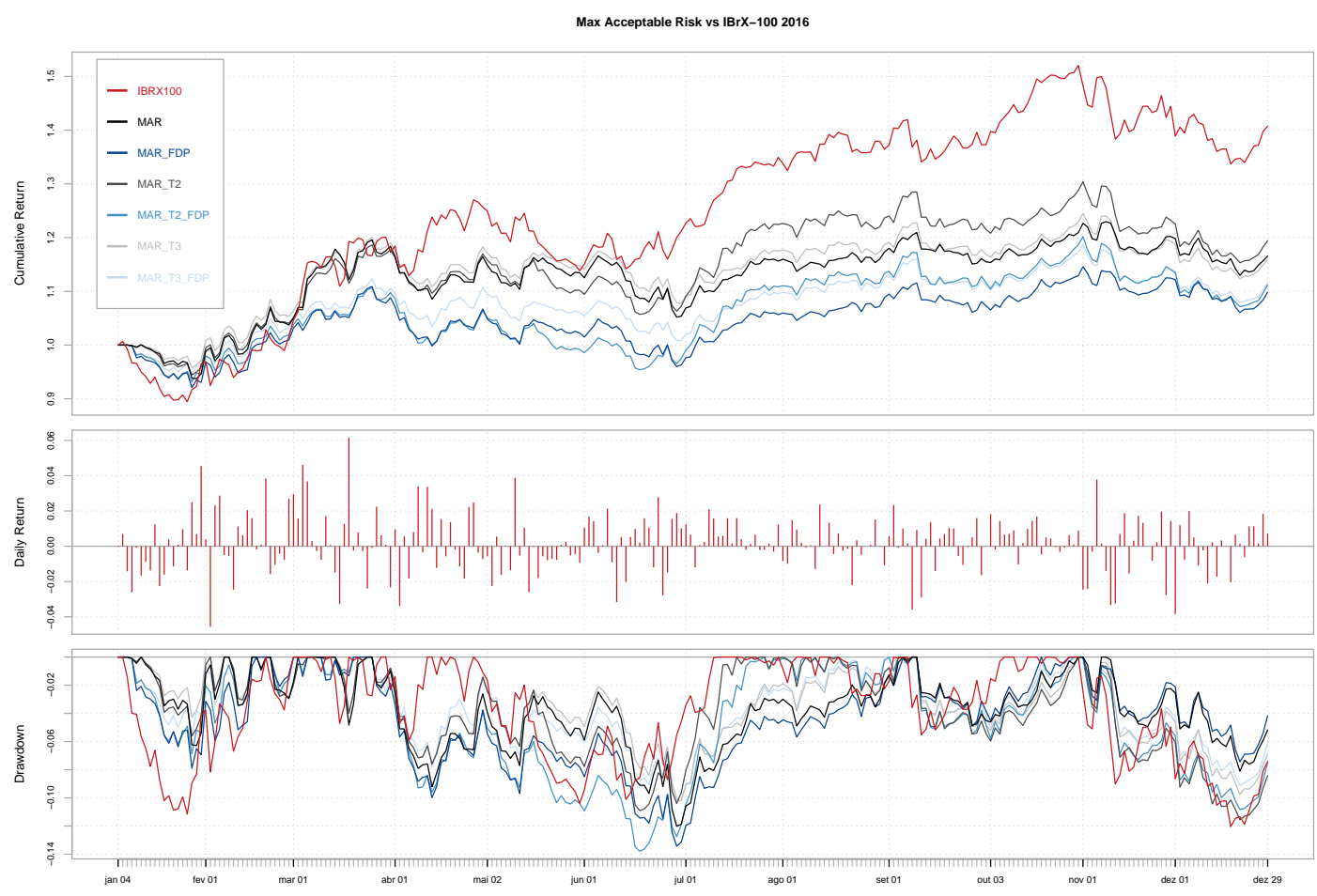

Table 37 - Desired Target Return - Portfolio Metrics for 2016

\begin{tabular}{l|c|c|c|c|c|c|c}
\cline { 2 - 8 } & IBrX 100 & DTR & DTR_FDP & DTR_T2 & DTR_T2_FDP & DTR_T3 & DTR_T3_FDP \\
\hline Experiment ID & - & 25 & 26 & 27 & 28 & 29 & 30 \\
\hline Number of Trades & - & 37 & 24 & 53 & 37 & 55 & 41 \\
\hline Annualized Return & $41,3 \%$ & $48,8 \%$ & $-5,8 \%$ & $73,2 \%$ & $19,7 \%$ & $39,4 \%$ & $-3,5 \%$ \\
\hline Annualized Std Dev & $25,2 \%$ & $27,2 \%$ & $23,6 \%$ & $26,5 \%$ & $23,7 \%$ & $23,6 \%$ & $21,1 \%$ \\
\hline Max Drawdown & $12,0 \%$ & $13,1 \%$ & $17,9 \%$ & $11,2 \%$ & $17,4 \%$ & $11,4 \%$ & $15,9 \%$ \\
\hline Annualized Alpha & - & $47,4 \%$ & $-9,0 \%$ & $69,5 \%$ & $23,3 \%$ & $36,2 \%$ & $-2,6 \%$ \\
\hline Active Premium & - & $7,5 \%$ & $-47,1 \%$ & $31,9 \%$ & $-21,6 \%$ & $-1,9 \%$ & $-44,8 \%$ \\
\hline Tracking Error & - & $34,9 \%$ & $31,4 \%$ & $33,9 \%$ & $34,7 \%$ & $32,0 \%$ & $32,2 \%$ \\
\hline Information Ratio & - & 0,22 & $-1,50$ & 0,94 & $-0,62$ & $-0,06$ & $-1,39$ \\
\hline Sharpe Ratio (Rf =0\%) & 1,64 & 1,80 & $-0,25$ & 2,77 & 0,83 & 1,67 & $-0,17$ \\
\hline
\end{tabular}

\section{LIMITED RISK-RETURN}

The results obtained for investor profile Limited Risk Return for 2016 is presented in Figure 27 and its summary is presented in Table 38.

All portfolios had a lower standard deviation than the benchmark, and those that used T3 recommendation had a lower standard deviation when compared to its peers.

\section{FREE RISK-RETURN}

The results obtained for investor profile Free Risk Return for 2016 is presented in Figure 28 and its summary is presented in Table 39. 
Figure 26 - Desired Target Return against Benchmark for 2016.

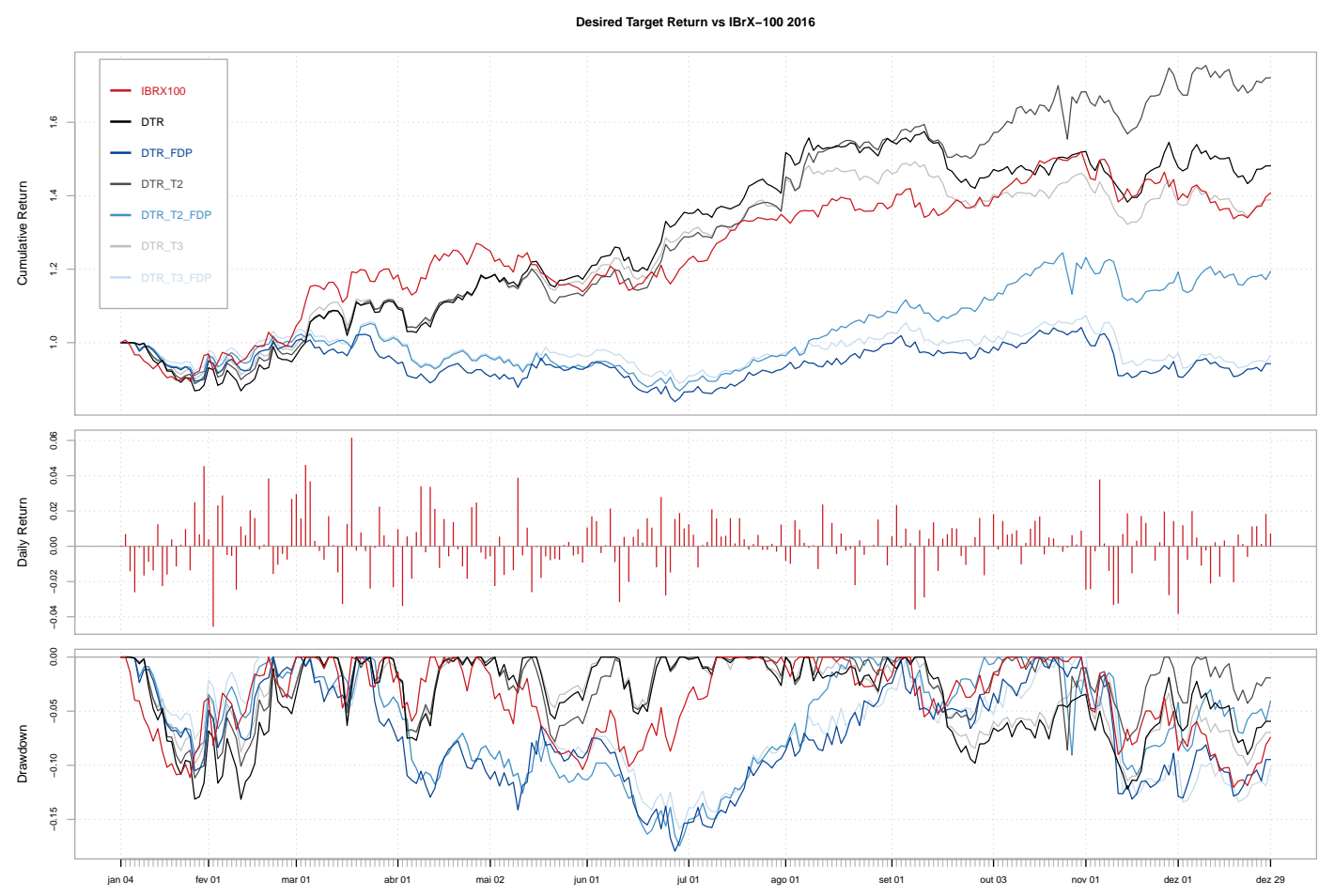

Table 38 - Limited Risk Return - Portfolio Metrics for 2016

\begin{tabular}{l|c|c|c|c|c|c|c}
\cline { 2 - 7 } & IBrX 100 & DTR & DTR_FDP & DTR_T2 & DTR_T2_FDP & DTR_T3 & DTR_T3_FDP \\
\hline Experiment ID & - & 43 & 44 & 45 & 46 & 47 & 48 \\
\hline Number of Trades & - & 108 & 107 & 120 & 116 & 129 & 122 \\
\hline Annualized Return & $41,3 \%$ & $16,8 \%$ & $9,9 \%$ & $21,8 \%$ & $11,3 \%$ & $15,1 \%$ & $10,8 \%$ \\
\hline Annualized Std Dev & $25,2 \%$ & $18,8 \%$ & $17,6 \%$ & $19,2 \%$ & $18,3 \%$ & $17,4 \%$ & $16,3 \%$ \\
\hline Max Drawdown & $12,0 \%$ & $12,0 \%$ & $13,4 \%$ & $11,4 \%$ & $13,8 \%$ & $10,2 \%$ & $10,2 \%$ \\
\hline Annualized Alpha & - & $18,2 \%$ & $10,7 \%$ & $22,2 \%$ & $11,2 \%$ & $15,9 \%$ & $11,1 \%$ \\
\hline Active Premium & - & $-24,5 \%$ & $-31,4 \%$ & $19,5 \%$ & $-30,0 \%$ & $-26,2 \%$ & $-30,5 \%$ \\
\hline Tracking Error & - & $31,1 \%$ & $30,3 \%$ & $30,9 \%$ & $20,1 \%$ & $30,2 \%$ & $29,4 \%$ \\
\hline Information Ratio & - & $-0,79$ & $-1,04$ & $-0,63$ & $-0,99$ & $-0,87$ & $-1,04$ \\
\hline Sharpe Ratio (Rf =0\%) & 1,64 & 0,90 & 0,56 & 1,14 & 0,62 & 0,87 & 0,66 \\
\hline
\end{tabular}

Here, the FDP model had a similar bad effect as with investor I2, and portfolios with technical recommendation had better results than its peers.

\section{C.3 BACKTEST FOR 2017}

In this section it is presented the portfolio comparison and results for each investor profile for the year of 2017. 
Figure 27 - Limited Risk Return against Benchmark for 2016.

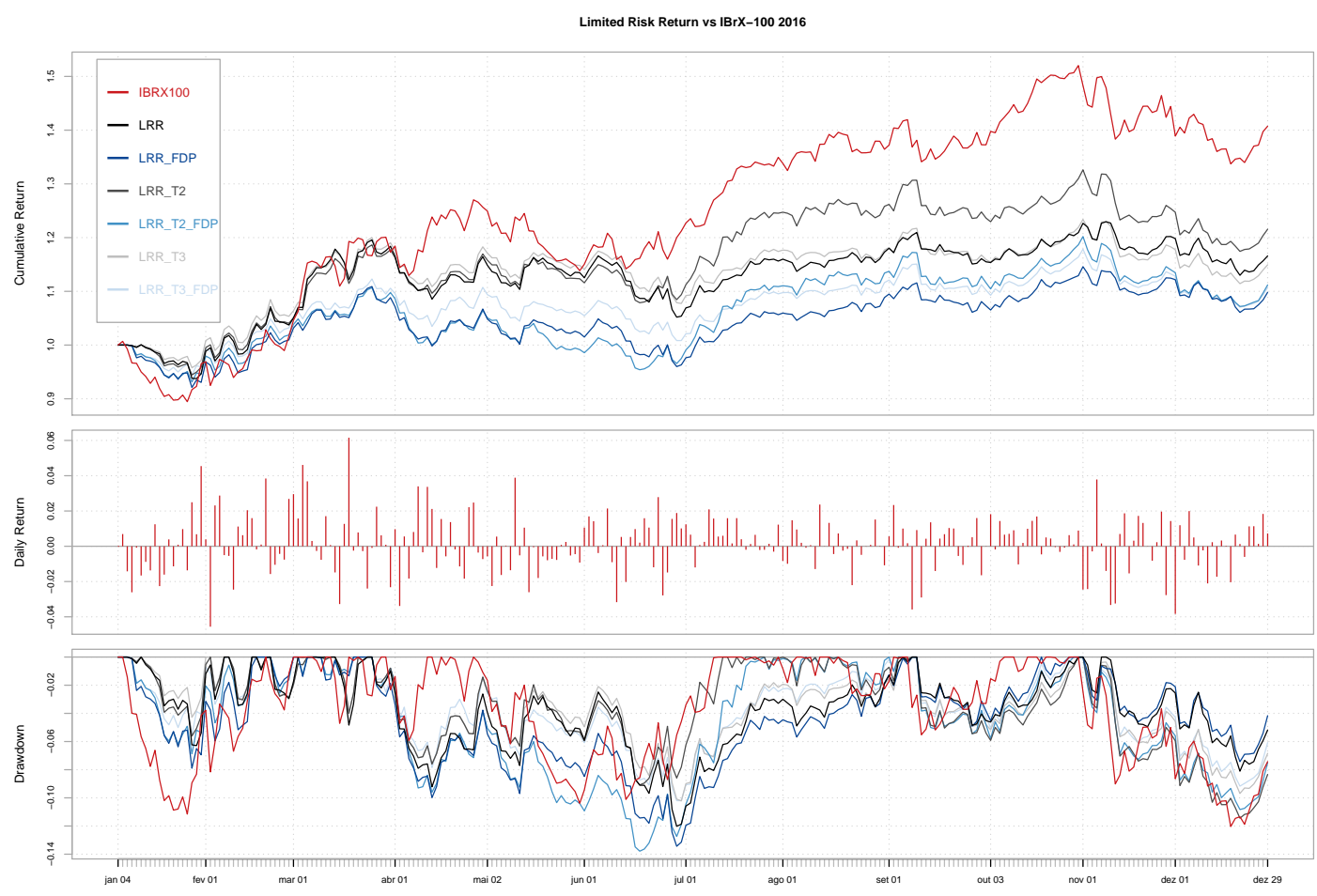

Table 39 - Free Risk Return - Portfolio Metrics for 2016

\begin{tabular}{l|c|c|c|c|c|c|c}
\cline { 2 - 8 } & IBrX 100 & FRR & FRR_FDP & FRR_T2 & FRR_T2_FDP & FRR_T3 & FRR_T3_FDP \\
\hline Experiment ID & - & 61 & 62 & 63 & 64 & 65 & 66 \\
\hline Number of Trades & - & 40 & 56 & 56 & 70 & 60 & 75 \\
\hline Annualized Return & $41,3 \%$ & $47,7 \%$ & $-2,9 \%$ & $72,5 \%$ & $2,2 \%$ & $38,3 \%$ & $-1,7 \%$ \\
\hline Annualized Std Dev & $25,2 \%$ & $27,1 \%$ & $22,5 \%$ & $26,0 \%$ & $22,7 \%$ & $24,2 \%$ & $20,5 \%$ \\
\hline Max Drawdown & $12,0 \%$ & $13,3 \%$ & $12,6 \%$ & $11,2 \%$ & $15,5 \%$ & $13,8 \%$ & $13,7 \%$ \\
\hline Annualized Alpha & - & $40,0 \%$ & $-6,0 \%$ & $63,5 \%$ & $2,3 \%$ & $30,8 \%$ & $-2,0 \%$ \\
\hline Active Premium & - & $6,3 \%$ & $-44,2 \%$ & $31,2 \%$ & $-39,1 \%$ & $-3,0 \%$ & $-43,0 \%$ \\
\hline Tracking Error & - & $32,7 \%$ & $30,7 \%$ & $31,9 \%$ & $32,7 \%$ & $30,5 \%$ & $31,3 \%$ \\
\hline Information Ratio & - & 0,19 & $-1,44$ & 0,98 & $-1,20$ & $-0,10$ & $-1,38$ \\
\hline Sharpe Ratio (Rf =0\%) & 1,64 & 1,76 & $-0,13$ & 2,79 & 0,10 & 1,58 & $-0,08$ \\
\hline
\end{tabular}

\section{MAX ACCEPTABLE RISK}

The results obtained for investor profile I1 for 2017 is presented in Figure 29 and its summary is presented in Table 40.

In 2017, all portfolios were better than the benchmark, in term of risk and sharpe ratio. $\mathrm{T} 2$ portfolios had a greater sharpe ratio and lower risk compared to its peers.

\section{DESIRED TARGET RETURN}

The results obtained for investor profile Desired Target Return is presented in Figure 30 and its summary is presented in Table 41. 
Figure 28 - Free Risk Return against Benchmark for 2016.

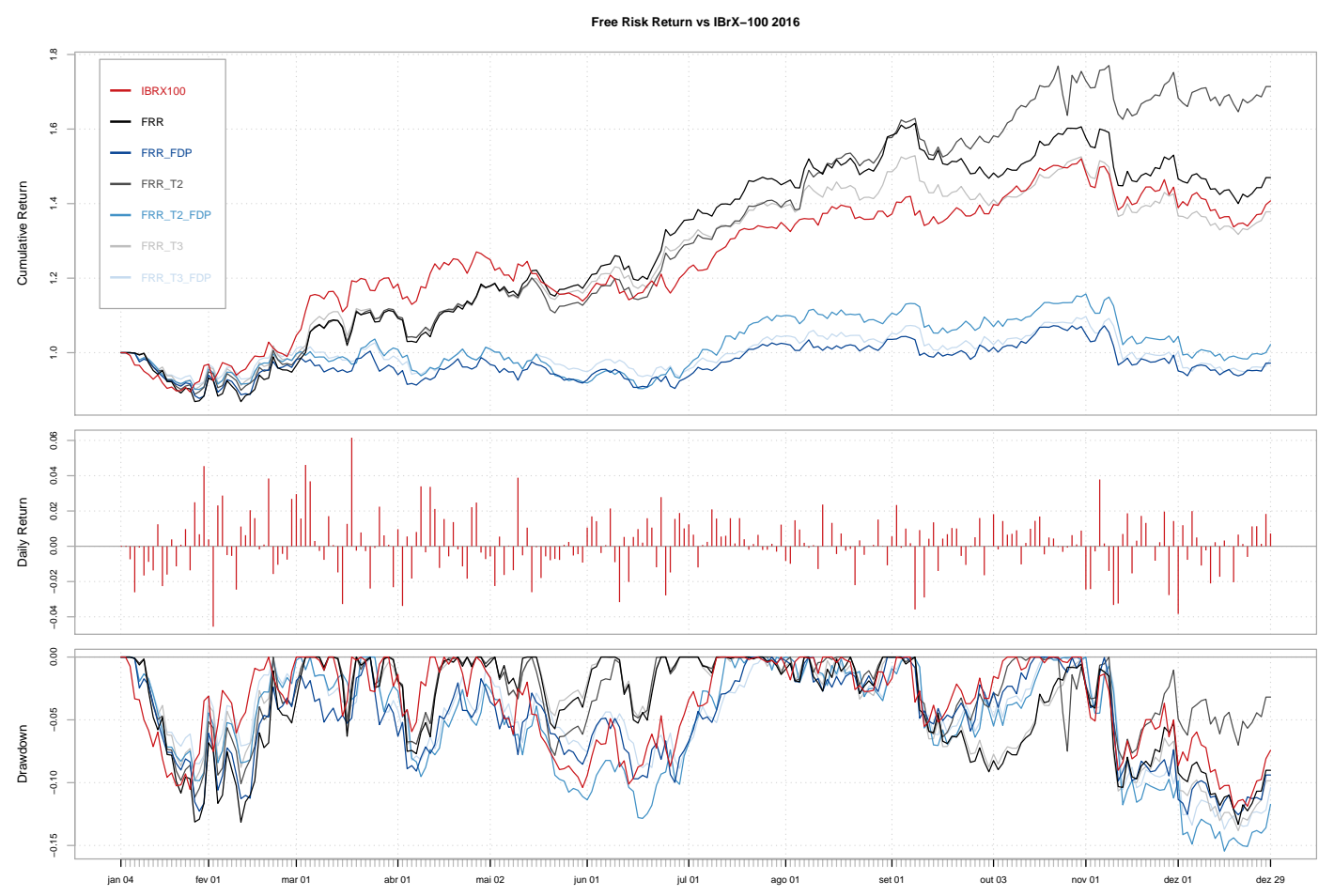

Table 40 - Max Acceptable Risk - Portfolio Metrics for 2017

\begin{tabular}{l|c|c|c|c|c|c|c}
\cline { 2 - 8 } & IBrX 100 & MAR & MAR_FDP & MAR_T2 & MAR_T2_FDP & MAR_T3 & MAR_T3_FDP \\
\hline Experiment ID & - & 13 & 14 & 15 & 16 & 17 & 18 \\
\hline Number of Trades & - & 104 & 80 & 117 & 90 & 123 & 95 \\
\hline Annualized Return & $29,6 \%$ & $43,7 \%$ & $44,2 \%$ & $53,2 \%$ & $53,5 \%$ & $37,3 \%$ & $37,9 \%$ \\
\hline Annualized Std Dev & $18,6 \%$ & $14,5 \%$ & $14,3 \%$ & $15,9 \%$ & $15,9 \%$ & $14,5 \%$ & $14,4 \%$ \\
\hline Max Drawdown & $11,2 \%$ & $9,7 \%$ & $8,6 \%$ & $7,7 \%$ & $6,9 \%$ & $9,6 \%$ & $8,6 \%$ \\
\hline Annualized Alpha & - & $25,9 \%$ & $26,5 \%$ & $31,6 \%$ & $31,8 \%$ & $18,9 \%$ & $19,4 \%$ \\
\hline Active Premium & - & $14,1 \%$ & $14,5 \%$ & $23,6 \%$ & $23,9 \%$ & $7,7 \%$ & $8,2 \%$ \\
\hline Tracking Error & - & $14,1 \%$ & $14,0 \%$ & $14,0 \%$ & $13,7 \%$ & $13,0 \%$ & $13,0 \%$ \\
\hline Information Ratio & - & 1,00 & 1,04 & 1,73 & 1,75 & 0,59 & 0,63 \\
\hline Sharpe Ratio (Rf =0\%) & 1,59 & 3,02 & 3,10 & 3,35 & 3,36 & 2,58 & 2,63 \\
\hline
\end{tabular}

All portfolios had a higher return than the benchmark, and also a higher sharpe ratio. When comparing portfolios, technical agent recommendations had a high impact on portfolios that used FDP model.

\section{LIMITED RISK-RETURN}

The results obtained for investor profile Limited Risk Return is presented in Figure 31 and its summary is presented in Table 42.

All portfolios were better than the benchmark in all metrics. The goal here was to minimize risk, and portfolios that used technical agent recommendation did a better work than those that did not used it, in terms of risk. 
Figure 29 - Max Acceptable Risk against Benchmark for 2017.

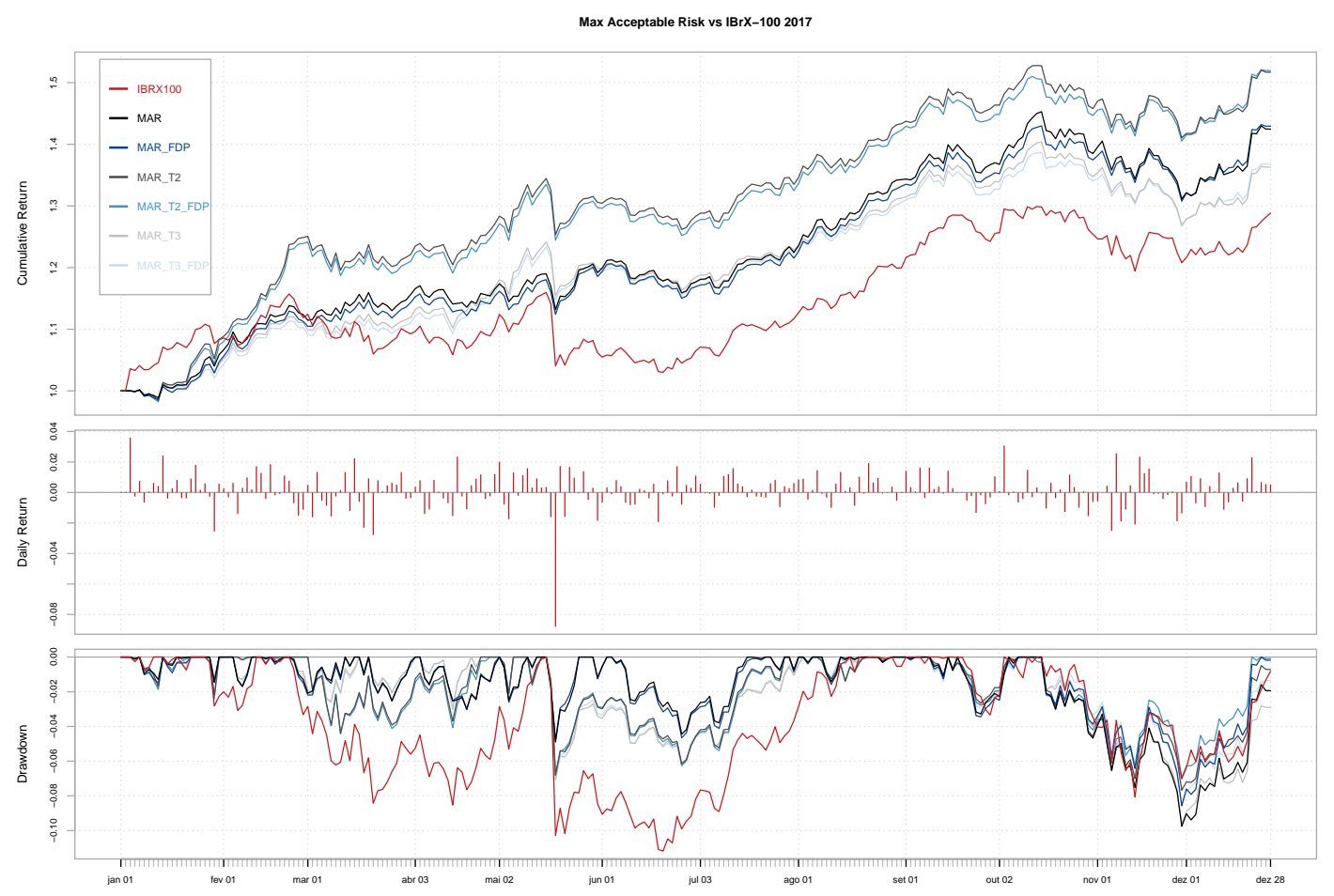

Table 41 - Desired Target Return - Portfolio Metrics for 2017.

\begin{tabular}{l|c|c|c|c|c|c|c}
\cline { 2 - 8 } & IBrX 100 & DTR & DTR_FDP & DTR_T2 & DTR_T2_FDP & DTR_T3 & DTR_T3_FDP \\
\hline Experiment ID & - & 31 & 32 & 33 & 34 & 35 & 36 \\
\hline Number of Trades & - & 54 & 58 & 74 & 69 & 74 & 73 \\
\hline Annualized Return & $29,6 \%$ & $53,8 \%$ & $41,4 \%$ & $53,3 \%$ & $50,8 \%$ & $54,3 \%$ & $52,2 \%$ \\
\hline Annualized Std Dev & $18,6 \%$ & $21,8 \%$ & $21,5 \%$ & $20,7 \%$ & $20,9 \%$ & $20,6 \%$ & $20,8 \%$ \\
\hline Max Drawdown & $11,2 \%$ & $12,9 \%$ & $8,8 \%$ & $11,7 \%$ & $10,1 \%$ & $11,6 \%$ & $9,9 \%$ \\
\hline Annualized Alpha & - & $25,4 \%$ & $19,0 \%$ & $24,3 \%$ & $25,1 \%$ & $25,6 \%$ & $25,9 \%$ \\
\hline Active Premium & - & $24,2 \%$ & $11,7 \%$ & $23,6 \%$ & $21,1 \%$ & $24,7 \%$ & $22,6 \%$ \\
\hline Tracking Error & - & $15,9 \%$ & $17,9 \%$ & $14,1 \%$ & $16,2 \%$ & $14,3 \%$ & $15,8 \%$ \\
\hline Information Ratio & - & 1,52 & 0,65 & 1,68 & 1,31 & 1,73 & 1,43 \\
\hline Sharpe Ratio (Rf =0\%) & 1,59 & 2,47 & 1,92 & 2,57 & 2,43 & 2,63 & 2,51 \\
\hline
\end{tabular}

\section{FREE RISK-RETURN}

The results obtained for investor profile I4 is presented in Figure 32 and its summary is presented in Table 43.

Portfolios that used FDP model in this year had a worse sharpe ratio than the benchmark. Looking at the number of trades, it is possible to see that a portfolio was formed with bad fair values, so positions were carried out for a long period. Maybe with a stop loss this kind of situation could have been prevented. 
Figure 30 - Desired Target Return against Benchmark for 2017.

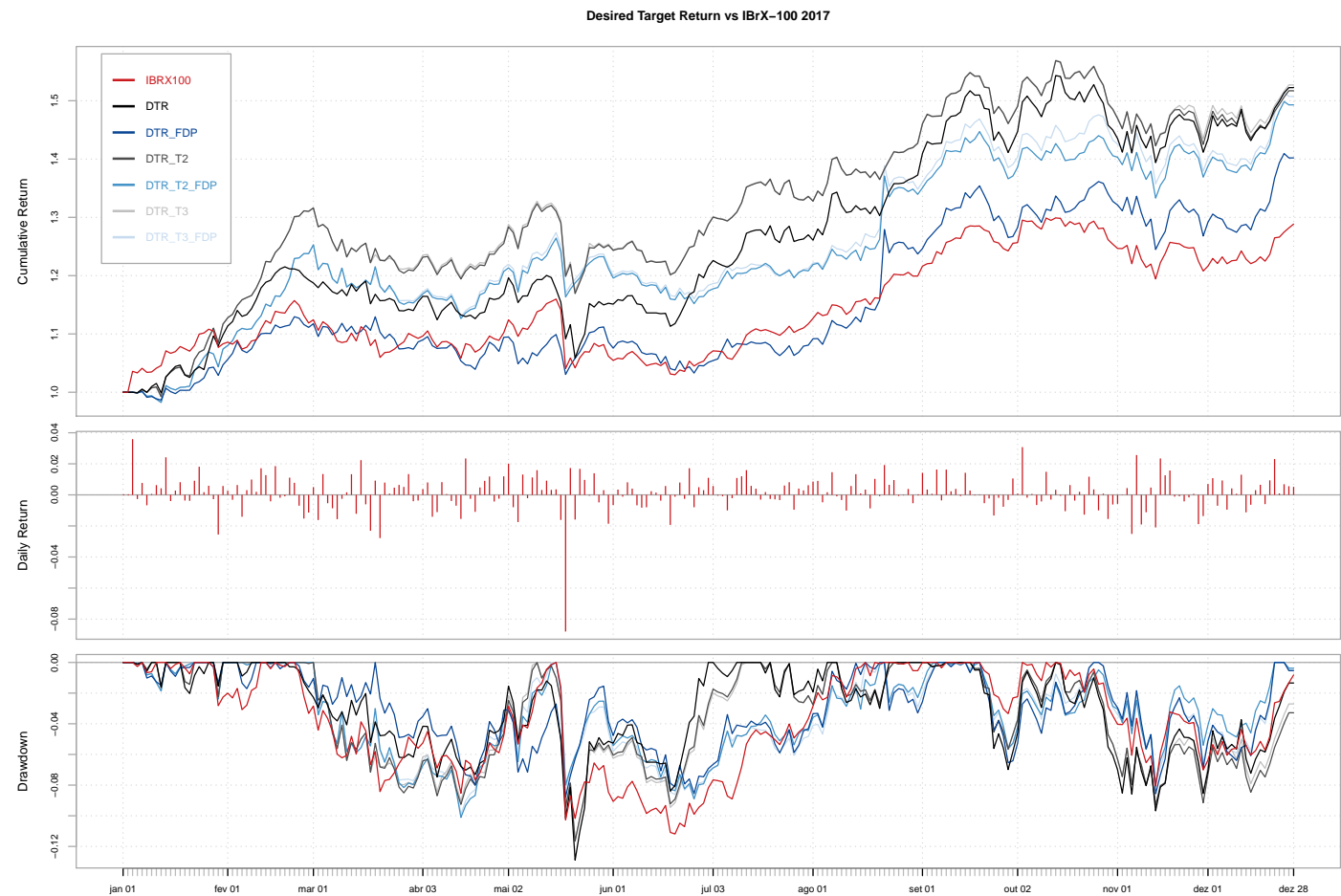

Table 42 - Limited Risk Return - Portfolio Metrics for 2017

\begin{tabular}{l|c|c|c|c|c|c|c}
\cline { 2 - 8 } & IBrX 100 & DTR & DTR_FDP & DTR_T2 & DTR_T2_FDP & DTR_T3 & DTR_T3_FDP \\
\hline Experiment ID & - & 49 & 50 & 51 & 52 & 53 & 54 \\
\hline Number of Trades & - & 104 & 80 & 125 & 90 & 121 & 97 \\
\hline Annualized Return & $29,6 \%$ & $43,4 \%$ & $44,2 \%$ & $32,9 \%$ & $38,5 \%$ & $32,8 \%$ & $33,3 \%$ \\
\hline Annualized Std Dev & $18,6 \%$ & $14,5 \%$ & $14,3 \%$ & $13,6 \%$ & $13,8 \%$ & $13,8 \%$ & $13,9 \%$ \\
\hline Max Drawdown & $11,2 \%$ & $9,7 \%$ & $8,6 \%$ & $10,4 \%$ & $7,0 \%$ & $9,9 \%$ & $9,1 \%$ \\
\hline Annualized Alpha & - & $25,9 \%$ & $26,5 \%$ & $16,5 \%$ & $21,0 \%$ & $15,9 \%$ & $16,4 \%$ \\
\hline Active Premium & - & $14,1 \%$ & $14,5 \%$ & $3,3 \%$ & $8,8 \%$ & $3,1 \%$ & $3,7 \%$ \\
\hline Tracking Error & - & $14,1 \%$ & $14,0 \%$ & $13,3 \%$ & $13,2 \%$ & $13,2 \%$ & $13,2 \%$ \\
\hline Information Ratio & - & 1,00 & 1,04 & 0,25 & 0,67 & 0,24 & 0,28 \\
\hline Sharpe Ratio $($ Rf $=0 \%)$ & 1,59 & 3,02 & 3,10 & 2,43 & 2,79 & 2,37 & 2,41 \\
\hline
\end{tabular}

Table 43 - Free Risk Return - Portfolio Metrics for 2017

\begin{tabular}{l|c|c|c|c|c|c|c}
\cline { 2 - 8 } & IBrX 100 & FRR & FRR_FDP & FRR_T2 & FRR_T2_FDP & FRR_T3 & FRR_T3_FDP \\
\hline Experiment ID & - & 67 & 68 & 69 & 70 & 71 & 72 \\
\hline Number of Trades & - & 73 & 16 & 81 & 29 & 91 & 39 \\
\hline Annualized Return & $29,6 \%$ & $42,8 \%$ & $23,0 \%$ & $50,9 \%$ & $32,6 \%$ & $35,6 \%$ & $18,8 \%$ \\
\hline Annualized Std Dev & $18,6 \%$ & $20,3 \%$ & $22,4 \%$ & $19,8 \%$ & $21,7 \%$ & $18,5 \%$ & $20,0 \%$ \\
\hline Max Drawdown & $11,2 \%$ & $12,1 \%$ & $20,6 \%$ & $11,9 \%$ & $18,5 \%$ & $11,6 \%$ & $15,9 \%$ \\
\hline Annualized Alpha & - & $14,7 \%$ & $-4,2 \%$ & $21,6 \%$ & $4,0 \%$ & $10,6 \%$ & $-5,6 \%$ \\
\hline Active Premium & - & $13,2 \%$ & $-6,6 \%$ & $21,3 \%$ & $3,0 \%$ & $6,0 \%$ & $-10,9 \%$ \\
\hline Tracking Error & - & $12,6 \%$ & $12,7 \%$ & $12,2 \%$ & $12,3 \%$ & $11,6 \%$ & $11,0 \%$ \\
\hline Information Ratio & - & 1,05 & $-0,52$ & 1,74 & 0,24 & 0,52 & $-0,99$ \\
\hline Sharpe Ratio (Rf=0\%) & 1,59 & 2,11 & 1,03 & 2,57 & 1,50 & 1,92 & 0,94 \\
\hline
\end{tabular}


Figure 31 - Limited Risk Return against Benchmark for 2017.

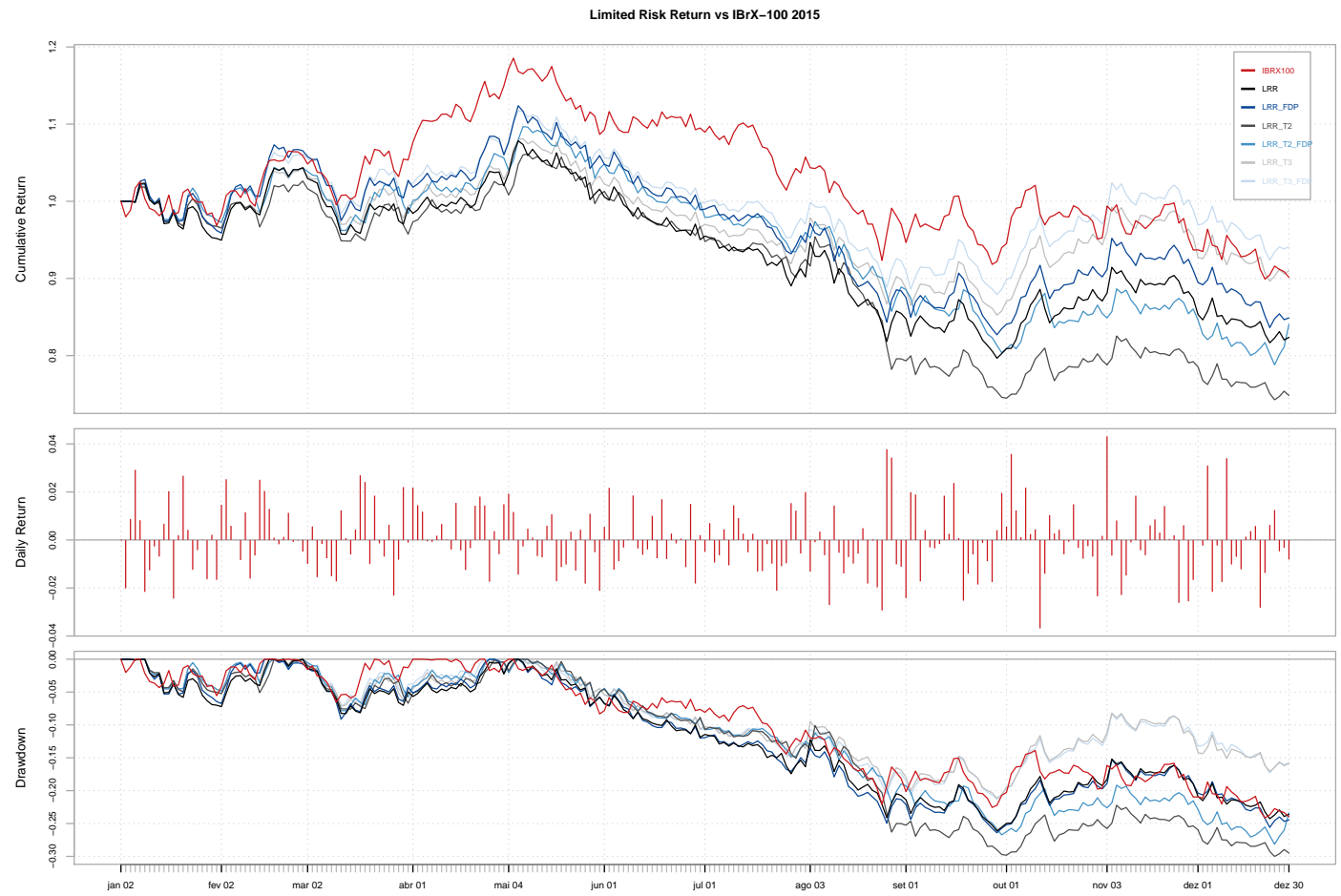

Figure 32 - Free Risk Return against Benchmark for 2017.

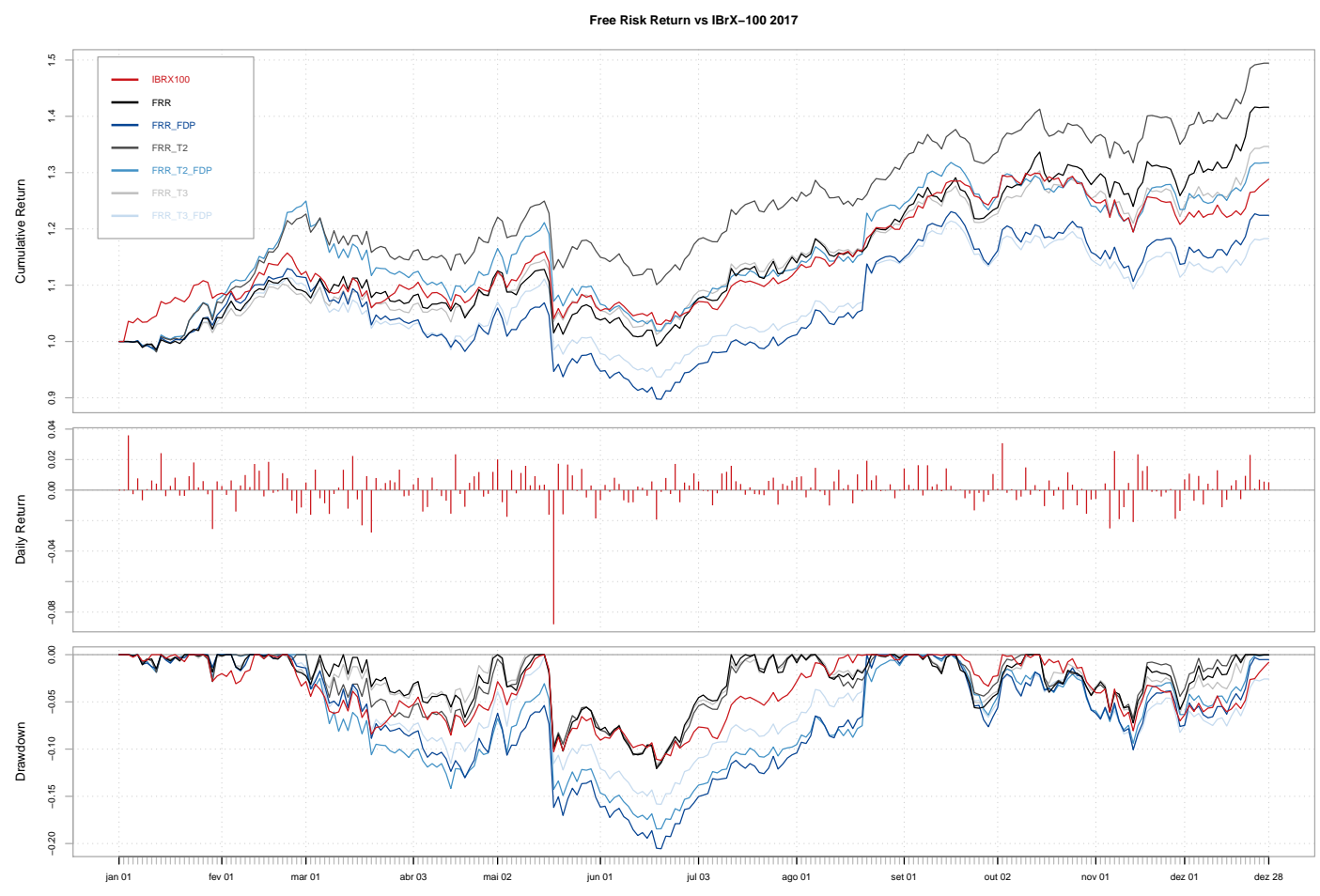




\section{HYPOTHESES TESTING RESULTS}

In this section, some additional information about hypotheses testing results are presented.

\section{D.1 FINANCIAL DISTRESS PREDICTION HYPOTHESIS}

In Table 44 it is presented all pairs, its standard deviation, maximum drawdown and their differences. It is possible to see that portfolios that used FDP model had an average standard deviation lower than those that did not use it (NFPD). For maximum drawdown metric, the average maximum drawdown of portfolios that used FDP model was higher than those that did not use it (NFDP), so H0 will clearly not be rejected.

Table 44 - Standard deviation and maximum drawdown results for hypotheses testing of FDP model.

\begin{tabular}{|c|c|c|c|c|c|c|}
\hline \multicolumn{4}{|c|}{ Standard Deviation } & \multicolumn{3}{|c|}{ Max Drawdown } \\
\hline FDP & NFDP & Difference & Pair & FDP & NFDP & Difference \\
\hline 0,20626 & 0,20598 & 0,00028 & $(1,2)$ & 0,26415 & 0,26127 & 0,00288 \\
\hline 0,19607 & 0,19259 & 0,00348 & $(3,4)$ & 0,28153 & 0,30007 & $-0,01854$ \\
\hline 0,18612 & 0,21495 & $-0,02883$ & $(5,6)$ & 0,21313 & 0,25321 & $-0,04009$ \\
\hline 0,17597 & 0,18751 & $-0,01154$ & $(7,8)$ & 0,13439 & 0,12022 & 0,01417 \\
\hline 0,18274 & 0,19311 & $-0,01038$ & $(9,10)$ & 0,13787 & 0,11557 & 0,02230 \\
\hline 0,16411 & 0,17565 & $-0,01153$ & $(11,12)$ & 0,10200 & 0,10218 & $-0,00018$ \\
\hline 0,14270 & 0,14476 & $-0,00206$ & $(13,14)$ & 0,08553 & 0,09748 & $-0,01195$ \\
\hline 0,15915 & 0,15909 & 0,00006 & $(15,16)$ & 0,06941 & 0,07677 & $-0,00737$ \\
\hline 0,14370 & 0,14497 & $-0,00128$ & $(17,18)$ & 0,08648 & 0,09600 & $-0,00952$ \\
\hline 0,23149 & 0,21148 & 0,02002 & $(19,20)$ & 0,25672 & 0,22397 & 0,03275 \\
\hline 0,21605 & 0,20109 & 0,01497 & $(21,22)$ & 0,28478 & 0,25361 & 0,03117 \\
\hline 0,20675 & 0,19322 & 0,01353 & $(23,24)$ & 0,21269 & 0,18789 & 0,02479 \\
\hline 0,23621 & 0,27207 & $-0,03586$ & $(25,26)$ & 0,17936 & 0,13147 & 0,04789 \\
\hline 0,23710 & 0,26480 & $-0,02770$ & $(27,28)$ & 0,17449 & 0,11173 & 0,06277 \\
\hline 0,21099 & 0,23606 & $-0,02507$ & $(29,30)$ & 0,15871 & 0,11429 & 0,04442 \\
\hline 0,21495 & 0,21810 & $-0,00315$ & $(31,32)$ & 0,08773 & 0,12890 & $-0,04117$ \\
\hline 0,20883 & 0,20723 & 0,00159 & $(33,34)$ & 0,10108 & 0,11654 & $-0,01545$ \\
\hline 0,20805 & 0,20616 & 0,00189 & $(35,36)$ & 0,09897 & 0,11617 & $-0,01720$ \\
\hline 0,20626 & 0,20598 & 0,00028 & $(37,38)$ & 0,26415 & 0,26127 & 0,00288 \\
\hline 0,19607 & 0,19259 & 0,00348 & $(39,40)$ & 0,28153 & 0,30007 & $-0,01854$ \\
\hline 0,18612 & 0,18976 & $-0,00364$ & $(41,42)$ & 0,21313 & 0,21150 & 0,00163 \\
\hline 0,17597 & 0,18751 & $-0,01154$ & $(43,44)$ & 0,13439 & 0,12022 & 0,01417 \\
\hline 0,18274 & 0,19214 & $-0,00940$ & $(45,46)$ & 0,13787 & 0,11445 & 0,02342 \\
\hline 0,16308 & 0,17404 & $-0,01096$ & $(47,48)$ & 0,10200 & 0,10218 & $-0,00018$ \\
\hline 0,14270 & 0,14476 & $-0,00206$ & $(49,50)$ & 0,08553 & 0,09748 & $-0,01195$ \\
\hline 0,13777 & 0,13551 & 0,00226 & $(51,52)$ & 0,07004 & 0,10426 & $-0,03423$ \\
\hline 0,13857 & 0,13844 & 0,00012 & $(53,54)$ & 0,09060 & 0,09908 & $-0,00848$ \\
\hline 0,19652 & 0,19468 & 0,00184 & $(55,56)$ & 0,14286 & 0,14332 & $-0,00046$ \\
\hline 0,19269 & 0,19150 & 0,00119 & $(57,58)$ & 0,18152 & 0,18202 & $-0,00050$ \\
\hline 0,18195 & 0,18018 & 0,00177 & $(59,60)$ & 0,11667 & 0,11692 & $-0,00025$ \\
\hline 0,22497 & 0,27133 & $-0,04637$ & $(61,62)$ & 0,12553 & 0,13325 & $-0,00772$ \\
\hline 0,22742 & 0,26021 & $-0,03279$ & $(63,64)$ & 0,15456 & 0,11173 & 0,04283 \\
\hline 0,20547 & 0,24211 & $-0,03664$ & $(65,66)$ & 0,13714 & 0,13820 & $-0,00106$ \\
\hline 0,22425 & 0,20326 & 0,02100 & $(67,68)$ & 0,20557 & 0,12070 & 0,08487 \\
\hline 0,21736 & 0,19818 & 0,01917 & $(69,70)$ & 0,18450 & 0,11881 & 0,06569 \\
\hline 0,19994 & 0,18534 & 0,01460 & $(71,72)$ & 0,15851 & 0,11638 & 0,04213 \\
\hline Average & 0,19242 & 0,19768 & $-0,00526$ & 0,15875 & 0,14998 & 0,00878 \\
\hline
\end{tabular}




\section{D.2 TECHNICAL AGENT HYPOTHESES}

In Table 45a it is presented the standard deviation and maximum drawdown for portfolios that used two technical agent's recommendation compared to those that did not use any technical agent's recommendations. In Table $45 \mathrm{~b}$ it is presented the same metric for those portfolios that received three technical recommendation. The performance metrics are presented in Table 46a for $\mathrm{T} 2$ and in Table $46 \mathrm{~b}$ for $\mathrm{T} 3$.

Table 45 - Standard deviation and maximum drawdown results for hypotheses testing.

(a) T2 technical agent recommendations.

\begin{tabular}{ccc|c|ccc}
\multicolumn{4}{c}{ Standard Deviation } \\
\hline T2 & NT & Difference & Pair & T2 & NT & Difference \\
\hline 0,1926 & 0,2060 & $-0,0134$ & $(1,3)$ & 0,3001 & 0,2613 & 0,0388 \\
0,1961 & 0,2063 & $-0,0102$ & $(2,4)$ & 0,2815 & 0,2641 & 0,0174 \\
0,1931 & 0,1875 & 0,0056 & $(7,9)$ & 0,1156 & 0,1202 & $-0,0046$ \\
0,1827 & 0,1760 & 0,0068 & $(8,10)$ & 0,1379 & 0,1344 & 0,0035 \\
0,1591 & 0,1448 & 0,0143 & $(13,15)$ & 0,0768 & 0,0975 & $-0,0207$ \\
0,1592 & 0,1427 & 0,0165 & $(14,16)$ & 0,0694 & 0,0855 & $-0,0161$ \\
0,1926 & 0,2060 & $-0,0134$ & $(37,39)$ & 0,3001 & 0,2613 & 0,0388 \\
0,1961 & 0,2063 & $-0,0102$ & $(38,40)$ & 0,2815 & 0,2641 & 0,0174 \\
0,1921 & 0,1875 & 0,0046 & $(43,45)$ & 0,1145 & 0,1202 & $-0,0058$ \\
0,1827 & 0,1760 & 0,0068 & $(44,46)$ & 0,1379 & 0,1344 & 0,0035 \\
0,1355 & 0,1448 & $-0,0093$ & $(49,51)$ & 0,1043 & 0,0975 & 0,0068 \\
0,1378 & 0,1427 & $-0,0049$ & $(50,52)$ & 0,0700 & 0,0855 & $-0,0155$ \\
\hline 0,1766 & 0,1772 & $-0,0006$ & Average & 0,1658 & 0,1605 & 0,0053 \\
\hline
\end{tabular}

(b) T3 technical agent recommendations.

\begin{tabular}{ccc|c|ccc}
\multicolumn{4}{c}{ Standard Deviation } \\
\hline T3 & NT & Difference & Pair & T3 & NT & Difference \\
\hline 0,2149 & 0,2060 & 0,0090 & $(1,5)$ & 0,2532 & 0,2613 & $-0,0081$ \\
0,1861 & 0,2063 & $-0,0201$ & $(2,6)$ & 0,2131 & 0,2641 & $-0,0510$ \\
0,1756 & 0,1875 & $-0,0119$ & $(7,11)$ & 0,1022 & 0,1202 & $-0,0180$ \\
0,1641 & 0,1760 & $-0,0119$ & $(8,12)$ & 0,1020 & 0,1344 & $-0,0324$ \\
0,1450 & 0,1448 & 0,0002 & $(13,17)$ & 0,0960 & 0,0975 & $-0,0015$ \\
0,1437 & 0,1427 & 0,0010 & $(14,18)$ & 0,0865 & 0,0855 & 0,0010 \\
0,1898 & 0,2060 & $-0,0162$ & $(37,41)$ & 0,2115 & 0,2613 & $-0,0498$ \\
0,1861 & 0,2063 & $-0,0201$ & $(38,42)$ & 0,2131 & 0,2641 & $-0,0510$ \\
0,1740 & 0,1875 & $-0,0135$ & $(43,47)$ & 0,1022 & 0,1202 & $-0,0180$ \\
0,1631 & 0,1760 & $-0,0129$ & $(44,48)$ & 0,1020 & 0,1344 & $-0,0324$ \\
0,1384 & 0,1448 & $-0,0063$ & $(49,53)$ & 0,0991 & 0,0975 & 0,0016 \\
0,1386 & 0,1427 & $-0,0041$ & $(50,54)$ & 0,0906 & 0,0855 & 0,0051 \\
\hline 0,1683 & 0,1772 & $-0,0089$ & Average & 0,1393 & 0,1605 & $-0,0212$ \\
\hline
\end{tabular}

Table 46 - Return and sharpe ratio results for hypotheses testing.

(a) T2 technical agent recommendations.

\begin{tabular}{ccc|c|ccc}
\multicolumn{3}{c}{ Return } & \multicolumn{3}{c}{ Sharpe Ratio } \\
\hline T2 & NT & Difference & Pair & T2 & NT & Difference \\
\hline$-0,0973$ & $-0,0677$ & $-0,0296$ & $(19,21)$ & $-0,4839$ & $-0,3201$ & $-0,1637$ \\
$-0,1264$ & $-0,1036$ & $-0,0228$ & $(20,22)$ & $-0,5850$ & $-0,4477$ & $-0,1373$ \\
0,7322 & 0,4884 & 0,2438 & $(25,27)$ & 2,7652 & 1,7953 & 0,9699 \\
0,1967 & $-0,0580$ & 0,2547 & $(26,28)$ & 0,8296 & $-0,2457$ & 1,0753 \\
0,5326 & 0,5382 & $-0,0055$ & $(31,33)$ & 2,5701 & 2,4675 & 0,1026 \\
0,5075 & 0,4135 & 0,0940 & $(32,34)$ & 2,4305 & 1,9237 & 0,5067 \\
0,0089 & 0,0757 & $-0,0668$ & $(55,57)$ & 0,0465 & 0,3890 & $-0,3425$ \\
0,0168 & 0,0861 & $-0,0693$ & $(56,58)$ & 0,0873 & 0,4383 & $-0,3510$ \\
0,7252 & 0,4766 & 0,2486 & $(61,63)$ & 2,7870 & 1,7563 & 1,0306 \\
0,0221 & $-0,0285$ & 0,0507 & $(62,64)$ & 0,0972 & $-0,1269$ & 0,2241 \\
0,5092 & 0,4282 & 0,0810 & $(67,69)$ & 2,5693 & 2,1065 & 0,4628 \\
0,3263 & 0,2302 & 0,0961 & $(68,70)$ & 1,5013 & 1,0267 & 0,4747 \\
\hline 0,2795 & 0,2066 & 0,0729 & Average & 1,2179 & 0,8969 & 0,3210 \\
\hline
\end{tabular}

(b) T3 technical agent recommendations.

\begin{tabular}{ccc|c|ccc}
\multicolumn{3}{c}{ Return } & \multicolumn{3}{c}{ Sharpe Ratio } \\
\hline T3 & NT & Difference & Pair & T3 & NT & Difference \\
\hline 0,0122 & $-0,0677$ & 0,0799 & $(19,23)$ & 0,0633 & $-0,3201$ & 0,3835 \\
$-0,0181$ & $-0,1036$ & 0,0856 & $(20,24)$ & $-0,0874$ & $-0,4477$ & 0,3602 \\
0,3940 & 0,4884 & $-0,0944$ & $(25,29)$ & 1,6692 & 1,7953 & $-0,1260$ \\
$-0,0351$ & $-0,0580$ & 0,0229 & $(26,30)$ & $-0,1666$ & $-0,2457$ & 0,0791 \\
0,5429 & 0,5382 & 0,0048 & $(31,35)$ & 2,6336 & 2,4675 & 0,1661 \\
0,5225 & 0,4135 & 0,1090 & $(32,36)$ & 2,5113 & 1,9237 & 0,5876 \\
0,1387 & 0,0757 & 0,0630 & $(55,59)$ & 0,7698 & 0,3890 & 0,3808 \\
0,1470 & 0,0861 & 0,0609 & $(56,60)$ & 0,8081 & 0,4383 & 0,3698 \\
0,3832 & 0,4766 & $-0,0933$ & $(61,65)$ & 1,5829 & 1,7563 & $-0,1735$ \\
$-0,0173$ & $-0,0285$ & 0,0112 & $(62,66)$ & $-0,0842$ & $-0,1269$ & 0,0427 \\
0,3564 & 0,4282 & $-0,0718$ & $(67,71)$ & 1,9228 & 2,1065 & $-0,1837$ \\
0,1876 & 0,2302 & $-0,0427$ & $(68,72)$ & 0,9382 & 1,0267 & $-0,0885$ \\
\hline 0,2178 & 0,2066 & 0,0113 & Average & 1,0468 & 0,8969 & 0,1498 \\
\hline
\end{tabular}




\section{BIBLIOGRAPHY}

ABELLÁN, J.; MANTAS, C. J. Improving experimental studies about ensembles of classifiers for bankruptcy prediction and credit scoring. Expert Systems with Applications, Elsevier, v. 41, n. 8 , p. 3825-3830, 2014. 24

ALAKA, H. A. et al. Systematic review of bankruptcy prediction models: Towards a framework for tool selection. Expert Systems with Applications, Elsevier, v. 94, p. 164-184, 2018. 24

ALEXANDER, C. Market risk analysis volume I: Quantitative methods in finance. Chichester,England Hoboken,NJ: John Wiley \& Sons, 2008. ISBN 978-0-470-99800-7. 18, 20

ARAÚJO, C. H. D.; CASTRO, P. A. L. D. Towards automated trading based on fundamentalist and technical data. In: SPRINGER. Brazilian Symposium on Artificial Intelligence. [S.1.], 2010. p. $112-121.39,40,41,42$

ATSALAKIS, G. S.; VALAVANIS, K. P. Surveying stock market forecasting techniques-part ii: Soft computing methods. Expert Systems with Applications, Elsevier, v. 36, n. 3, p. 5932-5941, 2009. 33

BARBOSA, R.; BELO, O. Multi-agent forex trading system. Agent and Multi-agent Technology for Internet and Enterprise Systems, Springer, p. 91-118, 2010. 42

BASU, S. Investment performance of common stocks in relation to their price-earnings ratios: A test of the efficient market hypothesis. The journal of Finance, Wiley Online Library, v. 32, n. 3, p. 663-682, 1977. 18

BELLIFEMINE, F.; POGGI, A.; RIMASSA, G. Developing multi-agent systems with a fipa-compliant agent framework. Software-Practice and experience, London, New York, Wiley Interscience [etc.], v. 31, n. 2, p. 103-128, 2001. 46

BELLIFEMINE, F. L.; CAIRE, G.; GREENWOOD, D. Developing multi-agent systems with JADE. [S.1.]: John Wiley \& Sons, 2007. v. 7. 12, 31, 47

BETTMAN, J. L.; SAULT, S. J.; SCHULTZ, E. L. Fundamental and technical analysis: substitutes or complements? Accounting \& Finance, Wiley Online Library, v. 49, n. 1, p. 21-36, 2009. 13

BISHOP, C. M. Pattern recognition and machine learning. [S.1.]: springer, 2006. 57

BRASIL, L. d. F. Nova lei de falências : estudo comparativo com o Dec-Lei 7.661/1945 e legislação correlata : Lei n. 11.101, de 9 de fevereiro de 2005, lei complementar 118, de 9 de fevereiro de 2005. São Paulo: Revista dos Tribunais, 2005. 24

CASTRO, P. A. L. D.; SICHMAN, J. S. Agex: A financial market simulation tool for software agents. In: SPRINGER. International Conference on Enterprise Information Systems. [S.1.], 2009. p. 704-715. 47

CASTRO, P. A. L. de. Uma Arquitetura para Administração Automatizada de Ativos Baseada em Agentes Competitivos. Thesis (PhD) — Universidade de São Paulo, 2009. 29, 39, 42, 43, 45 
CASTRO, P. A. L. de; SICHMAN, J. S. Coast: An architecture based on negotiation among competitive agents for automated asset management. In: International Conference on Artificial Intelligence - ICAI'11. [S.1.: s.n.], 2011. p. 808-814. 39

CAVALCANTE, R. C. et al. Computational intelligence and financial markets: A survey and future directions. Expert Systems with Applications, Elsevier, v. 55, p. 194-211, 2016. 39

CVM, C. d. V. M. Mercado de valores mobiliários brasileiro. 1. ed. [S.1.]: Comissão de valores mobiliários, 2013. ISBN 978-85-67896-00-7. 16

DAMODARAN, A. Damodaran on Valuation: Security Analysis for Investment and Corporate Finance-2/E. [S.1.: s.n.], 2006. 14, 22, 23

DAMODARAN, A. Avaliação de investimentos ferramentas e tecnicas para a determinação do valor de qualquer ativo. Rio de Janeiro: Qualitymark, 2010. ISBN 978-85-7303-902-3. 13, 22, 23,48

DECKER, K.; SYCARA, K.; ZENG, D. Designing a multi-agent portfolio management system. In: AAI PRESS MENLO PARK, CA. Proceedings of the AAAI Workshop on Internet Information Systems. [S.1.], 1996. v. 60. 42

DIMSON, E. Stock market anomalies. Cambridge Cambridgeshire New York: Cambridge University Press, 1988. ISBN 0-521-34104-3. 17, 18

EDWARDS, R. D.; MAGEE, J.; BASSETTI, W. Technical analysis of stock trends. [S.1.]: CRC Press, 2012. 21, 24

ELTON, E. Modern portfolio theory and investment analysis. Hoboken, NJ: Wiley, 2014. ISBN 978-1-118-46994-1. 12

FAMA, E. F. Efficient capital markets: A review of theory and empirical work. The journal of Finance, JSTOR, v. 25, n. 2, p. 383-417, 1970. 17

FREITAS, F. D.; FREITAS, C. D.; SOUZA, A. F. D. Intelligent trading architecture. Concurrency and Computation: Practice and Experience, Wiley Online Library, v. 28, n. 3, p. 929-943, 2016. 42

GAMIL, A. A.; ELFOULY, R. S.; DARWISH, N. M. Stock technical analysis using multi agent and fuzzy logic. In: World Congress on Engineering. [S.1.: s.n.], 2007. p. 6. 42

GHISELLI, E. E. Theory of psychological measurement. [S.1.]: McGraw-Hill New York, 1964. v. 13.32

GUYON, I.; ELISSEEFF, A. An introduction to variable and feature selection. Journal of machine learning research, v. 3, n. Mar, p. 1157-1182, 2003. 32

HAFEZI, R.; SHAHRABI, J.; HADAVANDI, E. A bat-neural network multi-agent system (bnnmas) for stock price prediction: Case study of dax stock price. Applied Soft Computing, Elsevier, v. 29, p. 196-210, 2015. 42

HALL, M. A. Correlation-based feature selection for machine learning. Thesis $(\mathrm{PhD})-\mathrm{The}$ University of Waikato, 1999. 33

HALL, M. A. Correlation-based feature selection of discrete and numeric class machine learning. University of Waikato, Department of Computer Science, 2000. 33 
HUANG, W.; NAKAMORI, Y.; WANG, S.-Y. Forecasting stock market movement direction with support vector machine. Computers \& Operations Research, Elsevier, v. 32, n. 10, p. 2513-2522, 2005. 33

JAMES, G. et al. An introduction to statistical learning : with applications in R. New York, NY: Springer, 2013. ISBN 978-1-4614-7137-0. 34, 35, 36, 49

JUNIOR, C. G. C.; GALDI, F. C. Avaliação de empresas por múltiplos aplicado em empresas agrupadas com análise de cluster. Revista de Administração Mackenzie (Mackenzie Management Review), v. 13, n. 5, 2012. 39, 41

KANJI, G. K. 100 statistical tests. [S.1.]: Sage, 2006. 67

KARA, Y.; BOYACIOGLU, M. A.; BAYKAN, Ö. K. Predicting direction of stock price index movement using artificial neural networks and support vector machines: The sample of the istanbul stock exchange. Expert systems with Applications, Elsevier, v. 38, n. 5, p. 5311-5319, 2011. 33

KAUFMAN, L.; ROUSSEEUW, P. J. Finding groups in data: an introduction to cluster analysis. [S.1.]: John Wiley \& Sons, 2009. v. 344. 37

KIM, K.-j. Financial time series forecasting using support vector machines. Neurocomputing, Elsevier, v. 55, n. 1, p. 307-319, 2003. 33

KUMAR, M.; THENMOZHI, M. Forecasting stock index movement: A comparison of support vector machines and random forest. 2006. 33

KUMIEGA, A.; VLIET, B. E. V. Automated finance: The assumptions and behavioral aspects of algorithmic trading. Journal of Behavioral Finance, Taylor \& Francis, v. 13, n. 1, p. 51-55, 2012. 12,13

LEE, J. W. et al. A multiagent approach to $q$-learning for daily stock trading. IEEE Transactions on Systems, Man, and Cybernetics-Part A: Systems and Humans, IEEE, v. 37, n. 6, p. 864-877, 2007. 42

LUI, Y.-H.; MOLE, D. The use of fundamental and technical analyses by foreign exchange dealers: Hong kong evidence. Journal of International Money and Finance, Elsevier, v. 17, n. 3, p. 535-545, 1998. 13

LUO, Y.; LIU, K.; DAVIS, D. N. A multi-agent decision support system for stock trading. IEEE network, IEEE, v. 16, n. 1, p. 20-27, 2002. 42

MARKOWITZ, H. Portfolio selection. The journal of finance, Wiley Online Library, v. 7, n. 1, p. 77-91, 1952. 19

MARSH, P. Equity rights issues and the efficiency of the uk stock market. The Journal of Finance, Wiley Online Library, v. 34, n. 4, p. 839-862, 1979. 18

MARSLAND, S. Machine learning : an algorithmic perspective. Boca Raton: CRC Press, 2009. ISBN 978-1-4200-6718-7. 32

MITCHELL, T. Machine Learning. New York: McGraw-Hill, 1997. ISBN 0070428077. 32 
MURPHY, J. Technical analysis of the financial markets : a comprehensive guide to trading methods and applications. New York: New York Institute of Finance, 1999. ISBN 0-7352-0066-1. 13,24

OBERLECHNER, T. Importance of technical and fundamental analysis in the european foreign exchange market. International Journal of Finance \& Economics, Wiley Online Library, v. 6, n. 1, p. 81-93, 2001. 13

OFFICER, R. R. Seasonality in australian capital markets: Market efficiency and empirical issues. Journal of Financial Economics, Elsevier, v. 2, n. 1, p. 29-51, 1975. 17

OLSON, D. L.; DELEN, D.; MENG, Y. Comparative analysis of data mining methods for bankruptcy prediction. Decision Support Systems, Elsevier, v. 52, n. 2, p. 464-473, 2012. 24

PATEL, J. et al. Predicting stock and stock price index movement using trend deterministic data preparation and machine learning techniques. Expert Systems with Applications, Elsevier, v. 42, n. 1, p. 259-268, 2015. 33

PETERSON, B. G.; CARL, P. PerformanceAnalytics: Econometric tools for performance and risk analysis. [S.1.], 2014. R package version 1.4.3541. Available from Internet: $<$ https://CRAN.R-project.org/package=PerformanceAnalytics $>.56$

PETERSON, B. G.; CARL, P. PortfolioAnalytics: Portfolio Analysis, Including Numerical Methods for Optimization of Portfolios. [S.1.], 2015. R package version 1.0.3636. Available from Internet: $<$ https://CRAN.R-project.org/package=PortfolioAnalytics $>.56$

R Development Core Team. R: A Language and Environment for Statistical Computing. Vienna, Austria, 2008. ISBN 3-900051-07-0. Available from Internet: <http://www.R-project.org>. 56

RAFTOPOULOS, S. The zigzag trend indicator. TECHNICAL ANALYSIS OF STOCKS AND COMMODITIES-MAGAZINE EDITION-, TECHNICAL ANALYSIS, INC., v. 21, n. 11, p. 26-33, 2003. 25

REILLY, F. Investment analysis \& portfolio management. Mason, $\mathrm{OH}$ : South-Western Cengage Learning, 2012. ISBN 978-0-538-48238-7. 12, 21

REIS, E. R.; CASTRO, P. A. de; SICHMAN, J. S. Enhancing classification accuracy through feature selection methods. In: XIII Encontro Nacional de Inteligência Artificial e Computacional. Recife, PE: [s.n.], 2016. p. 1-12. 32, 58

REIS, E. R.; SICHMAN, J. S. Mavis: A multiagent value investing system. In: IEEE. 2018 7th Brazilian Conference on Intelligent Systems (BRACIS). [S.1.], 2018. p. 372-377. 61

RITTER, J. R. Behavioral finance. Pacific-Basin finance journal, Elsevier, v. 11, n. 4, p. 429-437, 2003. 18

ROMANSKI, P.; KOTTHOFF, L. FSelector: Selecting Attributes. [S.1.], 2016. R package version 0.21. Available from Internet: <https://CRAN.R-project.org/package=FSelector $>$. 56

ROZEFF, M. S.; KINNEY, W. R. Capital market seasonality: The case of stock returns. Journal of financial economics, Elsevier, v. 3, n. 4, p. 379-402, 1976. 18

RUSSELL, S.; YOON, V. Heterogeneous agent development: A multi-agent system for testing stock trading algorithms. AMCIS 2005 Proceedings, p. 283, 2005. 42 
RUSSELL, S. J.; NORVIG, P. Artificial intelligence : a modern approach. Upper Saddle River, NJ: Prentice Hall, 2010. ISBN 0-13-604259-7. 13

RYAN, J. A.; ULRICH, J. M. quantmod: Quantitative Financial Modelling Framework. [S.1.], 2017. R package version 0.4-10. Available from Internet: <https://CRAN.R-project.org/package= quantmod>. 56

SAPANKEVYCH, N. I.; SANKAR, R. Time series prediction using support vector machines: a survey. IEEE Computational Intelligence Magazine, IEEE, v. 4, n. 2, 2009. 33

SEO, Y.-W.; GIAMPAPA, J. A.; SYCARA, K. Financial news analysis for intelligent portfolio management. 2004. 42

SHLEIFER, A. Inefficient markets : an introduction to behavioral finance. Oxford New York: Oxford University Press, 2000. ISBN 0-19-829228-7. 18

SMITH, R. G. The contract net protocol: High-level communication and control in a distributed problem solver. IEEE Transactions on computers, IEEE, n. 12, p. 1104-1113, 1980. 31

SONI, S. Applications of anns in stock market prediction: a survey. International Journal of Computer Science \& Engineering Technology, Citeseer, v. 2, n. 3, p. 71-83, 2011. 33

SOUZA, L. O.; RALHA, C. G.; HOELZ, B. W. Optimizing resource allocation with intelligent agents. In: INTERNATIONAL FOUNDATION FOR AUTONOMOUS AGENTS AND MULTIAGENT SYSTEMS. Proceedings of the 16th Conference on Autonomous Agents and MultiAgent Systems. [S.1.], 2017. p. 1742-1744. 42

SUN, J. et al. Predicting financial distress and corporate failure: A review from the state-of-the-art definitions, modeling, sampling, and featuring approaches. Knowledge-Based Systems, Elsevier, v. 57 , p. $41-56,2014.24$

TIREA, M.; TANDAU, I.; NEGRU, V. Stock market multi-agent recommendation system based on the elliott wave principle. Multidisciplinary Research and Practice for Information Systems, Springer, p. 332-346, 2012. 42

URBANEK, S. Rserve: Binary R server. [S.1.], 2013. R package version 1.7-3. Available from Internet: <https://CRAN.R-project.org/package=Rserve>. 56

WING, M. K. C. from J. et al. caret: Classification and Regression Training. [S.1.]. R package version 6.0-78. Available from Internet: <https://github.com/topepo/caret/>. 56

WOOLDRIDGE, M. Intelligent agents. In: WEISS, G. (Ed.). Multiagent systems : a modern approach to distributed artificial intelligence. Cambridge, Mass: MIT Press, 1999. ISBN 0-262-23203-0. 26, 28

WOOLDRIDGE, M. An introduction to multiagent systems. [S.1.]: John Wiley \& Sons, 2009. 12, $13,27,29,30,31$

ZWART, G. D. et al. The economic value of fundamental and technical information in emerging currency markets. Journal of International Money and Finance, Elsevier, v. 28, n. 4, p. 581-604, 2009. 13 